(Aus der Deutschen Forschungsanstalt für Psychiatrie in München und der Univ.-Klinik für Gemüts- und Nervenkrankheiten in Tübingen [Prof. Gaupp].)

\title{
Über herdförmige, protoplasmatische Gliawucherungen von syncytialem Charakter.
}

\section{Mit einem Ausblick auf ihre Bedeutung fïr den Verlauf des pathologisch- anatomischen Prozesses bei der Encephalitis opidemica.}

\author{
Von \\ W. Scholz, \\ Assistenzarzt der Klinik. \\ (Eingegangen am 18. Mai 1922.) \\ Mit 20 Textabbildungen.
}

In der Literatur der letzten Jahre hat eine zwar längst bekannte, aber bis dahin wenig beachtete Art gliöser Wucherung erhöhte Aufmerksamkeit gefunden. Es sind die von der Nissl-Schule als Gliastern und Gliarosette bezeichneten Bildungen. Nissl erwähnt sie bereits 1913 in seiner Mitteilung über die Großhirnanteile des Kaninchens. In einer nach seinem Tode veröffentlichten kasuistischen Mitteilung eines Falles einer eigenartigen Erkrankung des Zentralnervensystems mit bulbären Symptomen und schmerzhaften spastischen Krampfzuständen beschreibt Alzheimer als auffallendste histopathologische Erscheinung im Mark zerstreute Gliarosetten, bestehend aus Gliazellen mit gelegentlich etwas verlängerten Kernen, von denen dickere und dünnere, lange, manchmal verzweigte, oft mit bas. Anilinfarben ungemein intensiv gefärbte Fortsätze ausgehen. Die Zellen sind so angeordnet, daß die Kerne in dichten Klumpen beisammen liegen, während die langen Protoplasmafortsätze radienartig nach allen Seiten streben. Er fand diese Rosetten besonders zahlreich in den an die Ventrikel angrenzenden Teilen des Hemisphärenmarkes. Eine genauere Beschreibung dieser herdförmigen Wucherungen, insbesondere in anderen als den Nisslpräparaten, gibt Alzheimer nicht. Mit dem Auftreten der Encephalitis epidemica gewannen dann die dort als "Neuronophagien" (Economo) auftretenden Gliaherdchen allgemeineres Interesse. Aber erst Spielmeyer hat sich in seinen Arbeiten über das Fleckfieber und das Gliastrauchwerk der Kleinhinrinde eingehend mit den in Frage stehenden gliösen Erscheinungen beschäftigt. Er unterschied beim 
Fleckfieber außer den typischen Knötchen noch drei Arten atypischer Herde, die Rosette, den Stern und das Strauchwerk. Bei den ersten drei Formen von herdförmigen Wucherungen konnten die Beziehungen zu Gefäßen außer Zweifel gestellt werden, während es später gelang, die strauchartigen Wucherungen in der Molekularschicht der Kleinhirnrinde, die sich auch bei Typhus und Epilepsie fanden, mit Alterationen, die die Purkinjeschen Zellen als Ganzes oder nur partiell be. trafen, in Verbindung zu bringen. Nach seinen Ergebnissen und nach den Befunden anderer Autoren (Nissl, Economo, Dürck) konnte als erwiesen gelten, daß die gleiche Art der Gliawucherung als morpholo. gisch gut charakterisierte Reaktionsform einmal von den Gefäßen ihren Ausgang nehmen, das andere Mal als besondere Art der Neuronophagie oder der Ganglienzellumklammerung beim Untergang von nervösen Elementen oder deren Teilen zutage treten kann. Was die morphologische Seite dieser Erscheinungen anbetrifft, so hebt Spielmeyer hervor, daß die gliösen Elemente vielfach ihre Dignität als Einzelindividuen verlieren, da $\beta$ die Zellen untereinander symplasmatische Verbindungen eingehen, so da $\beta$ in mehr oder weniger ausgesprochenem Maße ein Syncytium zustande kommt. Dabei ist lebhafte Zellteilung mitotischer und amitotischer Art zu beobachten. In ausführlicher Weise beschreiben Creutzfeld und nach ihm Jakob symplasmatische Gliawucherungen in Fällen eigenartiger Erkrankungen des Zentralnervensystems, deren histopathologische Befunde von letzterem Autor mit dem von Alzheimer geschilderten Fall in nähere Beziehung gebracht werden. Hier wird der symplasmatische Charakter der um untergehende Ganglienzellen entstehenden Bildungen noch stärker betont. Weiterhin hat Gross eine ausführlichere und anschauliche Darstellung der bei Encephalitis vorkommenden Herdchen gegeben. Gliarosettenbildung als Nervenzellumklammerung und Neuronophagie hat ferner Dürck bei seinen Untersuchungen über Malaria gefunden. Er beschreibt dabei außerdem noch eine Art protoplasmatischer Glia. wucherung als Gänseblümchenherde, die er als spezifische Reaktionserscheinungen gegen die Reizwirkung der intravasculären Plasmodien auffaßt und den Granulomen des Bindegewebes an die Seite stellt.

In der rein morphologischen Beschreibung der als Gliasterne, -rosetten und -strauchwerk bezeichneten Bildungen decken sich die Befunde der Autoren, soweit es sich um die voll ausgebildeten Herdchen handelt. Hervorgehoben wird dabei besonders die Kleinheit, Vielgestaltigkeit und der Chromatinreichtum der Kerne, die starke Färb. barkeit des reichlichen Protoplasmas mit bas. Anilinfarben und seine Neigung, symplasmatische Verbindungen mit anderen gleichgearteten Zellen einzugehen. Betonung findet ferner das häufige Vorkommen mitotischer und direkter Kernteilungen, die rein protoplasmatische 
Natur der Gliaelemente, die jede Faserbildung vermissen lassen und der Befund von stäbchenförmigen Zellformen im Zusammenhang oder in unmittelbarer Umgebung der gliösen Herdchen, wodurch letztere häufig die charakteristische Stern- und Rosettenform erhalten. Dieselben Charakteristica gelten auch für die größeren und kompakteren Knötchen, wie sie sich beim Fleckfieber und der Encephalitis epidemica finden. Während aber bei den vorher erwähnten Bildungen ihre rein gliöse Natur außer Frage steht, sind beim Aufbau der letzteren zweifellos auch Elemente anderer Herkunft beteiligt (Economo, Spielmeyer, Gross). Dabei handelt es sich fast ausschließlich um Elemente hämatogener Herkunft, also Leukocyten in selteneren Fällen, häufigcr Lymphocyten und Plasmazellen und deren morphologische Zwischenformen.

Was das Schicksal der Herde anbetrifft, so nehmen Creutzfeld und Jakob an, daß ein großer Teil der Zellkerne völlig zugrunde geht, während der kleinere Teil weiter proliferiert, wobei die perisistierenden Kerne gleichzeitig größer und chromatinärmer werden, so daß schließlich ein gliarasenähnliches Gebilde entsteht. Auch Spielmeyer und Gross betonen die Labilität der gliösen Wucherungen und berichten über frühzeitige regressive Veränderungen an den Kernen und Degenerationserscheinungen an den Mitosen; die letztgenannten Autoren äußern sich aber im ganzen sehr zurückhaltend über das weitere Schicksal der Herde. Die regressiven Erscheinungen am Protoplasma sind nach Spielmeyer beim Fleckfieber verschieden einerseits an den Rosettenherden und dem Strauchwerk und andererseits an den kompakten Herdchen. Während bei ersteren die Protoplasmaausläufer ein knorriges, spangenartiges Aussehen erhalten und die Kerne pyknotisch werden, findet bei letzteren mit dem Kernzerfall ein Krümeligwerden und eine Auflösung des Protoplasmas statt. Die Verschiedenheiten werden mit dem örtlichen Unterschied des Baues der Glia, aus der die Herdbildungen entstanden sind, in Zusammenhang gebracht. Gross fand in der Umgebung älterer Herde bisweilen faserbildende Astrocyten in größerer Anzahl. Dürck hält die Gänseblümchenherde bei Malaria für dauernde Bildungen.

Als Prädilektionssitz werden übereinstimmend die Ganglienzellen enthaltenden Teile des Zentralnervensystems angegeben, d. h. im Großhirn die Rinde, im Hirnstamm und Rückenmark die Gebiete der Kerne bezw. Kernsäulen. Grundsätzlich abweichend davon ist der Befund von Alzheimer; doch beschreiben auch die anderen Autoren vereinzeltes Vorkommen der Herde in der Marksubstanz.

Wie bereits oben angedeutet wurde, können die in Frage stehenden Herde in zweifacher Weise entstehen: 1. beim Untergang nervöser Elemente oder deren Teilen, wobei es entweder nur zur Umklammerung 
oder auch zur völligen Substitution kommt oder 2. im Zusammenhang mit Gefäßen. Im ersten Falle kommt es kei Erkrankung der Purkinjezellen oder auch nur bei Abschmelzung der Purkinjedendriten in der Molekularschicht der Kleinhirnrinde zur Strauchwerkbildung (Spielmeyer), bei analogen Vorgängen an den Ganglienzellen anderer Gebiete zur Rosetten- oder Sternbildung (Spielmeyer, Creulzfeld, Jakob, Gross,u. a.). Ihr Vorkommen im Mark ohne Beziehung zu einem Gefäß führt Jakob auf Einzelausfälle nervöser Strukturen zurück. An eine besondere Erkrankungsform der Ganglienzelle scheint das Auftreten dieser gliösen Reaktion nicht gebunden, ebensowenig wie sie etwa gesetzmäßig bei allen erkrankten Zellen im besonderen Falle vorkäme. Sie betrifft sogar bisweilen anscheinend wenig veränderte Ganglienzellen, während sie augenscheinlich schwer erkrankte verschont (Spielmeyer, Gross, Economo). Im zweiten Falle finden wir die Sterne, Rosetten oder Knötchen in direkter Berührung mit manchmal erkrankten, häufig aber auch völlig unveränderten Gefäßen. Die reinste Form dieses Vorkommens präsentiert sich beim Fleckfieber, während man bei Encephalitis epidemica die Gliaherdchen sowohl in Beziehung zu Gefäßen wie zu Ganglienzellen und auch ohne erkennbare Beziehungen zu Gewebsbestandteilen antrifft (Creutzfeld). Die perivasculäre Entstehung der Herde ist mit exsudativ-infiltrativen Vorgängen vergesellschaftet, bei der zwar ein örtliches Zusammenvorkommen der letztgenannten Erscheinungen und der gliösen Wucherungen die Regel ist, insofern die beiden Erscheinungen in begrenzten Gebieten nebeneinander auftreten, wobei aber trotzdem eine direkte Abhängigkeit zwischen Infiltration und Herdbildung nicht besteht (Spielmeyer). Bei den mit exsudativ-infiltrativen Erscheinungen einhergehenden Erkrankungen nehmen am Aufbau der größeren Herde nun auch infiltrierende Elemente teil, und zwar nicht nur an den Gefäßherden, sondern auch an den pericellulären Herden (Gross), während bei nichtentzündlichen Prozessen die durchschnittlich auch kleineren Herde rein gliöser Natur sind (Creutzfeld, Jakcb). Ein Unterschied im Verhalten der Gliaherdchen ergibt sich auch nach der funktionellen Seite hin, und zwar nehmen sie in den Fällen von Jakob und Creutzfeld, die parenchymatöse Degenerationsvorgänge ohne exsudative Erscheinungen vorstellen, in ganz ausgesprochener Weise am Lipoidabbau teil. Dahingegen betont besonders Spielmeyer, da $\beta$ sowohl bei Fleckfieberherdchen als auch beim Gliastrauchwerk anderer Erkrankungen der Lipoidbefund recht spärlich sei und mit Degenerationserscheinungen der gliösen Elemente in Zusammenhang gebracht werden müsse. Im Gliastrauchwerk hat neuerdings Sagel in einem Falle von Status epilepticus reichlicher Lipoid gefunden, das wahrscheinlich durch den Abbau der nervösen Substanz entstanden ist. $O b$ in ge- 
wissen Fällen eine unmittelbare Einwirkung der Herde auf gesundes nerväs Gewebe stattfindet, ist unsicher. Bei den neuronophagischen Prozessen wird allgemein eine primäre Zellschädigung angenommen; bei den Fleckfieberherden, die dicht und solid gebaut sind, ist eine sekundäre Schädigung der durch die wuchernden Zellen eingeschlossenen nervösen Elemente, die sich in Markscheiden-, Axon- und Ganglienzellenausfall äußert, nicht völlig von der Hand zu weisen.

Wir haben oben gesehen, daß herdförmige, protoplasmatische Gliawucherungen der eben geschilderten Art bei einer ganzen Reihe von Erkrankungen vorkommen, die durch sie zum Teil ihr typisches Gepräge erhalten. Dies trifft vor allem beim Fleckfieber, bei der Encephalitis epidemica und den von Alzheimer, Creutzfeld und Jakob beschriebenen Fällen zu. Auch beim Status epilepticus (Sagel) und beim Typhus (Spielmeyer) wenigstens scheint das Gliastrauchwerk zu den häufigeren Befunden zu gehören. Außerdem sind derartige Gliawucherungen bei Gasödem und als Neuronophagien bei Malaria beschrieben. Hierher gehören zweifellos auch die von Lotmar als ,,initiale Körnchenzellherde" und „flächenhafte Herde mit fixen Abräumzellen" bezeichneten Bildungen, die er bei seinen Versuchen zur Erzeugung einer experimentellen Encephalomyelitis mit Dysenterietoxin gefunden hat.

Wir haben nun aus dem Material der Deutschen Forschungsanstalt für Psychiatrie in München eine Reihe von Fällen auf solche gliösen Erscheinungen untersucht und auch die uns dort und in der hiesigen (Tübinger) Klinik zufällig durch die Hand gehenden Fälle daraufhin angesehen. Es wurde dabei versucht, dem Wesen dieser Phänomene etwas näher zu kommen, wozu die epidemische Encephalitis besonders aussichtsreich erschien. Das Material wurde zum größten Teil in Serienschnitten mit den verschiedenen üblichen Methoden bearbeitet.

Im folgenden sollen nun in Kürze die histopathologischen Befunde skizziert werden, in denen sich Gliasterne, -rosetten oder größere Herdchen vorfanden.

\section{A. Erkrankungen, die mit ausgesprochen exsudativ-infiltrativen Vor- gängen am Gefäßapparat einhergehen ${ }^{\mathbf{1}}$.}

Fall 1. Z., 29 Jahre. Klinisch: Reflektorische Pupillenstarre, Sprachstörung, gehäufte paralytische Anfälle. Exitus im Anfall. Diagnose: Progressive Paralyse. Histopathologischer Befund: Typischer Befund der progressiven Paralyse, nur an einer Stelle der Hirnrinde ein miliares, in Entstehung begriffenes Gumma. Im Mark überall zerstreut, bisweilen im Zusammenhang mit kleinen Gefäßen meist Präcapillaren, öfter aber ohne jede nachweisbare Beziehung zum Gefäßapparat kleine, dichte oder lockere Gliasterne mit stark gefärbtem, weit verzweigtem Protoplasma der in symplasmatischem Zusammenhang stehenden Gliaelemente. Ihre

1) Eine zusammenfassende Schilderung der Befunde an unserem Encephalitismaterial folgt am Schlusse der Darstellung aller Einzelfälle. 
Kerne sind kaum vergrößert, teils mehr rund und am Rande, wo die Gliaelemente radienartig auseinanderstreben, vielfach länglich und oft geknickt. Neben deutlich progressiven Formen finden sich Pyknose und Hyperchromatose. Die Größe der Herde überschreitet 15-20 $\mu$ kaum, die Anzahl der in ihnen enthaltenen Kerne beträgt bei den größeren Herden durchschnittlich 20-30 und steigt herab bis zu etwa 6 und noch weniger, wenn man derartige kleine Bildungen noch als Glia. sterne bezeichnen will. In den Bezirken, in denen die Gliasterne vorkommen, ist die Glia in mäßiger, diffuser, protoplasmatischer Wucherung begriffen, wobei größere helle Kerne mit reichlichem Protoplasma seltener sind. In der Hauptsache besteht die diffuse Wucherung aus einzeln liegenden Elementen, die den Zellen gleichen, aus denen sich die Gliasterne zusammensetzen; nur das Protoplasma ist nicht so stark gefärbt. Andere als Gliazellen sind in den Herdchen nicht enthalten. Hier und da kleine Gliarasen. In der Rinde sind stern- oder rosettenähn. liche Bildungen nicht nachweisbar, wohl aber, wenn auch spärlicher als im Hemi-

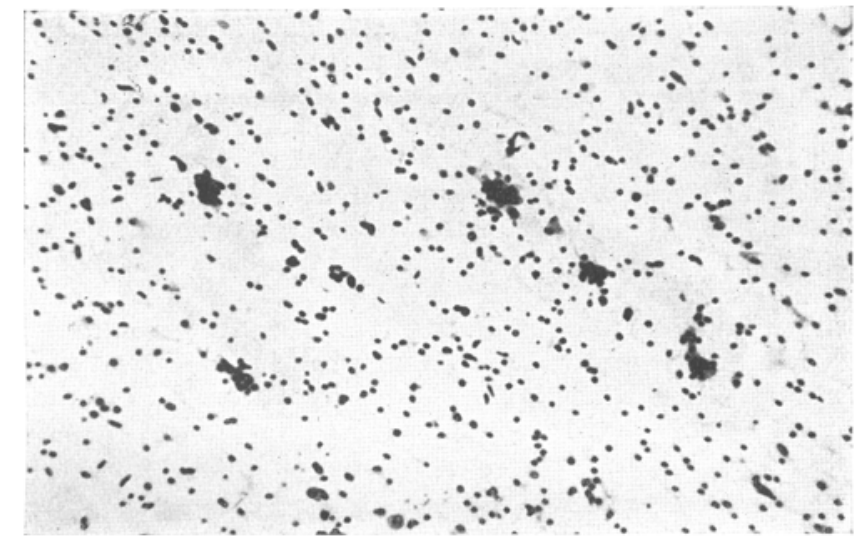

Abb. 1. Toluidinblau. Zeiß B. Ok. 2. Fall Zimmer, Paralyse. 5 Gliasterne im Großhirnmark inmitten einer allgemeinen Gliawucherung von der Art der Herdchenzellen.

sphärenmark, in der Medulla oblongata. Abb. 1. illustriert den Befund bei schwa. cher Vergrößerung. Eine Beteiligung der Gliasterne an der Faserbildung findet nicht statt, ebensowenig sind größere Mengen von Lipoid, das in feinkörniger, diffuser Verteilung überall im Mark zerstreut ist und sich besonders in den Gefäßwandzellen aufgestapelt findet, in ihnen nachweisbar. An Markscheidenpräpa. raten sind die Gliasterne nicht wiederzufinden, und auch an Bielschowskypräparaten ist es nicht immer möglich, sie mit Sicherheit zu identifizieren. Da, wo sie nachzuweisen sind, präsentieren sie sich als kernreiches Syncytium, das in seinen dichten Teilen die Nervenfasern auseinanderdrängt, Degenerationserscheinungen an Achsenzylindern im Herdbereich sind jedoch nicht beobachtet ${ }^{1}$ ).

Fall 2. Mau. Klinisch: Lues cerebri mit aphasischen und apraktischen Symptomen. Komplikationen: Ausgedehnte Bronchopneumonie, Lungengangrän. Histopathologischer Befund: Heubnersche Endarteriitis, die fast zum Verschluß der Aa. cerebri med. beiderseits geführt hat. Handtellergroße Rindenerweichungen

1) Pericelluläre und Gefäßherdehen haben wir inzwischen in der Medulla oblongata zweier weiterer Paralysefälle beobachtet. Im einen Falle, in dem die Ganglienzellen starke Fetteinlagerungen zeigten, gelang es uns auch, feinkörniges Lipoid in den Zellen der pericellulären Herdchen nachzuweisen. 
beiderseits in der Umgebung der Fossa Sylvii. Auch die kleinen Rindengefäße vielfach luetisch verändert. Neben vielen disseminierten Erweichungsherden im Gebiet der mittleren Hirnarterien eine Anzahl ischämischer Herde, in denen die nekrobiotischen Vorgänge zu keinerlei Reaktionserscheinungen geführt haben. Im übrigen typische weiße Körnchenzellerweichungen mit lebhafter Bindegewebsund Gliareaktion, bei letzterer massenhaft gemästete Formen. Pia und Gefäße nur teilweise und wenig infiltriert, hauptsächlich mit Lymphocyten. Im Hemisphärenmark in größerer Zahl zerstreute kleine Gliastern- und -rosettenbildungen, die den im vorhergehenden Fall beschriebenenen gleichen, zum Teil aber größer sind. Außerdem zahlreichere kleine Herdchen in der grauen und weißen Substanz der Medulla oblongata, und zwar sowohl vereinzelt um Ganglienzellen wie auch im Zusammenhang mit Gefäßen; die meisten jedoch ohne Beziehung zu Ganglienzellen oder Gefäßen. An einer Stelle ein schmächtiger Stern, der eine gequollene Achsenfaser umschließt. Die Herdchen, auch die größeren, bestehen ausschließlich aus Gliazellen. Die Gefäße, an denen sich Sterne und Rosetten etabliert haben, zeigen teils leichte progressive Erscheinungen, im Hemisphärenmark aber häufiger regressive Veränderungen; es handelt sich immer um kleine Gefäße, die nicht infiltriert sind. Neben den typischen Stern- und Rosettenbildungen im Hemisphärenmark finden sich in der Nähe von umfangreicheren Zerstörungen des Nervengewebes syncytiale Gliaherdchen, die cin abweichendes Verhalten zeigen. Hier beobachten wir eine weniger ausgesprochene Neigung der Kerne, schlanke, stäbchenförmige Gestalt anzunehmen; ein Teil bleibt rund, andere sind plump und länglich und häufig geknickt. Auch das Protoplasma erstreckt sich dann vom Rande der Rosetten aus weniger weit geißelförmig in die Umgebung. Sowohl im Zentrum dieser Herdchen wie in den Herdausläufern zeigen sich außer an den Kernen auch am Protoplasma frühzeitig regressive Veränderungen; es treten kleine Vakuolen auf, die teilweise zu großen Hohlräumen werden, die Ausläufer blähen sich auf, und schließlich hat das ganze Syncytium einen wabigen Bau, wobei es dann auch weniger intensiv gefärbt ist. Dabei lösen sich auch einzelne Elemente aus dem syncytialen Verbande los. Mitunter ist nur ein Teil des Symplasmas von dieser wabigen Degeneration ergriffen. Endlich finden sich typische Gliarosetten meist mit regressiven Erscheinungen in größerer Anzahl in der Hirnrinde in der Nähe von Erweichungsherden, und zwar an Stellen, wo die Ganglienzellen anfangen, gerade dem Untergange zu verfallen. Wir beobachten sie hier als Ganglienzellenumklammerung und wohl auch -substitution. Die erweichten Partien enthalten keine solchen Herdchen, wohl aber bemerkt man in der gliosen Reaktionszone, die in der Hauptsache aus mächtigen, protoplasmareichen Gliazellen und kleinen runden, stäbchen. und sternförmigen Zellen gebildet wird, herdartige Ansammlungen kleiner Gliakerne, die von wenig zerrissen und zerklüftet aussehendem Protoplasma umgeben sind, und die oft nur in lockerem, häufig aber auch in dichterem Verbande nebeneinanderliegen. Obwohl man hier auch syncytiale Verbindungen einzelner Zellen beobachten kann, ist im allgemeinen doch der Charakter der Einzelzelle viel mehr gewahrt. Außerdem sind die Kerne chromatinärmer als bei den eigentlichen Rosetten; sie neigen zu mehr bläschenförmiger Gestalt und enthalten oft eine größere, dunkle, nucleolusartige Chromatinanhäufung. Vom Rande nach außen hin erstrecken sich wie bei den typischen Rosetten die Zellausläufer in abenteuerlichen Formen weit in die Umgebung. Mitunter findet man eine gemästete Gliazelle von solchen Gliazellen direkt umklammert. Man wird diese Art der Gliawucherung wegen der Verschiedenartigkeit der Bausteine von den eigentlichen Gliasternen und -rosetten trennen müssen. Im Fettpräparat bemerkt man, daß die erweichten Gebiete in massenhafter Zahl Fettkörnchenzellen enthalten; in der peripher angrenzenden Zone, in der die Ganglienzellen gleichfalls zugrunde gegangen sind, ist 
das Fett in der Hauptsache von den gemästeten Gliazellen aufgenommen worden. Noch weiter peripherwärts, dort wo der Gliareaktionswall sich gegen das nur wenig oder gar nicht veränderte Nervengewebe absetzt, trifft man auf eine Zone, in der die Ganglienzellen sich in fettiger Degeneration befinden und nur teilweise schon völlig zugrunde gegangen sind. Hier ist als auffälligste Erscheinung das zahlreiche Auftreten von Stäbchenzellen zu beobachten, die häufig bis in die feinsten Ausläufer mit Fett vollgepfropft sind und zum anderen Teil die Neigung zur Abrundung bis zu kleinen, runden Körnchenzellen zeigen. Über die Teilnahme der Gliarosetten am Lipoidabbau ist folgendes zu sagen: Dort, wo an sich der Lipoidabbau lebhaft ist, also vornehmlich in der Rinde, enthalten auch die Rosetten gröbere und feinere rote Körnchen in fast gleichmäßiger Verteilung, während man an anderen Stellen ohne Lipoidabbau, z. B. im Mark keine lipoiden Stoffe in ihnen findet. Eine Anteilnahme an der Gliafaserbildung scheint den typischen Sternen und Rosetten nicht zuzustehen, wenigstens konnte eine solche nicht sichergestellt werden. Allerdings trifft man in Gegenden, wo an sich eine starke Faserbildung statthat, hier und da ein Häufehen von kleinen Gliakernen, die zwar meist rundliche, bisweilen aber auch eckige und längliche Formen haben, wo eine sichere Beziehung zu Fasern festzustellen ist. Bei der Schwierigkeit, kleine regellos verstreute Gliarosatten inmitten einer exzessiven Vermehrung der Gliakerne im Faserpräparat zu identifizieren, möchte ich aber mit der Vermutung, diese Gebilde Gliasternen gleichzusetzen, vorsichtig sein. Im Bielschowskypräparat endlich sieht man, daß die Achsenzylinder an den Stellen, wo sie nicht durch andere Ursachen schon zugrunde gegangen sind, durch die Zellherdchen auseinandergedrängt sind; ein direkter Zusammenhang zwischen Herdbildung und Axondegeneration konnte nicht sichergestellt werden.

Bezüglich der Lokalisation der Gliasternbildungen sei noch einmal hervorgehoben, da $B$ sie sich in charakteristischer Prägung nur außerhalb und am Rande des die Erweichungsherde umgebenden dichten Gliawalles finden. Dort, wo die Stärke der gliösen Reaktion ein gewisses Maß übersteigt, und zwar im vorliegenden Falle da, wo die großen Gliazellen in massenhafter Zahl auftreten, verlieren die Gliasterne ihre typische Form. Ob dabei die oben erwähnten, im Gliawall selbst gelegenen atypischen Bildungen aus bereits fertigen oder in der Entwicklung begriffenen Gliasternen entstanden sind, muß hier dahingestellt bleiben.

Fall 3. Zellner ${ }^{1}$ ). Klinisch: Atypische Paralyse (multiple Sklerose?). Anatomischer Befund: Atypisch lokalisierte multiple Sklerose mit zahlreichen Herden im Großhirn und wenigen im Hirnstamm. Histopathologischer Befund: Typischer Be. fund der multiplen Sklerose, jüngere und ältere Herde; stellenweise sehr lebhafter Lipoidabbau in den Herden. Plasmazellinfiltrate mäßigen Grades besonders in den Gefäßen der Herdumgebung. In größerer Zahl Gliasterne im Mark in der Nähe der Herde, und zwar nach außen von dem die Herde umgebenden kernreichen Gliareaktionswall da, wo die Glia eben erst beginnt, proliferative Veränderungen einzugehen. Ein Zusammenhang mit Gefäßen ist nur an einzelnen Gliaherdchen zu erweisen, andere zeigen keine Beziehung dazu. Die kleinen, wenig vergrößerten, zum Teil in die Länge gezogenen Kerne sind vereinzelt regressiv verändert, das Protoplasma stark metachromatisch mit syncytialen Verbindungen. Manche radienartig nach außen strebenden protoplasmatischen Fortsätze der Herdzellen sind plump und verbreitert und weisen einen kammerigen, bisweilen schlauchartigen Bau auf. Lipoid läßt sich in ihnen nieht nachweisen. Hin und wieder trifft man auf kleine Gliakernhaufen, die an der Faserbildung teilnehmen; der Boweis, da $B$ es sich dabei um echte Gliasteme handelt, steht jedoch aus.

1) Die ausfiuhrliche Beschreibung und kritische Würdigung des Falles ist von Stertz und Schob in den Nisslschen Beiträgen gegeben worden. 
Es handelt sich hier, wie im vorhergehenden Falle, um ausgedehnte herdförmige Zerstörungen nervösen Parenchyms mit lebhafter Gliawucherung. Das Vorkommen der Gliaherdchen ist auch hier auf eine außerhalb der exzessiven Glia. wucherung gelegene Zone beschränkt.

\section{B. Erkrankungen ohne ausgesprochen exsudativ-infiltrative Erschei- nungen, parenchymatöse Degenerationen.}

Fall 1. Lechner. Klinisch: Im 4. Lebensjahr Beginn der Erkrankung mit schwerem epileptischem Anfall. Mehrfache Wiederholung der Anfälle in der nächsten Zeit. Geistiges Zurückbleiben. Mit 4 ${ }^{1} / 2$ Jahren Aufnahme in die Kinderklinik München. Psychisch zunächst wenig auffallend, heiter, zärtlich, leicht zurückgeblieben, Pupillen und Papille o. B. Wassermann negativ. Im weiteren Verlauf Absencen, häufige epileptische Anfälle, zeitweise Status epilepticus; sehr häufige rudimentäre Anfälle: plötzliches Zusammenzucken, Hintenüberfallen, sehr rasche

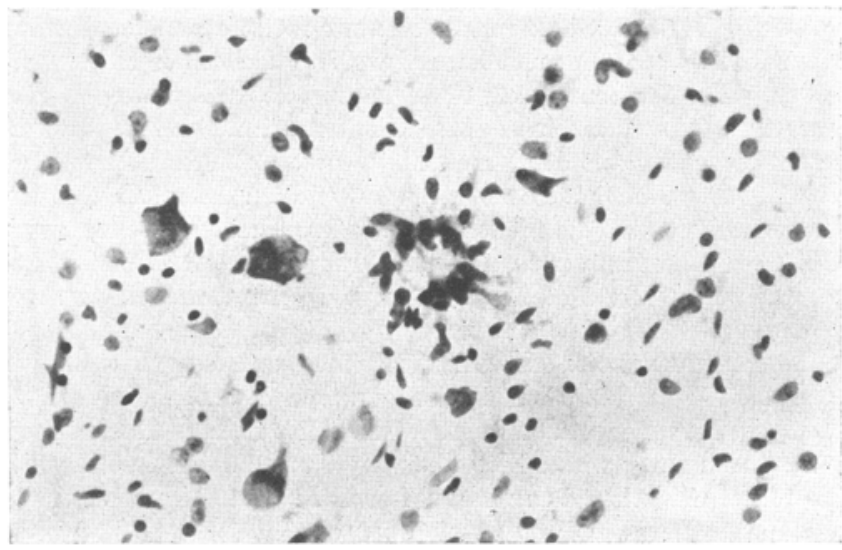

Abb. 2. Thionin. Zeiß B. Ok. 5. Fall Lechner. Amaurot. Idiotie. Gliarosette aus der Olive. Das helle Zentrum der Rosette wird von der Resten einer zerfallenen Ganglienzelle gebildet. Links vom Herdchen 3 ballonförmig aufgetriebene Ganglienzellen. deren Kerne an und zum Teil in den Hauptdendriten gedrängt sind. Die dıffuse Gliawucherung ist gemischtzellig; neben kleinen, chromatinreichen Gliakernen etwa in gleicher Anzahl großere, bläschenförmige Kerne.

Erholung. Allmählich starker geistiger Rückgang, Sprache schlechter, spielt nicht mehr, kann Personen nicht mehr unterscheiden, unrein, Schreianfälle und Zwangslachen. Tod an Bronchopneumonie. Histopathologisch: Befund der juvenilen Form der amaurotischen Idiotie mit den typischen Aufblähungen der Ganglienzellen in Hirnrinde und Hirnstamm; diffuse Ganglienzellausfälle. In den Ganglien- und Gliazellen findet sich eine mit Scharlach gelbrötlich angefärbte Substanz, während in den Gefäßwandzellen leuchtend rotes Lipoid erseheint. Typisches Auseinanderweichen der endocellulären Fibrillen. Nur ganz selten vereinzelte Infiltratzellen in den Gefä Bscheiden. Diffuse Vermehrung der Gliakerne in der Rinde; durchschnitt. lich progressiv veränderte, wenig vergrößerte Formen mit spärlichem, nach allen Seiten ausstrahlendem, eben sichtbarem Protoplasmaleib, seltener auch stäbchenförmige Elemente. Daneben in etwa gleicher Häufigkeit wenig größere, bläschenförmige Gliakerne mit reichlicherem Protoplasma. Dieselbe Art diffuser, gemischtzellig-gliöser Veränderung in der Medulla oblongata mit noch mehr Neigung zur Differenzierung gliogener Stäbchenzellen. Im Band der Olive zwischen den kugelförmig aufgeblähten Ganglienzellen finden sich in großer Anzahl typische Glia- 
rosetten von vorwiegend ziemlich dichter Struktur nach der Mitte zu; der Rand der Rosetten wird von meist radiär gestellten stäbchenförmigen Elementen gebildet (s. Abb. 2), die teilweise nur durch schmale Protoplasmabrïcken mit dem Haupt. teil des Syncytiums zusammenhängen. Die chromatinreichen Kerne, die die Merkmale progressiver Veränderung tragen, sind im Durchschnitt kaum vergrößert; viele Kerne bieten aber bereits regressive Erscheinungen, besonders Pyknose, aber auch Karyorrhexis dar. Manche lockerer gebaute Rosetten enthalten ausschließlich regressive Kernformen. Die Rosettenherde haben sich, was schon aus ihrer Anordnung zu schließen ist, offenbar um zugrunde gehende Ganglienzellen gebildet; durch den Befund von Ganglienzellresten in ihrem Inneren wird die Richtigkeit dieser Annahme bewiesen. Meist işt jedoch nichts mehr davon nachzuweisen. Der Aufbau der Herdchen ist rein gliös; eine Beziehung zu Gefäßen besteht nicht. Je nach der Schnittführung ist das Aussehen der Rosetten etwas verschieden; ist die Rosette in der Mitte durchgeschnitten, so wird ihr Zentrum aus einem metachromatisch gefärbten, aus körnigkrümeligen, oft auch Vakuolen enthaltenden Hofe gebildet, der in der Peripherie von einem einfachen oder doppelten Kranz dicht gestellter Kerne eingerahmt wird. Dieselbe Art von Rosettenherdchen findet sich ebenfalls, wenn auch nicht in so großer Anzahl im Nucleus dentatus; in der Rinde sind sie nicht zu entdecken gewesen. Deutlicher als im Nisslpräparat kann man im Fettpräparat beobachten, daß die Rosetten um untergehende Ganglienzellen herum entstehen. Die mit gelbroten Massen vollgepfropften Olivenzellen sind dort von einem Kranz von Zellen umgeben, deren Protoplasma zunächst noch frei von Einlagerungen ist (Abb. 3a). Mit dem fortschreitenden Zerfall der Ganglienzellen im Zentrum in größere Brocken und später feinere Krümel nehmen die Rosettenzellen unter gleichzeitigem Eindringen in die Zerfallmasse diese den Lipoiden ähnlichen Substanzen in unverändertem Zustande auf, und schließlich ist das ganze Syncytium bis in die Ausläufer der randständigen stäbchenförmigen Elemente erfüllt (s. Abb. 3 b). Dabei gewinnen die gliösen Elemente allmählich mehr Selbständigkeit, indem sie durch die Einlagerungen aufgebläht, immer mehr als Einzelelemente imponieren; schließlich ändert sich das Bild dergestalt, daß ein Teil der Rosettenzellen zu kleinen Körnchenzellen wird, die auch im Nisslpräparat einen deutlich kammerigen Bau aufweisen. Statt der Gliarosetten an Stelle der Olivenzellen finden wir dann kleine Körnchenzellhaufen (s. Abb. $3 \mathrm{c}$ ). Im Heidenhainpräparat zeigt sich an geeigneten Stellen, daß die von Spielmeyer mit dieser Färbung dargestellten schwarzen, körnigen Einlagerungen der Ganglienzellen auch in das gliöse Syncytium übergehen. Die Rosetten, die häufig mit einem dichten Flechtwerk von Gliafasern umsponnen sind, erweisen sich in ihrem Innern völlig frei von Gliafasern. Bisweilen sieht man am Rand der Rosetten einige faserbildende Astrocyten, die aber jeweils größere helle Kerne enthalten und einen direkten Zusammenhang mit den Herdzellen nicht erkennen lassen. Das Bielschowskypräparat stellt in der zentralen Zerfallsmasse bisweilen noch ein grobbalkiges, schwarz imprägniertes protoplasmatisches Netz dar, die letzten Reste der untergegangenen Ganglienzelle. Die Achsenzylinder sind in der ganzen Ausdehnung der Herdchen verschwunden.

Eine weitere für unsere Betrachtung interessante Erscheinung beobachten wir in der Kleinhirnrinde. Sehen wir uns die Abb. 4 an, so finden wir in der Molekular. schicht ein typisches lockeres Gliastrauchwerk und rechts daneben eine herdförmige Gliawucherung, bei der man im Zweifel sein kann, ob man sie den Gliarosetten oder dem Gliastrauchwerk zurechnen soll, eine Erscheinung, die zwischen beiden in der Mitte steht. Sie beweist deutlicher als manches andere, da.3 Gliastrauchwerk und Gliarosetten unter gewissen Voraussetzungen im Grunde genommen das gleiche sind. Das Scharlachpräparat läßt ohne weiteres erkennen, daß beide dem Verlaufe der mit rötlichen Massen angefüllten und dadurch aufgetriebenen Purkinjedendriten 


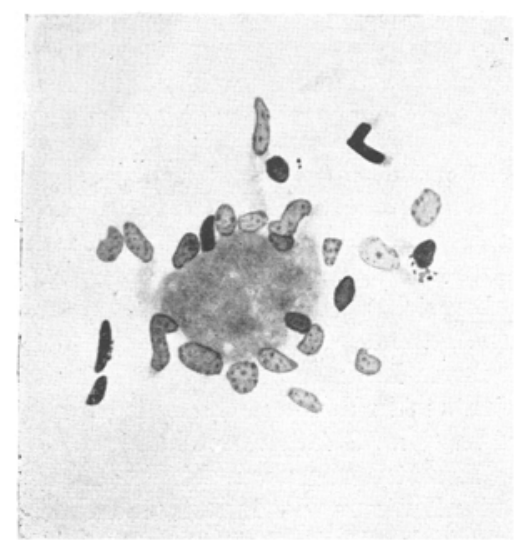

Abb. 3 a.
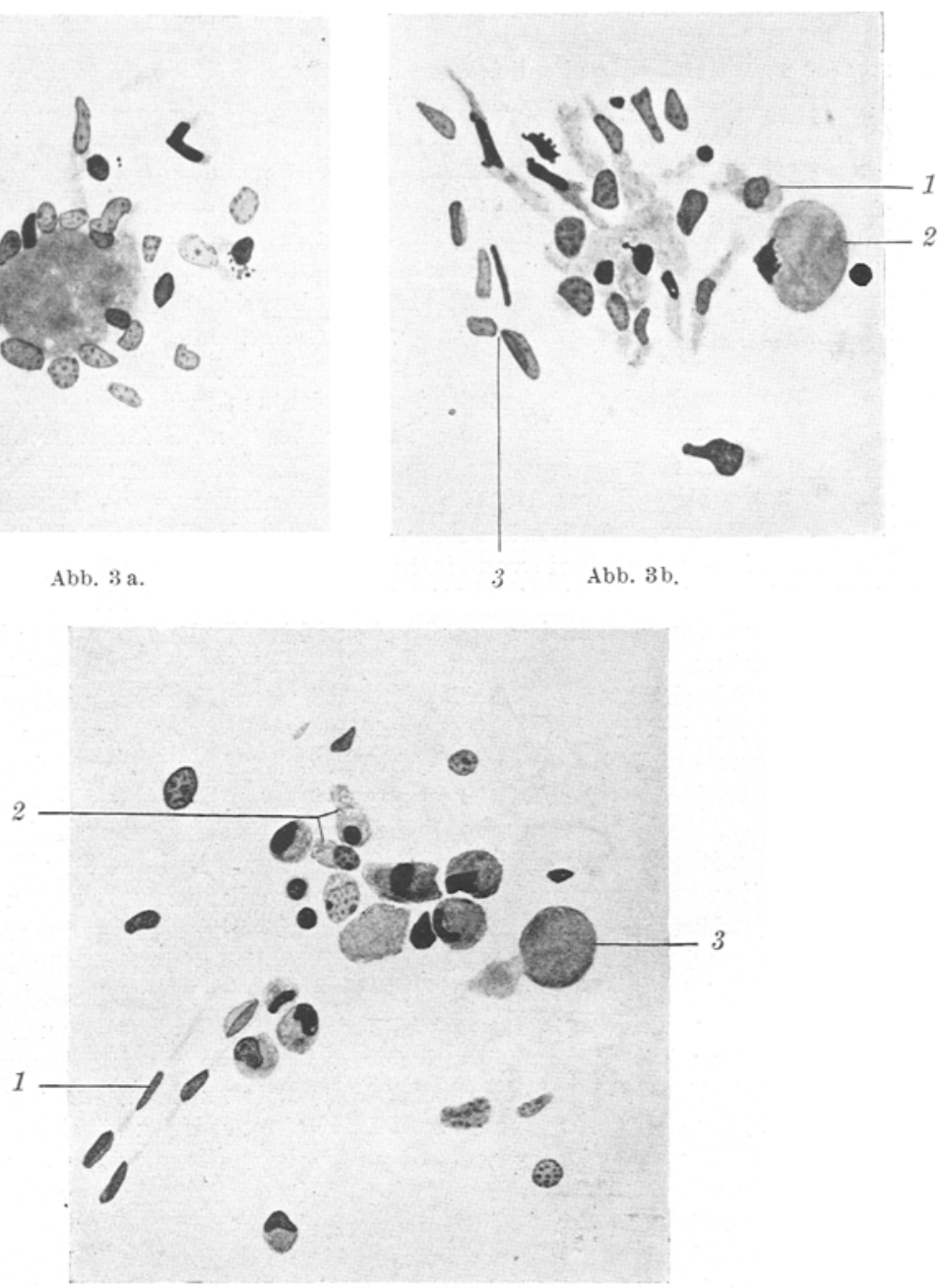

Abb. $3 \mathrm{c}$.

Abb. 3a-1. Doppelfárbung mit Scharlach und Hämatoxylin. Photographie nach einer Zeichnung. Fall Lechner, amaurot. Idiotie. Darstellung der abbauenden Tätigkeit der Gliarosetten und ihrer Umwandlung in Kornchenzellen. (Alle 3 Stadien sind in den Oliven eines Schnittes beobachtet.) a) zeigt den geschlossenen Ring einer Gliarosette um die Zerfallsmasse einer Olivenzelle. Das Protoplasma der Rosettenzellen ist ungefärbt, ihre Kerne erscheinen teils progressiv, teils pyknotisch; einige von ihnen zeigen das Bestreben, in die zentrale Masse vorzudringen. Ein paar"Zellen haben bereits begonnen, die krümeligen Zerfallsprodukte aufzunehmen.

b) Die Rosettenzellen sind in die amorphe Zerfallsmasse vorgedrungen und haben sich mit Abbaustoffen beladen, wodurch stellenweise ihre stäbchenförmige Gestalt deutlich hervortritt und mehr und mehr ihre Isolierung aus dem Zellsyncytium erfolgt. Bei 1 eine Zelle, die die Tendenz zur Abrundung zeigt. An den Kernen treten die regressiven Erscheinungen in vermehrtem Maße zutage, auBer Pyknose auch Kernsprossungen. 2 noch nicht zerfallene, von lipoidähnlichen Massen enorm aufgeblähte Ganglienzelle mit pyknotischem Kern. 3 Capillare.

c) Die mit Zerfallsmassen vollgepfropften Rosettenzellen haben sich teilweise zu runden Körnchenzellen umgewandelt, von denen einige bereits an ein benaehbartes Gefi $\beta$ (1) abgewandert sind. Eine Rosettenform des Herdchens ist nicht mehr erkennbar, ebensowenig ein syncytialer Zusammenhang der Zellen. Zwei Zellen (2) haben ihren ursprünglıchen Charakter noch einigermaßen erhalteı. Die Mehrzahl der Kerne ist pyknotisch. 3 eine geblähte Olivenzelle mit Auftreibung des Hauptdendriten. 
folgen, und daß sie durch Aufnahme der rötlichen, lipoidähnlichen Substanzen zum Abbau derselben beitragen. Sie haben bei dieser Tätigkeit nicht so gewaltige Massen zu verarbeiten, wie sie die zerfallenden Olivenzellen darstellen, und erscheinen aus diesem Grunde auch nicht derartig vollgepfopft mit Zerfallmassen wie die Olivenrosetten. Das mag auch der Grund sein, weshalb es hier nicht oder nur in den ersten Ansätzen zur Körnchenzellbildung aus Strauchwerkzellen kommt; denn allem Anschein nach genügt hier noch der fixe Abbau. Die Glia ist auch hier in diffuser Weise reichlich gewuchert, wobei etwas größere, helle, runde Kerne die Regel bilden. Auch diese diffus gewucherten Zellen haben in reichem Maße die lipoidähn-

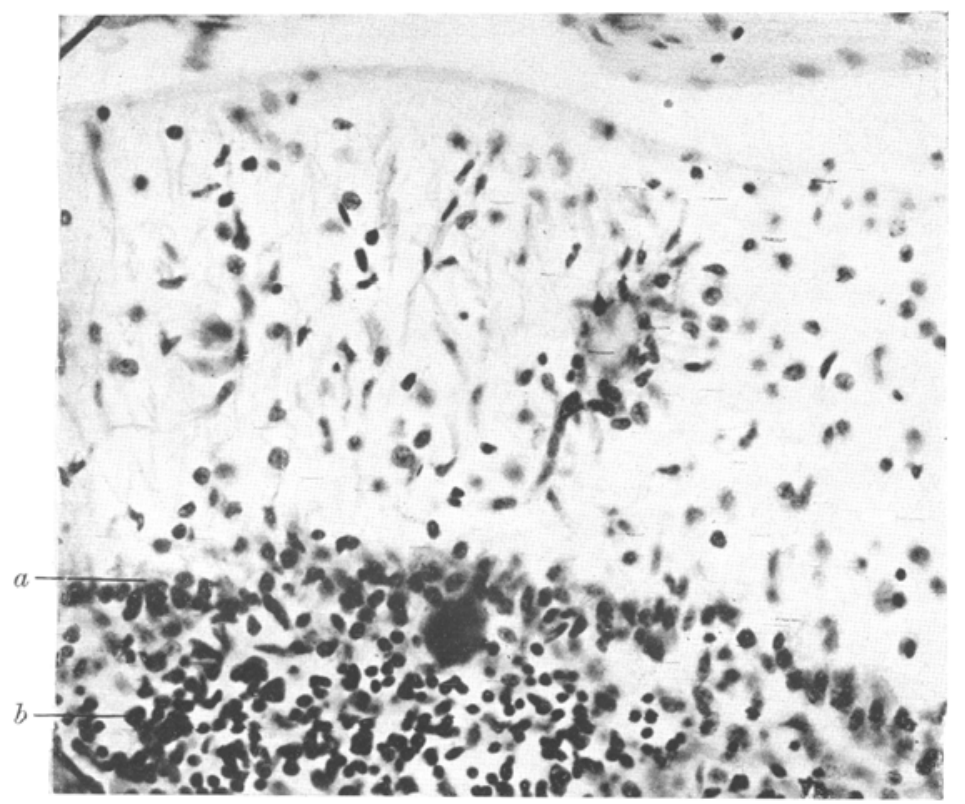

Abb. 4. Toluidinblau. Apochr. 8. Comp. Ok 6. Fall Lechner, amaurot. Idiotle. Gliarosette (rechts) und Gliastrauchwerk (links) in der Molekularschicht der Kleinhirnrinde, die beide dem Verlaufe der Purkinjedendriten folgen. Der Unterschied zwischen beiden besteht nur in der durch die Große der neurogenen Zerfallsmassen bedingten Zahl und Gruppierung der Zellen. Auch hier ist wie in der Olive die diffuse Gliawucherung gemischtzellig. $a$ Schicht der gewucherten Bergmannschen Zellen, $b$ Kornerschicht.

lichen Substanzen aufgenommen, die aus den Purkinjebäumchen stammen. In der Molekularschicht ist es überall zu einer lebhaften Gliafaserwucherung mit Bildung einer mehr oder weniger dicken Deckschicht gekommen, die an vielen Orten besondere Dicke erreicht; diese Stellen besonders dichter Gliafaserwucherung stehen mit dem Vorkommen des Gliastrauchwerks in keiner Beziehung, wie man auch nirgends eine Beteiligung der Strauchwerkzellen an der Faserbildung nachweisen kann. Die große Mehrzahl der in radiärer Richtung verlaufenden Gliafaserbünde] stammt vielmehr aus den stark gewucherten Bergmann schen Zellen.

Fall 2. Christiane Beeh. 55 Jahre. Klinisch: Arteriosclerosis cerebri mit Lähmungen und Demenz. Anatomisch: Allgemeine Arteriosklerose, eiterige Bronchitis und lobulärpneumonische Herde der linken Lunge. Hochgradige Arteriosklerose der Hirngefäße bis in die feinsten Verzweigungen. Multiple Erweichungen von Hanfkorn- bis Bohnengröße im Hemisphärenmark, in Stammganglien und Brücke. 
Histologisch: Mannigfache Degenerationserscheinungen an den Ganglienzellen, be. sonders verbreitet die ,,chronische Zellveränderung“. Die gliöse Randschicht und die tieferen Rindenschichten zeigen einen vermehrten Reichtum an progressiven Gliazellen, dem eine vermehrte Faserbildung in der Randzone und das zahlreiche Vorkommen von Vielstrahlern in Lam. VI im Gliafaserbild entspricht. Die Arterien besonders in Pia und Mark weisen hochgradige atheromatöse Intimaveränderungen auf. Vereinzelte Lymphocyten in den Gefäßscheiden größerer Gefäße. Zahlreiche

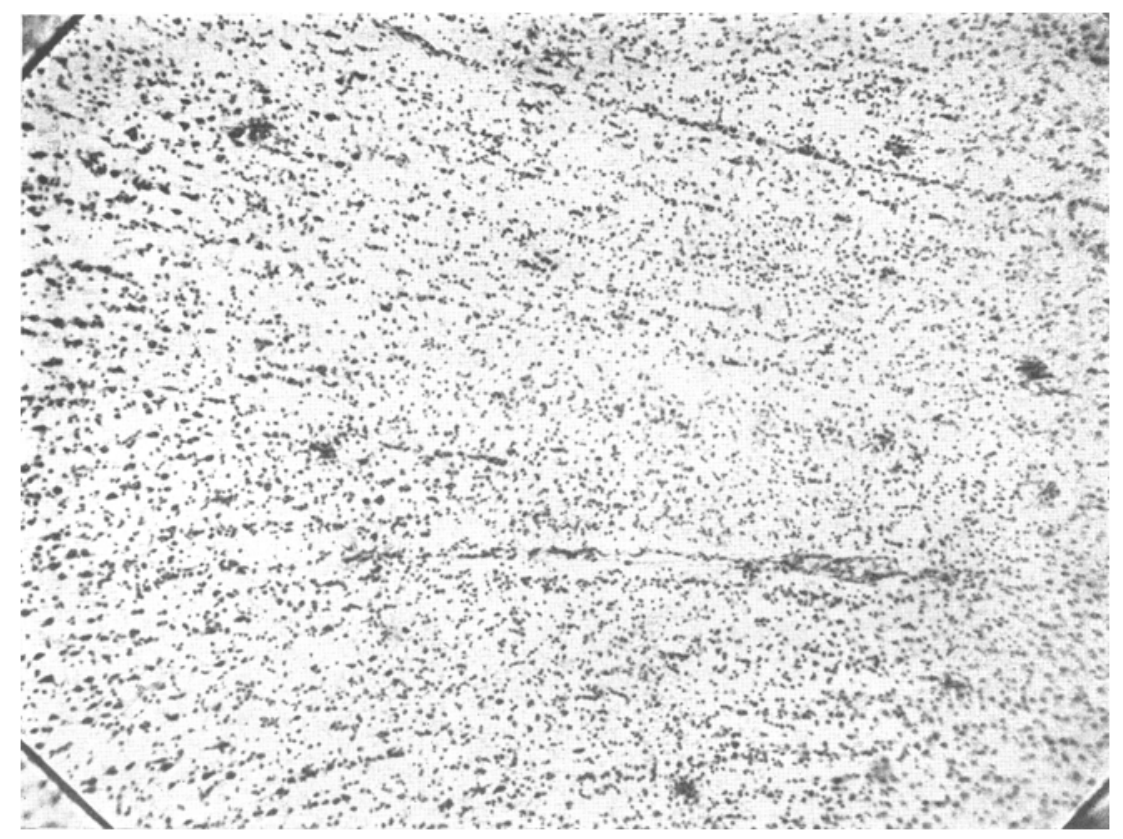

Abb. 5. Toluidinblau. Leitz 2. Ok. 2. Fall Beeh, Arteriosklerose. Eine Anzahl Gliakerne in der untersten Rindenschicht und im Mark Die Glia besonders des Markes befindet sich in lebhafter Wucherung von gemischtzelligem Charakter. Im Gebiet des Vorkommens der Herdchen wiegen die den Herdzellen gleichenden Elemente vor. In den hier nicht abgebildeten, tieferen Markteilen nehmen großkernige Zellen uberhand, womıt die Herdehen allmählich ein uncharakterıstisches Aussehen annehmen und schließlich ganz verschwinden.

hämorrhagische und typische Körnchenzellerweichungen und alle Übergänge zu letzteren. In der weiteren Umgebung dieser beginnenden und völligen Erweichungen noch außerbalb des dichten Gliawalles treten zahlreiche reine Gliasternbildungen auf, bestehend aus syncytial verbundenen Gliazellen mit bröckelig-krümelig aussehendem und stark metachromatisch gefärbtem Plasmaleib und kleinen, dunklen Kernen, die nach dem Rande zu radiäre Stellung einnehmen und dabei oft stäbchenförmig in die Länge gezogen werden (s. Abb. 5). Viele der zum Teil in amitotischer Kernteilung befindlichen progressiven Gliazellen zeigen bereits die regressiven Erscheinungen der Pyknose des Kernes. Mitosen wurden nirgends angetroffen. Auch das Protoplasma der Herdzellen zeigt mannigfaltige Veränderungen; so treten in der zusammenhängenden Protoplasmamasse der zentralen Partie des Herd. chensVakualenbildung bis zur Kerngröße und darüber hinaus auf, während die peripheren, bisweilen schlauchförmigen, protoplasmatischen Ausläufer oft einen unre- 
gelmäßig-feinkammerigen Bau zeigen, welcher sich mehr dem der Gitterzellen nähert, ohne jedoch dessen feine, regelmäßige Struktur anzunehmen. Es handelt sich in beiden Fällen offenbar um regressive Veränderungen des Protoplasmas; jedenfalls dürften sie kaum im Dienste des Lipoidabbaues stehen, denn in keinem der Gliasterne sind scharlachfärbbare Substanzen in irgendwie nennenswerter Menge vorhanden. Die hier und da gefundenen spärlichen Lipoidkörnchen dürften eher mit dem Eigenabbau der Gliazellen in Zusammenhang gebracht werden. In den Bezirken des Vorkommens der Gliasterne wird stärkerer Lipoidabbau überhaupt so gut wie ganz vermißt. Die Größe der Gliasterne beträgt durchschnittlich 20 bis $40 \mu$. Oft liegen sie in der Nähe von Gefäßen, sitzen ihnen auch manchmal auf, häufig ist aber keinerlei Beziehung zu Gefäßen erweisbar. Nur in seltenen Fällen lassen die Herdgefäße leichte regressive Erscheinungen an den Endothelzellen er-

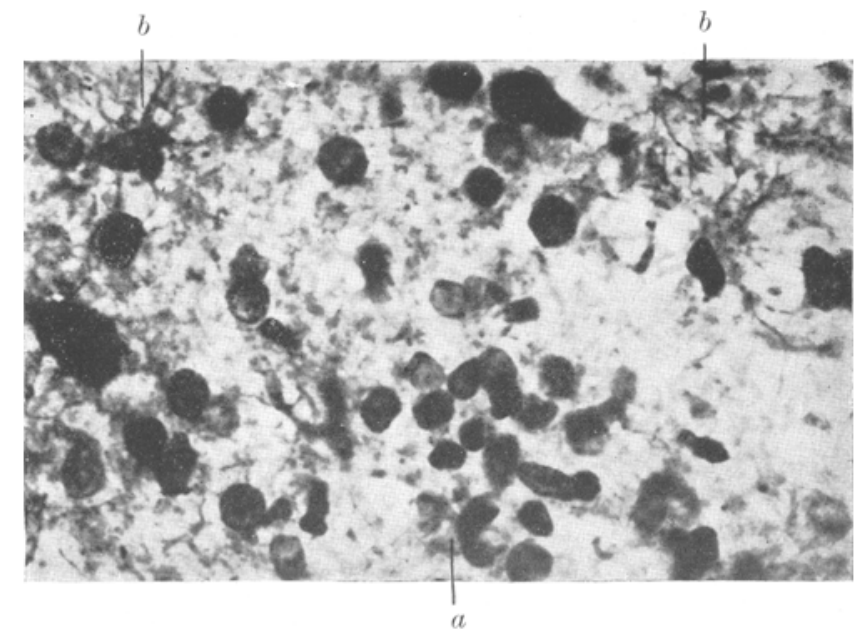

Abb. 6. Gliafaserfärbung nach Holzer (aus Alkohol). Apochr. 4, Comp. Ok. 4. Fall Beeh, Arteriosklerose. Gliastern $a$ der untersten Rindenschicht, faserbildende Gliazellen bel $b$. Die Zellen des Herdchens nehmen an der Gliafaserbildung keinen Anteil.

kennen. Je mehr man sich von der Peripherie her dem die Erweichungen umgebenden Gliawall nähert, der hauptsächlich aus Gliaelementen mit großem, hellem Kern und großem Zelleib (gemästete Formen) besteht, um so mehr verlieren die Gliasterne ihre charakteristische Gestalt, indem sie sich mit anderen progressiven, großkernigen und protoplasmareichen Gliaelementen mischen, die wahrscheinlich aus den eigentlichen Gliasternzellen hervorgegangen, ihre protoplasmatischen Verbindungen zum Gliasterne noch nicht aufgegeben haben. Noch weitergehend in der Richtung der Erweichung findet man schließlich überhaupt keine Gebilde mehr, die als Gliasterne anzusprechen wären, geschweige denn, daß im Gebiet der Körnchenzellbildung noch etwas davon anzutreffen wäre. Das Gliafaserpräparat läßt eine Beteiligung der Gliasterne an der Faserbildung im allgemeinen nicht erkennen, nur in einem lockeren syncytialen Herdchen in der Olive erscheinen die Fasern im Gebiete des Herdchens etwas vermehrt, wobei es jedoch nicht möglich ist, Beziehungen der Fasern zu den einzelnen Zellkernen sicherzustellen. $\mathrm{Zu}$ bemerken ist, da $\beta$ im Bereiche des Vorkommens der typischen Gliasterne das Gewebe, das eine mäßige protoplasmatische Gliawucherung vorwiegend vom Charakter der Herdzellen aufweist, durchaus arm an Gliafasern ist. Aber auch in der VI. Rindenschicht, wo ziemlich reichlich faserbildende Zellen vorkommen, verhalten 
sich die Herdchen, was die Gliafaserproduktion anbelangt, durchaus passiv (siehe Abb. 6). Im Markscheidenpräparat waren die Gliasterne nicht aufzufinden; ein Achsenzylinderausfall ist mit Sicherheit im Herdbezirk nicht nachzuweisen, sie ziehen vielfach ohne sichtbare Veränderungen glatt durch.

\section{Erkrankungen ohne charakteristischen anatomischen Hirnbefund.}

Fall 1. Fischer. 39 Jahre. Klinisch: Seit ca. 1/2 Jahr Gedächtnisabnahme, Kopfweh. Schwindel und Erbrechen. Steifigkeit der Glieder. Wegen Klimax praecox am 3. II. 22 Aufnahme in die Frauenklinik Tiubingen. Am 5. II. 22 wegen gehäuften Auftretens epileptiformer Anfälle in die Psychiatrische Klinik verlegt. Hier noch mehrere Anfälle und anschließend tiefes Koma. Im Urin viel Eiweiß. Diagnose: Urämie. 6. II. 22 Exitus. Sektionsbefund: Chronische Schrumpfniere, keine entzündlichen Veränderungen an den Organen. Gehirn makroskopisch o. B. Histologischer Befund: Keine infiltrativen Erscheinungen an Pia und Gefäßen. Mannigfache Degenerationserscheinungen an den Ganglienzellen der Rinde, lebhafte Wucherung der Trabantzellen. Sehr starke Fetteinlagerungen in Nerven- und Gliazellen, auch in die Gliazellen der Lamina zonalis. Erhebliche Vermehrung der Gliakerne im subcorticalen Mark. Durchschnittlich Elemente von gleicher bis doppelter Größe von Trabantkernen, manche sehr hell, bläschenförmig, mit Kernkörperchen. Das Gliazellprotoplasma ist vermehrt und metachromatisch gefärbt. In den Markleisten des Stimhirnes und der vorderen Zentralwindung finden sich einzelne größere, lockere Herdchen rein gliöser Natur von syncytialem Bau, immer im Zusammenhang mit Gefäßen, die ganz allgemein teils degenerative Erscheinungen der Endothelzellen, teils Wucherungserscheinungen der adventitiellen Elemente aufweisen. Die Gliaherdchen sind nicht ganz typisch, die kleinen, zum Teil regressiv veränderten Kerne relativ wenig chromatinreich, allerdings immer noch mehr als die Zellen der diffusen Wucherung, das stark metachromatische Protoplasma vakuolisiert und sehr zerrissen und zerklüftet. Am Herdrande unterhalten Gliaelemente mit größeren hellen Kernen symplasmatische Beziehungen zu den eigentlichen Herdzellen, möglicherweise sind sie aus ihnen hervorgegangen. Auch die Gliazellen des Markes enthalten reichlich Fettkörnchen, die Herdzellen eher weniger als die diffus gewucherten. Unter letzteren befinden sich eine erhebliche Anzahl faserbildender Astrocyten, die aber an der Herdbildung keinen Anteil haben. Ganz typische Gliasterne und -rosetten waren im vorliegenden Fall nicht auffindbar.

Fall 2. Bauer. 40 Jahre. Klinisch: Schwangerschaftsnephritis mit urämischen Symptomen. Wegen deliranter Unruhe von der Frauenklinik München am 7. VI. 17 in die Psychiatrische Klinik verlegt. Hier halluzinatorische Verwirrtheit mit Angst, völlige Anurie, urämischer Blutbefund. 19. VI. 17 Exitus. Histologischer Hirnbefund: Keine Infiltration der Pia und Gefäße. Tigrolyse und hochgradige Lipoideinlagerungen in die Ganglienzellen der Rinde mit Vermehrung der Trabantund Gefäßbegleitzellen. Einzelne, teils lockere, teils dichtere größere und kleinere symplasmatische Gliaherdchen im subcorticalen Mark, die aus Zellen mit progressiven, aber nur wenig vergrößerten Kernen zusammengesetzt sind, und deren metachromatisches Protoplasma eine teils feinkörnige, teils kammerige Struktur hat. Vom Herdrande aus strahlt das Protoplasma mit vielfachen Ausläufern ins diffuse Gliareticulum aus. Auch die diffus gewucherten Gliazellen, die im Durchschnitt von ähnlicher Beschaffenheit wie die Herdzellen sind, zeigen die Neigung mit gleichgearteten Elementen symplasmatische Verbindungen einzugehen. Größere Gliazellen fehlen. Die syncytialen Herdchen weisen alle Beziehungen zu Gefäßen auf, ohne daß die Gefäßwandzellen auffällige Veränderungen darböten; der Aufbau der Herdchen ist rein gliös. 
Fall 3. Bode. 41 Jahre. Klinisch: Seit 2 Jahren vor der Aufnahme Kopfweh, Erbrechen, 1/4 Jahr vorher Netzhautblutung. 27. X. 15 Krankenhaus 1. d. Isar. Diagnose: Urämie. Wegen deliranter Unruhe in die Psychiatrische Klinik verlegt am 26. XI. 15. Exitus am 29. XI. 15. Sektionsbefund: Chronische Schrumpfniere. Perikarditis, hämorrhagisch-seröse Pleuritis, urämische Darmgeschwüre. Histologischer Hirnbefund: Keine Infiltration der Pia und Gefäße. Ganglienzellen vorwiegend im Zustand der ,"chronischen Veränderung“" mit Auflösungserscheinungen und Fetteinlagerungen. Geringe Vermehrung der Gliakerne in der Rinde, durchweg trabantzellähnliche Elemente. Im subcorticalen Mark der vorderen Zentralwindung ein größeres und ein kleineres syncytiales Gliaherdchen, beide von Capillaren durchzogen, deren Wandzellen alle Anzeichen progressiver Veränderung darbieten. Eines der Herdchen enthält zwei Lymphocyten. Das größere Herdchen ist insofern atypisch, als am Herdrande an seiner Zusammensetzung auch größere protoplasmareiche Gliazellen teilnehmen und das Protoplasma der Herdzellen eine gequollene und schaumige Struktur aufweist. Die Kerne der Herdzellen sind rela. tiv wenig chromatinreich, progressiv und teilweise auch wieder regressiv verändert. Auch die diffuse Gliawucherung ist uneinheitlich und enthält in der Nähe des größeren Herdchens Zellen mit großen, hellen Kernen und reichlichem Protoplasma.

Fall 4. Ritter. 25 Jahre alt. Schizophrenie mit depressi nehmenden Beziehungs- und Beeinflussungsideen; später unrein und gewalttätig. Tod im katatonischen Erregungszustand unter den Zeichen der Kreislaufschwäche. Krankheitsdauer ca. 2 Jahre. Histopathologisch: Mannigfache Nervenzellveränderung, vornehmlich Chromolyse und chronische Zellveränderung mit leichter diffuser Vermehrung der wenig vergrößerten Gliakerne in der Rinde. Vereinzelt Erscheinungen der schweren Zellveränderung; keine Gefäßinfiltration in Rinde und Pia. In der Medulla oblongata vereinzelte Infiltratzellen an einzelnen größeren Gefảßen (Lymphocyten und Plasmazellen). Chromolytische Veranderungen an den Nervenzellen, mäBige diffuse protoplasmatische Gliawucherung, die an manchen Stellen Verdichtungen aufweist, besonders in den Gebieten grauer Substanz. Im Seitenstrang ein längliches Gliaherdchen im Zusammenhang mit einer Capillare. Das Zentrum wird von einer Protoplasmamasse von kornig-krümeliger Beschaffenheit mit eingestreuten Gliakernen gebildet, nach dem Rande zu gewinnt es mehr und mehr die Struktur eines syncytialen Netzes mit weiten Maschen. In das Herdchen sind einige Lymphocyten und typische Plasmazellen, die sich zum Teil im Zustande der Degeneration befinden, eingelagert. Die teils länglichen, teils runden, nicht sehr chromatinreichen Gliakerne, die bisweilen die doppelte Größe von Plasmazellkernen erreichen, zeigen hier und da Veränderungen im Sinne der Pyknose. Es finden sich noch mehrere ähnliche Herdehen in der Medulla oblongata und ein rein gliöses Herdehen im subcorticalen Mark der vorderen Zentralwindung ohne Beziehung zu einem Gefäß.

Fall 5. Zeuß. 28 Jahre. Aufnahme in die Psychiatrische Klinik in München am 26. I. 21. Diagnose: Katatonie. Beginn mit paranoiden und religiösen Ideen, ängstlicher Abwehr, die sich schnell zu einem heftigen, katatonischen Erregungszustand steigerte. Stereotypien und bisweilen choreatisch aussehende Armbewegungen. Viel Eiweiß und Zylinder im Urin, in den letzten Tagen Fieber zwischen 38 und $39^{\circ}$. Am 4. II. 21 Exitus an Pneumonie.

Histopathologisch: Diffuse Ganglienzellveränderungen leichteren Grades und mả Bige diffuse Gliawucherung trabantzellähnlicher Zellen in der Rinde. Keine Infiltrationserscheinungen an den Rindengefäßen. In der Medulla oblongata außer Fetteinlagerungen und hier und da zentraler Chromolyse keine sehr auffälligen Veränderungen an den Ganglienzellen. Die Lymphscheiden vereinzelter größerer 
Gefäße, deren Endothelien teilweise leichte Degenerationserscheinungen aufweisen, enthalten in spärlicher Zahl und nur hier und da in kleinen Ansammlungen auftretend Lymphocyten und Makrophagen, die gröbere Einschlüsse erkennen lassen. Die Glia befindet sich hier in diffuser protoplasmatischer Wucherung, wobei die Gliakerne ziemlich chromatinreich und nur wenig vergrößert sind und oft langliche und geknickte Formen annehmen. Ihr weit verzweigtes Protoplasma tritt deutlich hervor. In den grauen Teilen finden sich eine ganze Anzahl symplasmatischer Gliaherdchen oft bis zu vier in einem Schnitt, die teils locker, teils kompakter gebaut sind, in ihren größeren Exemplaren bis zu 80 und mehr Kerne enthalten und den im vorigen Fall beschriebenen Herdchen ähnlich sind. In den meisten Fällen gelingt es, die Beziehung zu Capillaren oder Präcapillaren nachzuweisen, bisweilen folgen sic in ihrem Verlauf auch einem Markfaserzug. Mitunter finden sich auch Ganglienzellen in ihrem Bereich, abcr als regelrechte Umklammerung oder Substitution treten sie nicht auf. Einzelne Herdchen sind an. scheinend rein gliös, in der Mehrzahl aber enthalten sie mehrere $Z /$ llelemente, die von typischen Plasmazellen nicht zu unterscheiden sind. Jie Herkunft einzelner andere $r$ Kerne ist nicht mit Wicherheit festzustellen; sie könnten ebensogut pyknotische Plasmazellkerne oder pyknotisch veränderte Gliakerne sein. Außer pyknotischen Erscheinungen finden sich noch hyperchromatische und vereinzelte karyorrhektische Veränderungen an den Gliakernen der Herdchen, die im ubrigen ganz denen der diffusen Gliawucherung gleichen. Im subcorticalen Mark der vorderen Zentralwindung stößt man auf e in gleichgeartetes Herdchen mit exzentrische $m$ Gefä $\beta$, dessen Wandelemente regre ssiv verandert sind. Das Protoplasma der Herd. zellen ist sehr zerklüftet und zerrissen, stark metachromatisch, hicr und da mit Vakuolen versehen, die teilweise geplatzt erseheinen. Der Lipoidabbau ist gering; man findet nur in einzelnen großeren Ganglienzt llen stärkere Mengen feinkơrnigen Lipoids; in den Gliazellen fehlt es fast vollig, und auch in den Gefäßwandzellen ist es nur sehr spärlich. Die Herdehen enthalten gleichfalls kein Lipoid. Eine vermehrte Gliafaserbildung besteht nicht. - Die als symplasmatische Gliaherdehen zu identifizierenden Anhäufungen von Gliakernen sind zum Teil von einzelnen Gliafasern durchzogen, einen erkennbaren Anteil an der Faserbildung nehmen die Herdehen jedoch nicht. Dabei ist allerdings zu bemerken, daß sie nur in faserarmen Gegenden zu finden sind.

Fall 6. Lang, Xaver. 25 .Jahre alt. Klinisch: Ende 1914 im Feld als hysterischer Dammerzustand aufgefaßte psychische Veränderung, die sich rasch zuruckbildete. Dieser Zustand, der sich teils in Verträumtheit und Ratlosigkcit, teils in cinem läppisch-heiteren Stuporzustande äußerte und mit eincr rezidivierenden linksseitigen Facialisparese und rechtsseitigen Hypoglossusparese, cinmal auch mit gleichzcitigem rechtem Facialiskrampf einherging, wiederholte sich in kurzen Pausen etwa funfmal. Ende 1916 wurde in einem Lazarett die Diagnose Hebephrenie gestellt. Trotzdem kam L. im Frühjahr 1917 wieder ins Feld und hielt sich im allgemeinen gut bis zu seiner Entlassung Ende 1918. Winter 1919/20 Erregungszustand mit Verfolgungswahn und nachfolgendem negativistischen Stupor. Nach weitgehender Besserung bis zu volliger Arbeitsfähigkeit Neuerkrankung unter allmählicher Herausbildung eines Stupors, die am 12. II. 21. zur Aufnahme in die Psychiatrische Klinik Tübingen führte. Hier Wechsel von Zuständen völligen Stupors mit Negativismus und Flexibilitas und solchen hochgradiger, motorischer Erregung mit Rededrang, Grimassieren, Verbigerieren und völliger Inkohärenz. Neurologischer Befund ohne Besonderheiten. Ende Juni Phlegmone der Kopfschwarte, an die sich eine hämolytische Allgemeininfektion anschließt. 17. VII. 21 Exitus, nachdem er am Tage zuvor bei völlig klarem Bewußtsein ganz geordnete Briefe nach Hause geschrieben hatte. Diagnose: Katatonie. Sektion: Multiple 
Abscesse in Nieren und Lunge, Infiltration beider Unterlappen. Starke milchige Trübung und Verdickung der Pia von der Zentralfurche bis zum Stirnpol beiderseits. Histopathologisch: Pia bindegewebjg verdickt, kernarm, ohne nennenswerte Infiltration. Die Ganglienzellen der Rinde und der Stammganglien befinden sich im Zustand mehr oder minder weit fortgeschrittener Chromolyse. In der Medulla oblongata sind besonders die größeren Ganglienzellen der Kerngebiete noch sehr gut erhalten. Ganz elektiv sind die Ganglienzellen der Oliven befallen. Im ganzen Band treten die Ganglienzellen im Nisslbild nur wenig hervor; sie sind mit Aus. nahme ganz weniger, die beiderseits im ventralen Gebiet der Oliven liegen, ballonartig aufgetrieben und enthalten ein gelblichgrunliches Pigment, das sich mit Scharlach gelblichrot färbt, ähnlich den pathologischen Zelleinlagerungen der amaurotischen Idiotie. Der Protoplasmarest mit dem scharfkantigen mehr oder weniger gut färbbaren Kern sitzt dem Ballon als Häubchen auf. Ähnliche, wenn auch nicht so hochgradige Veränderungen zeigen die Ganglienzellen des Nucleus dentatus, wohingegen die Purkinjeschen Zellen nur eine unvollständige Auflösung des Tigroids aufweisen. An den Gefäßen sind hier und da leichte Quellungserscheinungen an den Endothelien zu beobachten; nur sehr vereinzelt enthalten die Lymphscheiden Lymphocyten und Plasmazellen. Polynucleare Leukocyten sind außer in einigen Gefäßlumina der Stammganglien nirgends zu finden. Von den Veränderungen der Glia ist außer den gleich zu schildernden Befunden nur eine etwas lebhaftere Wucherung der GefäBbegleitzellen, die im Großhirnmark vereinzelt zu kleinen Rosettenbildungen geführt hat, zu vermerken. In der Medulla oblongata von der Höhe des oberen Endes des Nucleus XII bis herunter zur Schlei. fenkreuzung finden sich in der Gegend des sensiblen Trigeminus- und des Vaguskernes eine ganze Reihe von Zellherdehen, die simtlich an die dort befindlichen Gefaße verankert erscheinen. Diese zeigen stellenweise deutliche progressive Erscheinungen der Adventitialzellen. Die Herdchen, die im Zentrum dichter, an der Peripherie lockerer gebaut sind, bestehen zum größten Teil, und zwar besonders in der Peripherie, aus syncytial gewucherten Gliazellen mit vielfach stabchenförmigen Kernen, deren Protoplasmaausläufer zum Teil ein Netz bilden, das sich nach außen hin in das diffuse Gliareticulum verliert. Im Zentrum der Herdehen, wo die Zellen sehr dicht liegen und vielfach keine deutlichen Zellgrenzen zeigen, ist es nicht immer moglich, die Herkunft der Zellen einwandfrei zu bestimmen. Eine geringe Anzahl weist bei absolut scharfen Zellgrenzen die Mehrzahl der für Plasmazellen charakteristischen Merkmale auf, keine jedoch in soleher Vollständigkeit, daß sie den z. B. bei Paralyse massenhaft zu findenden Plasmazellen gleichzusetzen wäre. Man wird sie am ehesten als morphologische Zwischenstufen von Plasmazellen und Lymphocyten ansehen durfen. Eine weitere Reihe von Zellen mit langen, oft recht dunnen Kernen lassen cinen unmittelbaren /usammenhang mit einer Gefáßwand erkennen, so daß man mit Wahrscheinlichkeit auf gewucherte mesodermale Elemente schließen darf. Aus Form und Struktur der Kerne allein ist hier eine Zelldifferenzierung jedenfalls nicht moglich. Außer den eben geschilderten größeren Herdchen, die sich unter fortwährender Formänderung (Teilung und Verschmelzung) über 10 und mehr $20 \mu-S c h n i t t e$ erstrecken und eine Art perivascularer Zellmäntel darstellen, beobachtet man noch kleine rein gliöse Herdchen von der Art der Glia. sterne in derselben Gegend der Medulla oblongata. Das Protoplasma der symplasmatischen Gliazellen ist metachromatisch gefärbt, vielfach krümelig und stark zerklüftet, die Kerne sind sehr chromatinreich, dunkel, wenig vergrößert, viele pyknotisch. Etwa im Bereich der Herdchen liegende Ganglienzellen werden, ohne schwerere Veränderungen ihrer Struktur zu zeigen, schalenförmig von den Herdgliazellen eingeschlossen. Im Fettpräparat enthalten die Herdchen nirgends Einschlüsse von mit Scharlach färbbaren Substanzen, wie überhaupt Lipoide außer 
in den Olivenzellen und einigen größeren Ganglienzellen nirgends in größerer Menge mit der Scharlachmethode nachweisbar sind. Die Herdchen werden von wenigen starken Gliafasern durchzogen, deren Zugehörigkeit zu außerhalb liegenden großen, hellen Kernen oft unschwer zu erweisen ist. Hier und da treten einzelne allerfeinste, sehr schwach gefärbte Gliafasern zutage, die Beziehungen zu innerhalb der Herdehen liegenden Gliakernen zu haben scheinen. Das Protoplasma der Herdzellen umfließt die unverändert durchziehenden Markscheiden und Achsenzylinder vielfach völlig.

In der Molekularschicht der Kleinhirnrinde findet sich das von Spielmeyer und neuerdings von Sagel witder beschriebene Gliastrauchwerk an sehr zahlreichen

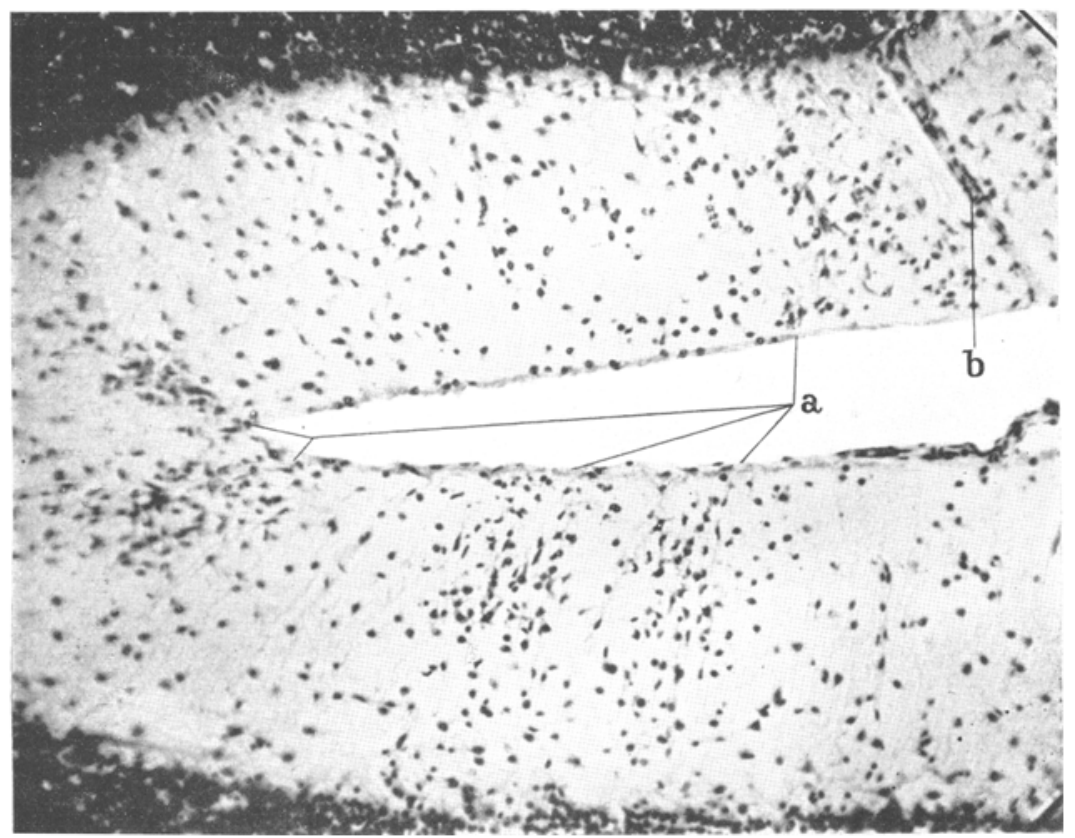

Abb. 7. 'Tolud(inblau. ZeiB B, Ok. 2. Fall Lang, Katatonie. Sepsis. 5 Crliastrauchwerke in der Klemhirnmole $a$. Die Reihe der Purkinjezellen ist luckenhatt. Lin großeres Gefaß bes $b$

Stellen in typischer Weise (s. Abb. 7) und außerdem eine große Anzahl von Gliasternen und -rosetten im Kleinhirnmark, zum Teil in Verbindung mit Gefäßen, zum Teil ohne erkennbare Beziehung dazu. Die Zellen des Strauchwerkes zeigen besonders in ihren protoplasmatischen Anteilen zahlreiche regressive Veranderungen, die in blasigen Auftreibungen und Zerreißungen der ehemals mehr schlanken, geißelartigen Fortsätze in Erscheinung treten, wobei die Kerne oftmals noch rein progressiv erscheinen. Andererseits findet man nicht selten Pyknose und karyorrhektische Veränderungen, besonders Kernsprossungen. Zahlreich sind auch amitotische Kernteilungen; Mitosen waren in unserem Falle selten. Mesenchymale Elemente sind im Gliastrauchwerk und den Rosetten und Sternen des Kleinhirnmarkes nicht enthalten. Während die Purkinjezellen im Nisslbild hier keine schwereren Veränderungen aufweisen, zeigen die Kerne der Körnerschicht vielerorts schwere karyorrhektische Erscheinungen. Lipoide Stoffe waren mittels der 
Scharlachmethode weder im Strauchwerk noch in den Gliasternen des Kleinhirn. markes nachzuweisen; ebensowenig war irgendwo eine Beteiligung an der Gliafaserbildung vorhanden. Lipoidabbau und Gliafaserbildung traten aber auch sonst im Kleinhirn nirgends in auffallender Weise hervor.

Fall \%. Reichle, Jakob. 42 Jahre. Klinisch: Bekam Anfang April 1921 im Anschluß an einen religiösen Vortrag aus völliger Gesundheit heraus plötzlich einen Erregungszustand mit religiösen Wahnideen. 17. IV. 1921 Aufnahme in die Psychiatrische Klinik Tübingen. Hier starke motorische und sprachmotorische Erregung, zusammenhanglose Äußerungen meist religiösen oder obszönen Inhalts. Gewalttätig, ängstlich, verkennt die Umgebung, schmiert, Nahrungsverweigerung. Dazwischen kurzdauernde klare Zeiten mit Orientierung und Krankheitseinsicht. Rascher korperlicher Verfall. Phlegmonen am Kreuzbein, Knie- und Ellenbogen.

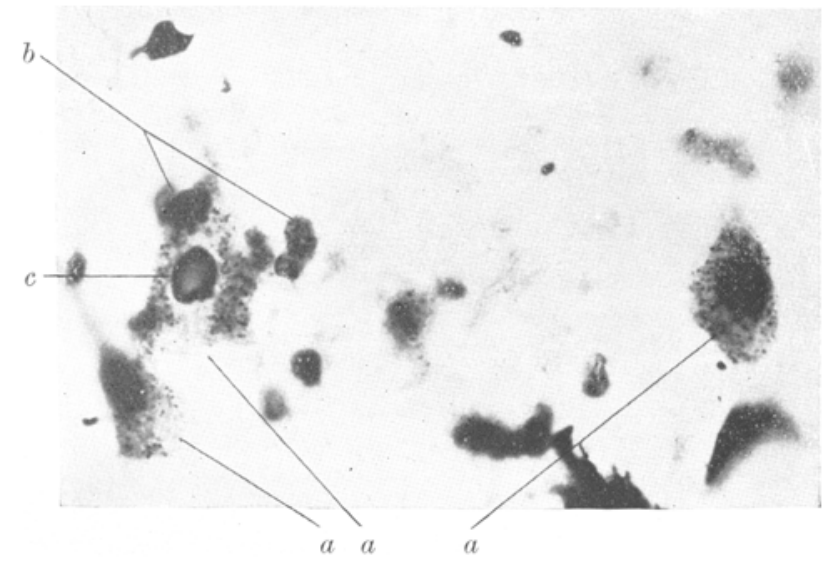

Abb. 8. Holzer-Krystallviolett aus Alkohol. 1/12 Imm. Conı\}. Ok. 4. Fall Relchle, Katatonie. Drei degenerierende Ganglienzellen $a$. Keine Gliafaserbildung der umklammernden Gliazellen $b$. Das im Nisslbild farblose Prostoplasma der untergehenden Ganglienzellen zeigt hier eine Unmenge fein* körniger Eunlagerungen. Bei $c$ homogener Ganglienzellkern.

gelenk; Exitus am 3. V. 21. - Diagnose: Katatonie. Körpersektion ergibt keine entzündlichen Veränderungen der inneren Organe. Gehirn blutreich, geringer Hydrocephalus internus, sonst ohne Besonderheiten. Histologisch: In der Pia stellenweise etwas lebhaftere Wucherung junger Bindegewebszellen, einzelne hämatogene Infiltratzellen. In den Scheiden der größeren Rindengefäße, die sonst keine auffälligen Veränderungen darbieten, ganz vereinzelte Lymphocyten und Mastzellen. Polymorphkernige Leukocyten finden sich vielfach in größerer Menge in den Gefäßlumina, nie in den Gefäßscheiden oder frei im Gewebe. Die meisten Ganglienzellen befinden sich im Zustand mehr oder weniger fortgeschrittener Chromolyse; andere, besonders die größeren, erscheinen völlig intakt. Die Glia in der Rinde und den grauen Kernen ist in leichter diffuser Wucherung begriffen, keine großkernigen Zellformen. In der Rinde findet ein ziemlich lebhafter, fixer Lipoidabbau statt; eine vermehrte Gliafaserwucherung ist nicht vorhanden. Im Stratum pyramidale des linken Ammonshorns nahe dem Ansatz der Fimbria sitzt ein einzelner, kleiner, weißer Erweichungsherd, der, obwohl es zur Körnchenzellenbildung gekommen ist, relativ zellarm ist. Die Ganglienzellen des dichten Stratum pyramidale sind hier völlig zugrunde gegangen und spurlos verschwunden. Es fallen außer den verhältnismäßig spärlichen Körnchenzellen gliösen und mesen- 
chymalen Ursprungs, die oft nur undeutlich die typische Gitterbildung zeigen, vor allem eine Menge von siegelringartigen Zellen auf, die zum Teil geformte Einschlüsse enthalten. Die Glia befindet sich in ziemlich lebhafter protoplasmatischer Wucherung, wobei die kaum vergrößerten Kerne eine Neigung zum Längenwachstum zeigen und das metachromatisch gefarbte Protoplasma in breiten Bändern vom Kern aus in verschiedenen Richtungen ausstrahlt. Freie hämatogene Elemente sind nicht nachzuweisen. Die Gefäße innerhalb des Erweichungsherdes sind deutlich vermehrt, an vielen sind Sprossungen vorhanden. Alle diese progressiven Veränderungen am gliösen und mesodermalen Gewebe bieten nun in sehr auffälliger Weise weitgehende degenerative und Zerfallserscheinungen dar. Es ist die repara-

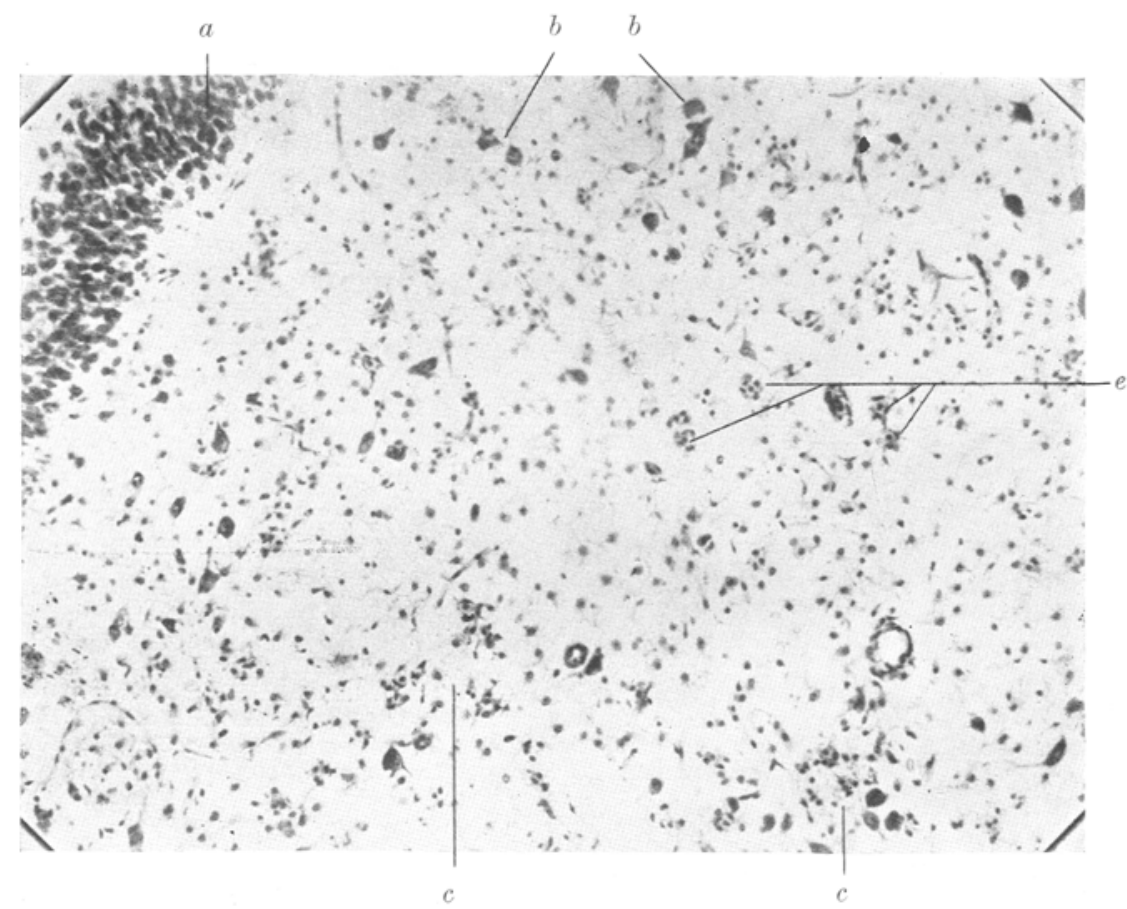

Abb. 9. Toluidinbla1, Apochr. 16, Comp. Ok. 4. Fall Relchle, Katatone. Wigenartige Form ausgedehnten, disseminierten Ganglienzellunterganges in der Lage der Pyramidenzellen der Fascia dentata a stratum granulosum des Ammonshornes, $b$ erhaltene Ganglienzellen, $c$ untergehende Ganglienzellen, die von symplasmatischen Glazellen umklammert sind.

torische Wucherung mitten in ihrer Entwicklung unterbrochen worden, indem ihre Bausteine mit wenigen Ausnahmen so weit geschädigt worden sind, daß sie dem Untergang verfallen sind, ohne die ihnen zufallenden Aufgaben vorher erfüllt zu haben. Gegen das Stratum radiatum setzt sich die Erweichung in eine zarte strauchwerkartige Gliazollwucherung fort, die im Nisslbild durchaus dem zu vergleichen ist, was man in der Kleinhirnrinde als Gliastrauchwerk bezeichnet. Es handelt sich um meist lange stäbchenförmige Elemente, die außer den Spitzenfortsätzen noch einen oder mehrere seitliche Protoplasmafortsätze tragen, durch welche sie mit benachbarten Zellen in Verbindung stehen. Das Protoplasma zeigt. bereits Vakuolisierung und Zerreißung, während die Kerne noch progressiv erscheinen und kaum Rückbildungserscheinungen erkennen lassen. Am Übergang 
des Stratum pyramidale des Ammonshornes in die Lage der Pyramidenzellen der Fascia dentata stoßen wir auf einen ausgedehnteren Bezirk, in dem als auffälligste Erscheinung die Ganglienzellen eine einheitliche Veränderung darbieten. Ihr Protoplasma ist bei ziemlich gut erhaltener äußerer Form fast bis zur Unsichtbarkeit abgeblaßt, während die Kerne klein, rund und in blaulichem Ton ziemlich dunkel gefärbt sind, so daß sie den Kernen bei der ,schweren Ganglienzellveränderung““ Nissls gleichen. Ihr Chromatin ist zu feinstem Staub zerfallen. Bei der Fürbung mit Krystallviolett nach Holzer erscheinen sie rötlich-violett, von homogener Struktur, wohingegen sich im Ganglienzellprotoplasma, das ja im Nissbild farblos ist, bis in die Dendriten in ziemlich regelmäßiger Verteilung eine Unmenge feinster, dunkelbìauer Körnchen eingestreut finden (s. Abb. 8). Um jede dieser untergehenden Ganglienzellen liegt mit ganz wenigen Ausnahmen ein Kranz protoplasmatisch gewucherter Gliazellen in einfacher oder doppelter Lage, die die Gan.

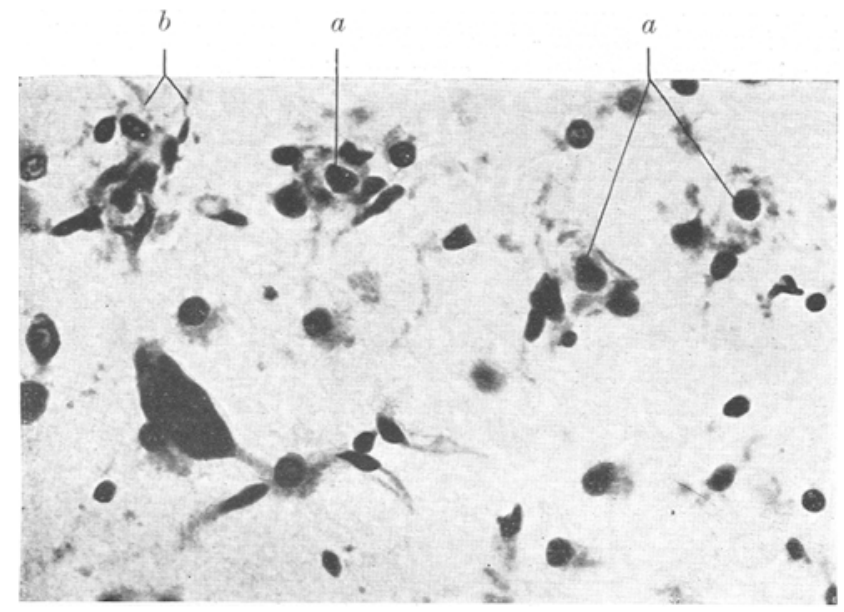

Abb. 10. Vergroßertes Teilbıld von Abb. 9. Apochr. 4, Comp. Ok. 4. Vier untergehende und eine erhaltene Ganglienzelle. Die umklammernden Gliazellen respektieren das Territorium der Ganglienzellen, deren Protoplasma fast völlig farblos und strukturlos erscheint. Die Ganglienzellkerne sind dunkel, geschrumpit und gleıchfalls ohne deutliche Struktur. Die außere Form der Ganglienzellen ist trotz der schweren Veränderungen gut gewahrt. $a$ die einheltlich veränderten Kerne zugrunde gehender Ganglienzellen. $b$ Protoplasmıauslänfer der umklammernden Glazellen.

glienzellen schalenförmig einschließen und dabei protoplasmatische Ausläufer radienartig in die Umgebung senden; immer bleibt das Territorium der Ganglien. zelle unangetastet (Abb. 9 u. 10). Die Elemente dieses Zellkranzes weisen gegeneinander keine scharfen Abgrenzungen auf, vielmehr geht ihr metachromatisches Protoplasma an vielen Stellen brückenartige, syncytiale Verbindungen ein. Letzteres sowie die meist länglich geformten Kerne weisen deutliche degenerative Anzeichen auf, die sich in Vakuolisierung und Auffaserung des Protoplasmas und in Kernpyknose dokumentieren. Auffällig ist die Kernarmut dieser Zellkränze den pericellulären Gliasternen gegenüber, die man bei Encephalitis epidemica findet. Es nehmen oft nur etwa sechs Zellkerne an dem ganzen Vorgang teil. Wahrschein. lich ist dieser Befund so zu erklären, daß bei zunehmender Stärke der Noxe die progressive Entwicklung vor ihrer Vollendung durch regressive Vorgange unterbrochen worden ist, wie es ja auch bei dem vorhin beschriebenen, kleinen Erweichungsherd angenommen wurde. Die Gefäßveränderungen in diesem Gebiet sind geringfügig, einzelne Endothelzellen in den Capillaren sind etwas gequollen, 
Infiltrate finden sich nicht. Im Gliafaserpraparat sind weder im Gebiet der strauchwerkartigen Gliawucherung noch in dem der degenerierten Ganglienzellen Gliafasern zu bemerken, während im umgebenden, weniger alterierten Gewebe einzelne faserbildende Spinnenzellen eingestreut liegen, der Alvt us und der Hilus fasciae dentatae sogar eine auffallende Gliose zeigen. Leider war infolge der Kleinheit dieser herdförmigen Erkrankung von den beiden Gebieten Formolmaterial nicht vorhanden, so daß das Verhalten des Lipoidabbaues und der Verlauf der Achsenzylinder nicht untersucht werden konnte. Es gelang auch trotz langem Suchens nicht, àhnliche Stellen im Gehirn wiederzufinden.

Fall 8. Braun, Clara. 47 Jahre. Klinisch: 1900 nach Entbindung schwermütig, suicidal, dann manisch erregt, Heilung nach 7 Monaten; 1913 aufgeregt, widerwärtig, reizbar, dann Umschlag in gehemmte Depression, von 1913-1919 in der Anstalt. In der Folgezeit zu Hause, war umgänglich, versah ihren Haushalt, behielt eine eigenartige Sprach- und Haltungsmanier. Anfang September 1921 allmählich wieder erregt geworden, sang ununterbrochen, beschimpft den Ehemann, ist eifersüchtig, obszön, vielgeschäftig, schlagfertig und von außerordentlichem Rede- und Bewegungsdrang. 17. IX. 21 Aufnahme in die Psychiatrische Klinik Tübingen. Singt, schreit, queruliert, obszön, erotisch. Starke Ablenkbarkeit und Ideenflucht. Völlig orientiert. Auffallender Mangel an Schamgefühl, unsauber, onaniert, wird schnell ziemlich stumpf, dabei dauernd motorisch erregt. Körperlich keine Anzeichen für eine organische Erkrankung. 8. X. 1921 plötzlicher Exitus. Diagnose: Manisch-depressives Irresein? Kórpersektion: Die Körperorgane weisen keine krankhaften Veränderungen auf. Todesursache nicht feststellbar. Blasses Gehirn von sehr weicher Konsistenz, Gewicht 1340 g. Makroskopisch o. B. Histopathologisch: Abgesehen von leichteren chromolytischen Erscheinungen an den Ganglienzellen sind gröbere Veränderungen in Rinde, Stammganglien und Nachhirn nicht nachweisbar. Auffällig ist nur das massenhafte Vorkommen von Corp. amylacea in der Kleinhirnrinde, wo man in jedem Gesichtsfeld (Zeiss D) eines oder mehrere findet, oft von einer Gliazelle eingeschlossen. Die Glia bietet nirgends auffällige proliferative oder degenerative Erscheinungen dar, die Gefäße sind von normaler Beschaffenheit, Infiltrate sind nirgends vorhanden. In dem Kerngebiet der Medulla oblongata, besonders in der Gegend der Vaguskerne und des sensiblen Trigeminuskernes ist die Glia in diffuse protoplasmatische Wucherung geraten; manche der Ganglienzellen haben hier ein zentral homogenisiertes Protoplasma, andere sind im Nisslbild kaum verändert. Im Scharlachpräparat erweisen sich alle in reichem Maße mit Fett beladen; auch in den Gliazellen ist Fett, allerdings in weit geringerem Maße enthalten. Gefäßinfiltrate sind auch hier nirgends nachweisbar, abgesehen von ganz vereinzelten Lymphocyten und atypischen Plasmazellen. In dem genannten Kerngebiet treten nun hier und da pericelluläre und perivasculäre Gliaherdchen zutage, die aus Zellen mit kleinen, dunklen, in der Herdmitte meist runden, an der Peripherie länglichen Kernen bestehen, deren stark metachromatisches Protoplasma im Herdzentrum zu einer einheitlichen, von Zelle zu Zelle nicht abgrenzbaren Masse von körnig-krümeliger Beschaffenheit verschmolzen erscheint, während es am Rande dendritenartig in das diffuse Glianetz ausstrahlt. Manche Herdchen sind lockerer und haben netzartige Struktur (Abb. 11). Die Zellteilung erscheint vorwiegend amitotisch zu geschehen, worauf viele oft grotesk in die Länge gezogene Kernfiguren mit Abschnürungen hinweisen. In dem progressiven Gesamtbild sind aber auch schon manche Zeichen regressiver Veränderung enthalten, die besonders in der Pyknose vieler Kerne in Erscheinung treten. Hämatogene Elemente sind in den Herdchen nicht enthalten, ebensowenig wie mesenchymale nachzuweisen waren. Allerdings zeigen die adventitiellen Elemente der im Herdchen liegenden 
Gefäße bisweilen auch leichtere progressive Erscheinungen ihrer Kerne. Die zufällig im Herdgebiet liegenden Ganglienzellen werden auch, ohne daß sie Untergangserscheinungen darböten, von den Herdzellen schalenförmig eingeschlossen. Die Herdchen erstrecken sich im Durchschnitt über 4-6 $15 \mu$-Schnitte. Lipoid enthalten nur einzelne Herdzellen in verschwindender Menge; an der Gliafaserbildung, die in den Gebieten des Vorkommens der Herdchen allerdings nirgends hohe Grade erreicht, nchmen sie nicht teil. Die Färbung nach Alzheimer V ergibt nichts Neues; amöboide Zellformen sind jedenfalls nicht vorhanden. Ein Markscheidenausfall im Herdbercich ist nicht zu erkennen, ebensowenig wie Axondegenerationserscheinungen. Die Achsenzylinder sind hier höchstens etwas auseinandergedrängt.

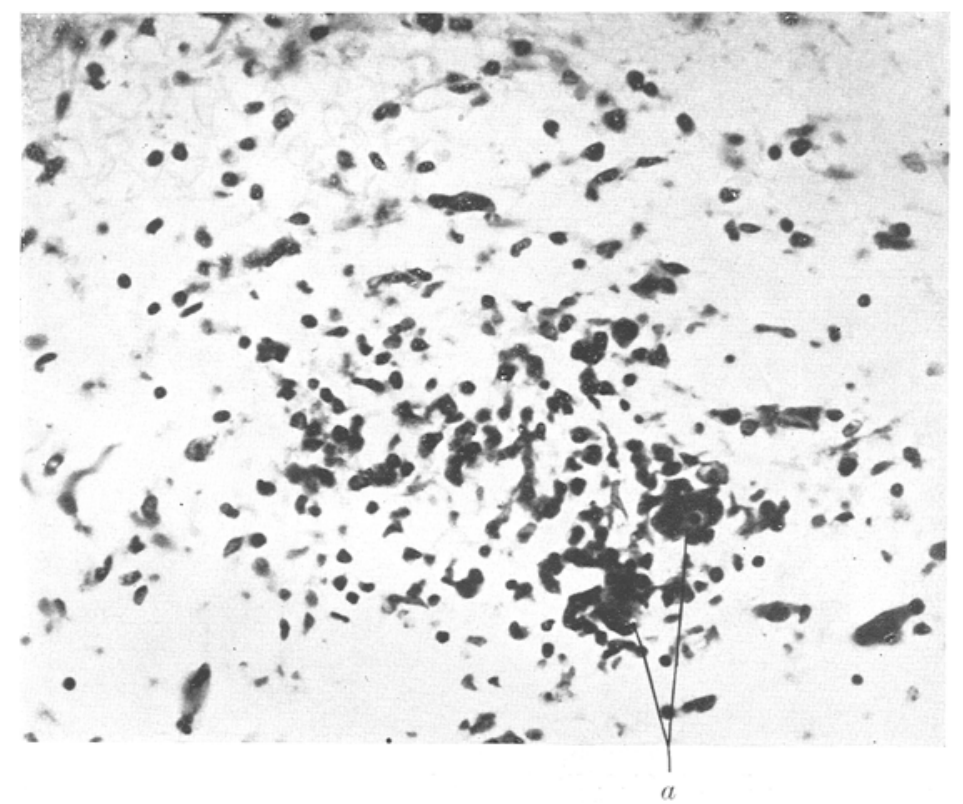

Abb. 11. Toluidiublau. Apochr. 8, Comp. Ok. 6. Fall Braun, Manisch-depr. Irresein. Lockeres Gliaherdchen in der Med. obl. I)ie teils runden, tells länglıchen Gliakerne liegen in einem deutlich hervortretenden, grobbalkigen Protoplasmanetz. Bei $a 2$ in den Herdbereich gezogene und umklammerte Ganglienzellen, dı in ihrer Strulstur keine gröberen Veränderungen aufweisen.

Fall 9. Franer, Hellmuth. 42 Jahre. Klinisch: Seit Jahren Sonderling, brachte es trotz guter Begabung nicht zum zweiten juristischen Examen. Schrieb jahrelang an einem Werk über Völkerrecht. Seit Herbst 1921 zunehmende Planlosigkeit, Anfang Januar 1922 allmählich erregter. 15. I. 22 in die Psychiatrische Klinik Tübingen aufgenommen. Zunächst starr, wenig zugänglich, steht völlig unter dem Einfluß seiner Sinnestäuschungen und immer reichlicher werdenden Wahnbildungen. Dann immer heftigere Erregung, glaubt sich vergiftet, spricht mit Gott, gewalttätig und rücksichtslos gegen sich selbst. Zieht sich mehrere Verletzungen zu, die sich infizieren; septische Erscheinungen, hohes Fieber. 5. II. 22 Exitus. Diagnose: Katatonie; Sepsis. Sektionsbefund: Mehrere vereiterte Rippenbrüche beiderseits und einige Hautdefekte mit teils phlegmonöser, teils abscedierender Eiterung. An den inneren Organen keine entzündlichen Veränderungen. Hirn- 
gewicht $1570 \mathrm{~g}$. Hirnsubstanz stark flüssigkeitshaltig, fleckige Rindenzeichnung, Hyperämie. Anormaler Verlauf der Striae acusticae, weites Cavum septi pellucidi. Histologisch: In Pia und Rindengefaßen spärliche Infiltrationszellen (Lymphocyten), etwas stärkere Infiltration der größeren Gefäße der Medulla oblongata. Chromolyse und wabige Degeneration des Protoplasmas der Ganglienzellen der Rinde, in geringerem Maße auch der Medulla oblongata. Ziemlich starke Fettablagerung in allen Ganglienzellen, in extremem Maße in den kugelförmig aufgetriebenen Olivenzellen. Vermehrung der Trabantzellen mit Neigung zur Neuronophagie besonders in der Rinde, in der Medulla oblongata diffuse, kleinzellige, protoplasmatische Gliawucherung besonders in den grauen Kernen mit zahlreichen

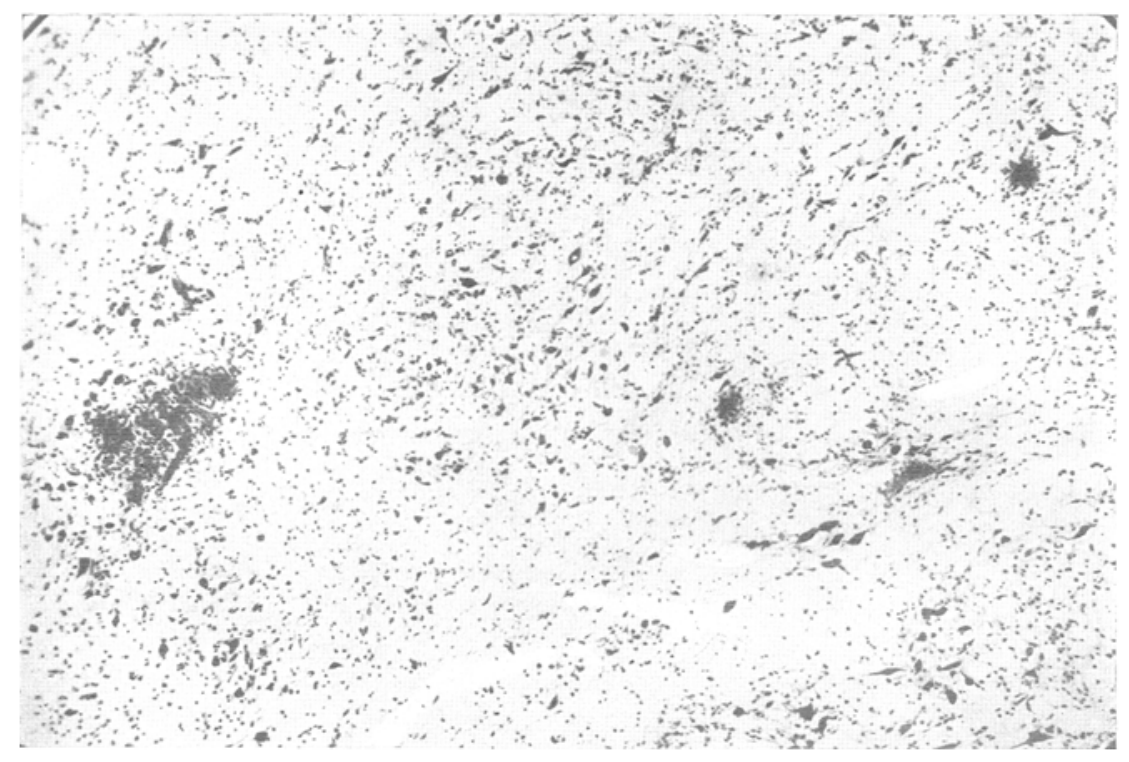

Abb. 12. Toluidinblau. Leitz 2. Ok.2. Fall Frauer. Katatonie. Mehrere Gliaknótchen in der Med. obl.; links ein Herdkonglomerat und an dessen Peripherie unten ein infiltriertes Gefaßchen.

rosetten- und knötchenförmigen Herdbildungen, die zum größeren Teil perivasculär, zum kleineren pericellulär als Ganglienzellumklammerungen auftreten (Abb. 12 und 13). Sie bestehen wie der größte Teil der diffusen Gliawucherung aus Zellen mit kleinen, runden und stäbchenformigen, sehr chromatinreichen Kernen mit progressiven und progressiv-regressiven Merkmalen, die von einem lebhaft metachromatisch gefärbten, besonders am Herdrande reich verzweigten und sich all. mählich in die Umgebung verlierenden Protoplasma umgeben sind, welches mit den Nachbarzellen syncytiale Verbindungen unterhält. Regressive Erscheinungen an Protoplasma und Kernen sind noch ziemlich selten, Mitosen wurden nicht beobachtet. Es finden sich oft 12 und mehr Herdchen von sehr wechselnder Größe und Dichte in einem Schnitt. In manchen Gefảßherdchen sind 1 oder 2 Plasmazellen enthalten, sonst ist der Aufbau rein gliös. Die Herdgefäße, deren es meist mehrere gibt, sind gewöhnlich nicht infiltrierte Capillaren. Nicht immer zeigen die Wandzellen der Herdgefäße Veränderungen, bisweilen aber doch pyknotische Veränderungen der Kerne, Quellungserscheinungen des Protoplasmas und eine undeutliche 
Zeichnung der Elastica. In Alzheimer IV- und V- und Bielschowskypräparaten sieht man die Nervenfasern wohl auseinandergedrängt, aber ohne Veränderungen an Markscheiden und Axonen durch die Herdchen, mitunter sogar durch das Protoplasma der Herdzellen hindurchziehen. An den Alzheimerpräparaten tritt die syncytiale Natur der Herdchen deutlich zutage, die Beteiligung der Astrocyten an der Herdbildung wird auch an Cajalgliapräparaten immer vermißt. Eine Mit. wirkung der Herdchen an der Faserbildung war nirgends zu erkennen. Nicht ganz einheitlich war die Beteiligung der Herdchen am Lipoidabbau. Schon im Nisslpräparat war an derGanglienzellpigmentaufnahme durch die pericellulären Herdchen ihre Eigenschaft, geformte Bestandteile aufnehmen zu können, erkennbar. Im Fettpräparat war dann auch das aus der umklammerten Ganglienzelle stammende

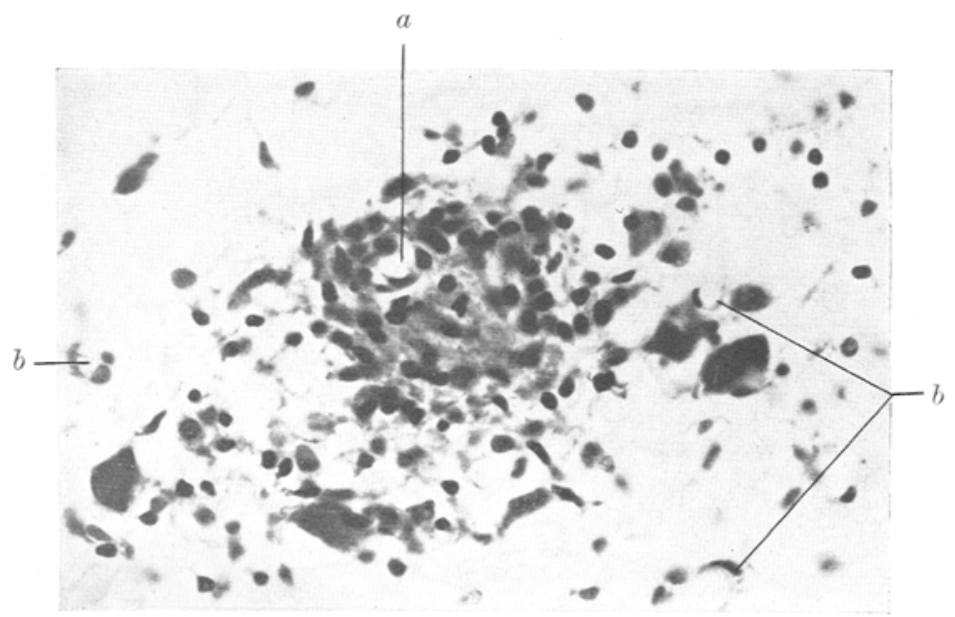

Abb. 13. Tolutunblau. Zeiß, Aporhrom. 8, Comp. Ok. 6. Fall Frauer. Katatonie. Perivasculäres Gliaknotchen aus der Med. obl. a Herdgetaß, b Capillaren. Sehr deutlich tritt hier das metachronatische Protoplasma der Herdzellen hervor.

Lipoid in den Herdzellen in annähernd gleichmäßiger Verteilung wiederzufinden. Dagegen enthielten die Zellen der Gefäßherdchen nur dann mit Scharlach färbbare Abbauprodukte, wenn zufällig fettig degenerierende Ganglienzellen in den Herdbereich einbezogen waren oder an der Herdperipherie lagen; es handelte sich dabei aber immer nur um einzelne kleine Körnchen. Im allgemeinen erwiesen sie sich als völlig lipoidfrei. In der Kleinhirnrinde zeigten sich die ersten Anfänge zur Gliastrauchwerkbildung.

\section{Gliom.}

Fall 1. Hess, Hans. Klinisch: Ponstumor. Anatomisch: Große weißliche Geschwulst, die die Brücke unförmig aufgetrieben hat und auf der rechten Seite hornartig aus dem Niveau vorspringt. Histologisch: Sehr zellreiches, nur aus einer Zellart bestehendes Gliom, das den gesamten Brücken- und Hirnschenkelfuø einnimmt und sich nach der Haube zu ganz allmählich im Gesunden verliert. Die spindeligen Gliomzellen folgen mit ihrer Längsrichtung dem Verlauf der Mark. faserung; an längsgetroffenen Faserzügen sind die Zellkerne lang, spindelig oder Stäbchenzellkernen ähnlich, an Markfaserquerschnitten als Querschnitte klein und 
rund, Das ziemlich spärliche, scharf metachromatische Zellprotoplasma sitzt in der Hauptsache den Kernpolen auf und verzweigt sich nach kurzem Verlauf vielfältig. Im übrigen sind die Kerne nur von einem gewöhnlich recht schmalen Protoplasmasaum umgeben. Die Protoplasmaausläufer gehen mehr oder weniger deutlich erkennbar symplasmatische Verbindungen mit Nachbarzellen ein. Besonders dicht sind die Gefálße von Gliomzellen umlagert. Die inmitten des Glioms liegenden Ganglienzollen sind meist gut erhalten; dagegen findet sich cin erheblicher

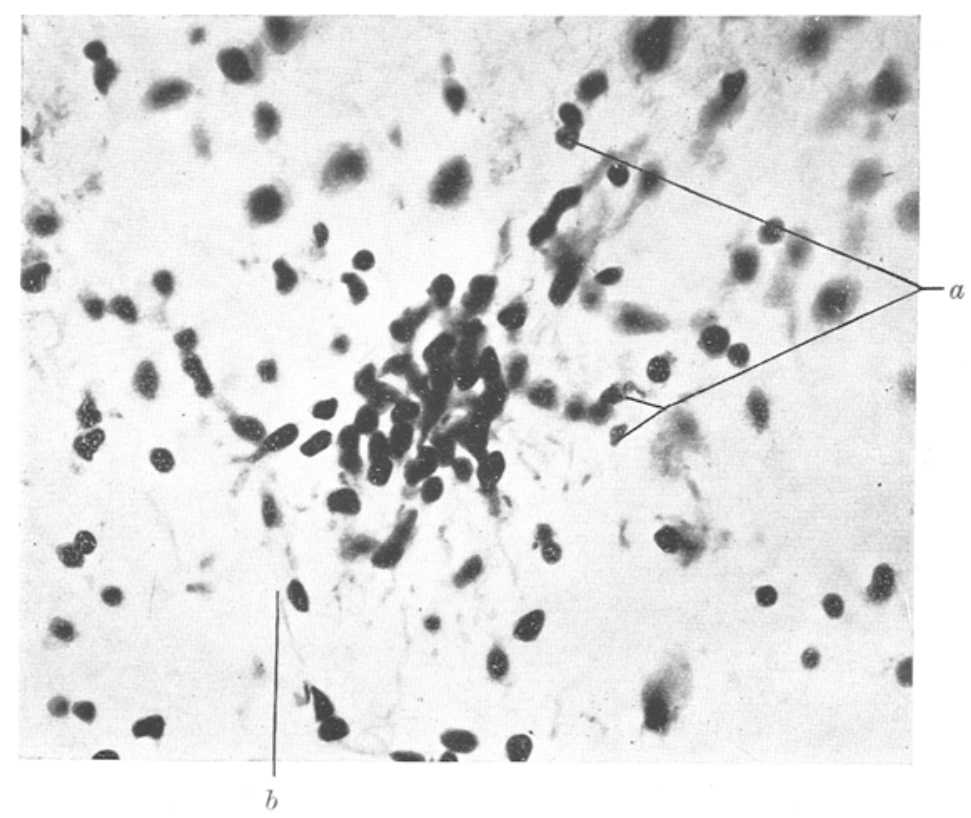

Abb. 14. Toluidinblau. Zeiss D. Ok. 2. Fall Hess. Rosette aus Ghomzellen auf einem Querschnitt durch die Pyrarnide. Man beachte die im Gliareticulum verlaufenden, langen Protoplasmaauslaufer der Geschwulstzellen, die untereinander syncytial verbunden sind. $a$ ursprünglich vorhandene Gliazellen, $b$ Capillare.

Ausfall an Markscheiden, dem aber wieder ein unvermuteter Reichtum an Axonen gegenübersteht. Gehen wir nun tief in die Medulla oblongata hinunter bis dicht oberhalb der Pyramidenkreuzung, wo von einem soliden Tumor längst nichts mehr zu bemerken ist, so begegnen wir in den Pyramidensträngen einer mäßigen diffusen Vermehrung der Gliazellen, die zum Teil gewöhnlichen progressiven, zum Teil den Charakter der Geschwulstzellen haben. Und hier finden wir nun um einzelne Gefäße herum Rosetten, die aus Gliomzellen bestehen, deren Kerne außerordentlich chromatinreich sind, und deren metachromatisches Protoplasma in ganz bizarre Gabelungen und Verzweigungen ausläuft (Abb. 14). Es dirfte schwer sein, ohne Kenntnis des Gliombefundes diese Rosetten ohne weiteres von den bisher beschriebenen zu unterscheiden. Das Protoplasma dieser Gliomzellenherdchen, das gegen die Herdmitte eine zusammenhängende Masse bildet und sich nach außen hin geißelartig in die Umgebung verliert, wobei häufig Stäbchenzellformen zu beobachten sind, bietet jedenfalls dafür keine charakteristischen Unterschei- 
dungsmerkmale. Nur der durchgehends ganz auffällige starke Chromatingehalt der Kerne läßt die gliomatöse Natur der Herdchen erkennen. Das Gliom enthält sehr reichlich äußerst feine, nur mit besonderen Kunstgriffen durch die Holzer sche Methode darstellbare Fasern, die vielfach noch den Eindruck feinfädiger Protoplasmastrukturen erwecken. In den Teilen stärkster Zellwucherung des Tumors finden sich Fasern aber ebensowenig wie in den gliomatösen Rosetten.

Das Bemerkenswerte im vorliegenden Falle, der dem Gegenstand unserer Untersuchungen nicht eigentlich zugehört, ist das Wachstum der Geschwulst. Sie folgt hier in auffallendem Maße dem normalen Bauplane des Organs, sie hat nur geringe aggressive Tendenzen dem Nervenparenchym gegenüber, dem sie wohl hauptsächlich durch den von ihr ausgeübten Druck verderblich wird. Die Wachstumsbahnen des Glioms liegen hier innerhalb des diffusen Gliareticulums, das zwar in loco deformiert, aber in seinem architektonischen Aufbau nicht zerstört wird. Da es sich bei den Gliomrosetten um dieselbe Art der Geschwulstzellen handelt, wird man auch für sie dieselbe Art des Wachstums annehmen dürfen und daraus weiterhin auf das Wachstum der unseren Betrachtungen zugrunde liegenden Gliaherdchen Schlüsse ziehen können.

\section{Encephalitis epidemica.}

Die Untersuchungen erstreckten sich auf 12 Fälle, die in den verschiedensten Stadien der Krankheit ad exitum gekommen waren. Die Ergebnisse sollen in folgendem in zusammenfassender Weise wiedergegeben werden, wobei auf eine alles umfassende Darstellung verzichtet werden kann, um so mehr als die Befunde eines Teiles der Fälle bereits von Creutzfeld dargelegt worden sind ${ }^{1}$ ). Erwähnt sei nur, daß sich die Befunde mit den von Creutzfeld und Gross mitgeteilten im wesentlichen decken. Unser Augenmerk soll in der Hauptsache auf die herdförmigen gliösen Wucherungen gelenkt sein, zu deren Studium sich die Encephalitis epidemica in hervorragendem Maße eignet. Vor allem mußte unser Bestreben darauf gerichtet sein, Fälle von möglichst verschiedener Krankheitsdauer miteinander zu vergleichen, um Werden und Schicksal der Herdchen studieren zu können. Die ältesten Fälle hatten eine Krankheitsdauer von ca. $1 / 2 \mathrm{Jahr}$; der jüngste Fall kam innerhalb von 10 Tagen zum Tode. Bei fast allen Fällen war die Diagnose Encephalitis epidemica intra vitam gestellt worden; die klinischen Erscheinungen waren so polymorph, wie sie bei der Erkrankung eben sein können; einer der älteren Fälle bot das striäre Syndrom in fast isolierter Ausprägung.

Um eine übersichtlichere Darstellung der Befunde zu ermöglichen, soll hier gleich vorausgenommen werden, daß unsere Untersuchungen dazu geführt haben, zwei histopathologisch verschiedene Arten des Krankheitsverlaufes einander gegenüberzustellen, die in folgendem Schema skizziert sind.

1) Creutzfeld 1. c. 


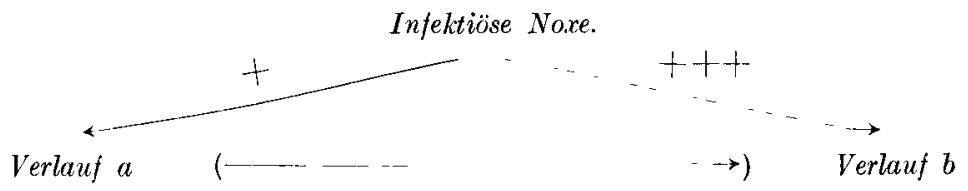

Gefäßinfiltration mit nur mäßiger Ausstreuung hämatogener Zellen. Lebhafte diffuse und herdformige syncytiale Gliawucherung (Gliasterne-Rosetten-Knotchen), keine nennenswerten Fettablagerungen in Ganglien- und Gliazellen, disseminierter Ganglienzcllenuntergang mit und ohne Gliaumklammerung bzw. Neuronophagie. MäßigeGliafaserbildung durchweg von kleinen Zcllen ausgehend.

Verschwinden der diffusen Gliawuche. rung und eines Teiles der Herdchen. An den noch vorhandenen ausschließlich oder vorwiegend regressive Erscheinungen. Verschwinden der verstreuten hämatogenen Flemente und $\operatorname{der}$ Gefä $\beta$. infiltrate. Disseminierter Ganglienzellausfall, mäßige Vermehrung der fascrigen Glia.

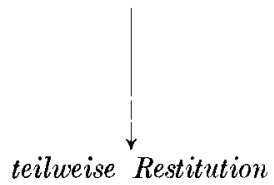

Enorme Gefäßinfiltration mit massenhafter Ausstreuung von Lymphocyten und Plasmazellen zwischen eine diffuse und herdformige Gliawucherung, die auch in den herdförmigen Wucherungen von uneinheitlichem Zellcharakter ist. Zurücktreten des syncytialen Baues der gliösen Veränderungen. Dafür Auftreten großkerniger, plasmareicher Elemente, die Fasern differenzieren. Auffälliges Hervortreten umfangreicher Fettablagerungen in Ganglien- und Gliazellen. Wucherungserscheinungen an den Gefäßwandzellen.

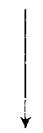

Allgemeine fettige Degeneration der Nervenzellen, lebhafter, zunächst fixer Lipoidabbau, wozu sich allmählich mobile Abräumezellen gliöser und mesodermaler Abkunft ge'sellen. Sehr starke Fascrproduktion besonders von seiten der Gliamonstrezellen.

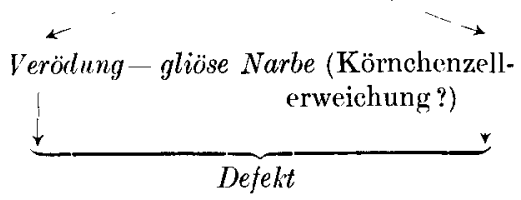

Die Zahl der + Zeichen soll den Intensitätsgrad der einwirkenden Noxe andeuten, auf den die Verschiedenartigkeit des histologischen Bildes zurückzuführen ist, $(-\rightarrow \rightarrow)$ die Möglichkeit des Überganges des milderen Verlaufes in den stürmischeren bei erneuter oder stärkerer Einwirkung der infektiösen Schädlichkeit.

Wir werden uns in folgendem bei Beschreibung der gliösen Erscheinungen und ihrer Begleitumstände in den verschiedenen Krankheitsphasen und Verlaufsarten der Einfachheit und Kürze halber immer wieder auf das vorstehende Schema beziehen, wobei wir die beiden Ver. laufsarten mit $a$ und $b$ bezeichnen.

Betrachten wir zunächst das akute Stadium des Verlaufes a, so stand immer eine starke Infiltration der größeren Gefäße mit Lympho- 
cyten und Plasmazellen im Vordergrund und an die Versorgungsgebiete der infiltrierten Gefäße gebunden eine lebhafte, diffuse Wucherung von Gliazellen. In dieser Wucherung steht eine Zellart im Vordergrund, die durch folgende Merkmale charakterisiert ist: Kleine, runde und längliche, vielfach stäbchenförmige Kerne, die oft in ihrem Verlaufe Knickungen unterworfen sind oder auch seitliche Sprossen tragen. Besonders die länglichen Kernformen besitzen ein polar angeordnetes, deutlich metachromatisch gefärbtes Protoplasma von körnig- krümeliger oder mehr homogener Beschaffenheit, das durch seine dendritenförmige Aufsplitterung meist irgendwo Verbindungen zu oft ziemlich weit entfernt liegenden, ähnlichen Zellen unterhält. Wir haben dadurch im Schnitt ein weitmaschiges Netz vor uns, das stereometrisch als ein lockeres, schwammähnliches Gebilde zu denken wäre. Neben dieser Art Gliazellen begegnen wir einer anderen, anscheinend im Ruhezustand befindlichen mit vornehmlich runden Kernen, die einen nach allen Seiten wohlabgegrenzten Zelleib besitzen, der die Farbe nur in ganz geringem Maße angenommen hat. Ferner wieder anderen, die durch progressive Veränderung aus diesen hervorgegangen sind, was sich hauptsächlich in einer leichten Vergrößerung ihres Kernes. einer stärkeren des Protoplasmaleibes mit vermehrter Färbbarkeit äußert. Ubberall zerstreut, bald vereinzelt, bald $\mathrm{zu}$ mehreren beieinanderliegend findet sich außerdem eine Art Zellen, die alle charakteristischen Merkmale von Plasmazellen, meist allerdings ohne den bekannten perinucleären, hellen Hof aufweist. In der lockeren Gliawucherung treten nun hier und da, und zwar mit Vorliebe an kleinen, meist nicht infiltrierten Gefäßchen und an Ganglienzellen, bisweilen aber auch ohne nachweisbaren Zusammenhang mit beiden herdförmige Verdichtungen auf, die die bekannten Gliasterne, -rosetten oder größere syncytiale Gliaherdchen darstellen. Die Zellbestandteile sind dieselben, wie die der diffusen Gliawucherung, nur treten hier die syncytial verbundenen Gliazellen der zuerst beschriebenen Art an Zahl und Dichte stark in den Vordergrund. Neben lebhafteren Proliferationserscheinungen, die sich vornehmlich in amitotischen Kernteilungen und auch in einzelnen Mitosen dokumentieren, sind auch eine Reihe regressiver Veränderungen, besonders in den ziemlich zahlreichen pyknotischen Kernen zu bemerken. Freie Bindegewebselemente waren mit Sicherheit weder in der diffusen Wucherung noch in den Herdchen nachzuweisen. Zahl und Größe der herdartigen Verdichtungen sind außerordentlichen Schwankungen unterworf $\in \mathbf{n}$. Sie bevorzugen die markarmen Teile. Am konstantesten in der Größe sind die pericellulären, symplasmatischen, von Gross ,Ganglienzellgräber" genannten Gliawucherungen; sie bilden durchschnittlich 2-3 Zellagen. Das ganze Gebilde überschreitet gewöhnlich $50 \mu$ nicht. Die Bausteine sind im 
allgemeinen nur Gliazellen (s. Abb. $15 \mathrm{a}$ und b), allerdings kommen auch bisweilen einzelne Plasmazellen im Herdchen vor, ohne daß ein Gefäß in unmittelbarer Nähe wäre. Erheblicher sind die Größenunterschiede der Gefäßherdchen. Die syncytialen Gliazellen umscheiden

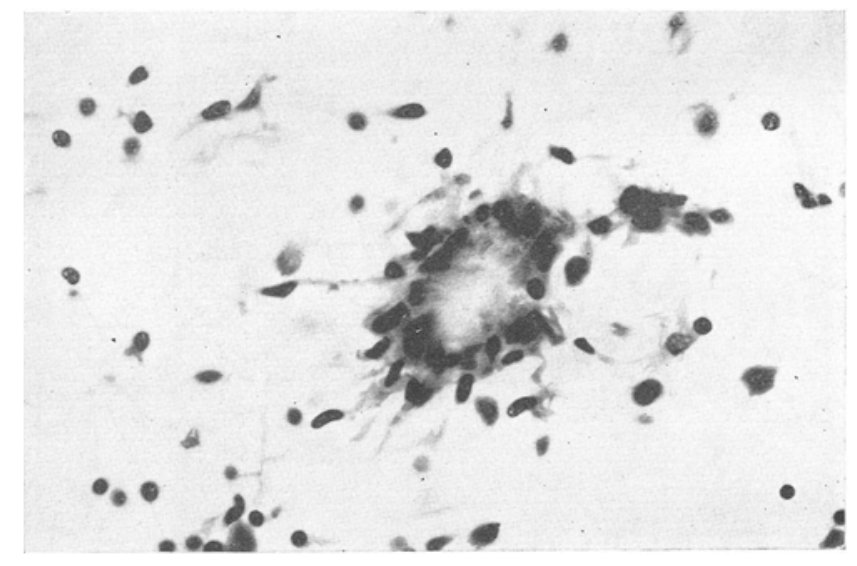

Abb. 15 a.

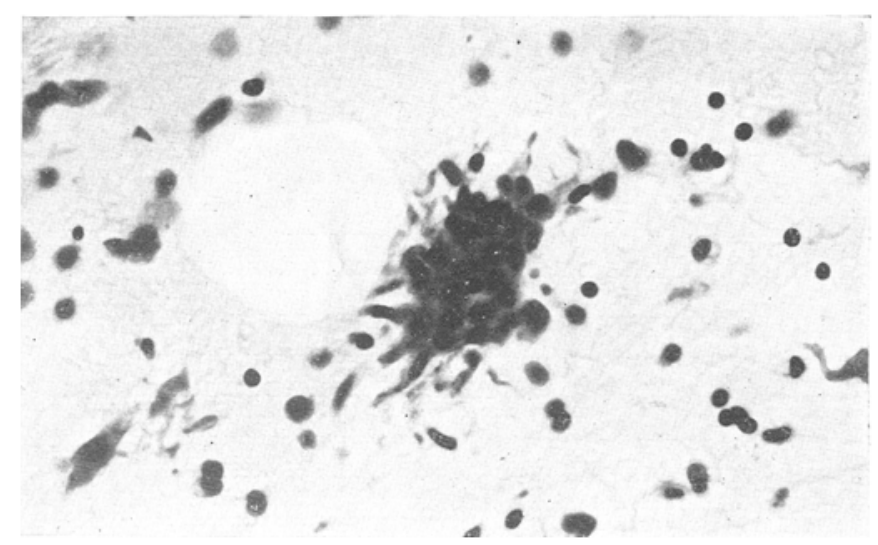

Abb. 15 b.

Abb. $15 a$ und $b$. Toluidinblau. A pochr. 8, Comp. Ok. 8. Encephalitis epldemica. Typisches nur ca. $45 \mu$ dickes Rosettenherdchen in Aufsicht und im Durchschntt in 2 aufeinanderfolgenden Serienschnitten. Das Herdınnere in $b$ wird aus den Resten einer zerfallenen Ganglieuzelle gebildet, die vom Herdchen schalenförmig eingeschlossen werden.

hier die Gefäße oft auf lange Strecken mit dichten Mänteln, die häufig auch den Verzweigungen der Gefäße folgen. Abb. 16 stellt ein solches langgestrecktes Herdchen mit Verzweigungen im Verlaufe eines Gefäßes dar, das fast ausschließlich aus Gliazellen besteht. Es ist durch 
eine ganze Serie von 15 Schnitten zu $15 \mu$ zu verfolgen; auf Querschnitten erscheint es als mehrere nebeneinanderliegende Rosettenherdchen, die den Gefäßästen konzentrisch oder exzentrisch aufsitzen. Bemerkenswerterweise zeigen die derart eingescheideten Gefäße in keinem Falle, abgesehen von vereinzelten Lymphocyten oder Plasmazellen, Infiltrate; die Gefäßwandelemente weisen nur geringfügige Veränderungen im

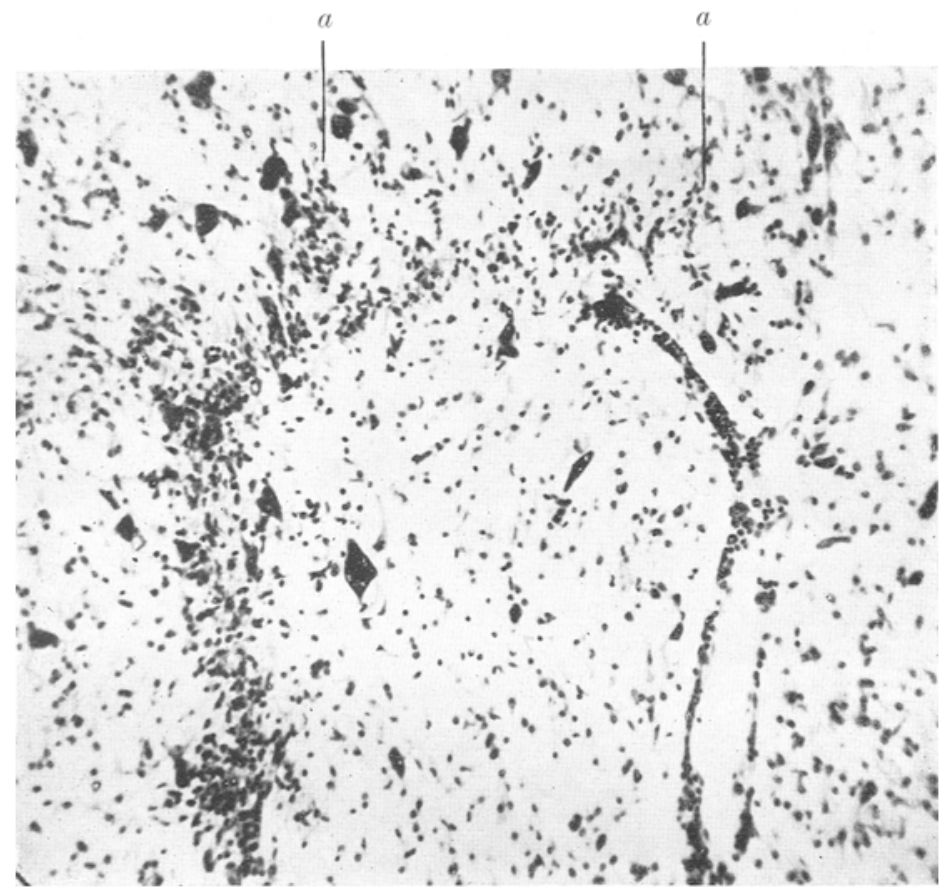

Abb. 16. Toluidunblau. Zeı B OK 2 Encephalıtis epidemica. Perivascularer, gliöser Zellmantel mit mehreren Ausläufern entsprechend den Gefaßverzweigungen $(a)$ in der Med. obl. In anderen Schnitten der Serie präsentıert sıch der Zellmantel im Querschnitt als Rosette oder Knotchen. Rechts davon in der Abbildung infiltriertes Gefäß. Die diffuse Gliawucherung bewahrt vorwegend den Charakter der Herdzellen.

progressiven oder regressiven Sinne auf, in vielen Fällen scheinen sie sich aber völlig im Ruhezustand zu befinden. Ebensowenig lassen sich die Beziehungen der Herdchen zu Ganglienzellen im Nisslpräparat auf einen gemeinsamen Nenner bringen. Die Art der Nervenzellerkrankungen ist äußerst polymorph. Es läßt sich allerdings erkennen, daß die Veränderungen vielfach von Anfang an zu morphologisch darstellbaren Zerstörungen und Autlösungserscheinungen an den Nervenzellen führen (vgl. Gross), aber man hat auch nicht selten Gelegenheit, anscheinend langsamer verlaufende Nervenzellerkrankungen zu beobachten, unter welchen relativ häufig eine Art der Ganglien- 
zellerkrankung anzutreffen ist, die mit zentraler Chromolyse und Homogenisierung des Zellplasmas beginnt. Dabei wird der Kern randständig, so daß Bilder entstehen, die der primären Reizung ähneln. Oft bleibt der geblähte Kern aber auch inmitten der homogenen Substanz im Zellzentrum liegen. Gesetzmäßige Beziehungen zwischen Herdbildung und Art und Schwere der Ganglienzellerkrankungen waren hier ebensowenig wie in den Fällen von Gross feststellbar, die syncytiale Umklammerung oder Neuronophagie geschieht scheinbar wahllos.

Die eben besprochenen Veränderungen der Glia sind in den frischen Fällen graduell recht verschieden. Sie gehen mit der Stärke der infiltrativen Erscheinungen bis zu einem gewissen Grade parallel. Einen qualitativen Unterschied in der gliösen Reaktion bemerken wir aber an den Orten sehr stürmischer Erscheinungen. Hier kommt es dann zum ersten Stadium des Verlaufes b. Dabei halten sich die dichten Infiltratmäntel viel weniger an die Gefäßscheiden. Wir finden das ganze Gewebe dicht übersät mit infiltrierenden Elementen, Plasmazellen, Lymphocyten und deren morphologischen Zwischenstufen. Zwar trägt die diffuse Gliawucherung immer noch manches von dem syncytialen Charakter an sich, es kommt aber nicht mehr in typischer Weise zu den oben beschriebenen Herdbildungen. Was bei oberflächlicher Betrachtung so aussieht, erweist sich bei näherem Zusehen in der Hauptsache als eine Ansammlung von Lymphocyten und Plasmazellen in buntem Durcheinander mit allen möglichen gewucherten Gliaelementen. Die typischen Zellformen der syncytialen Herdchen sucht man dabei jedenfalls vergebens. Und nun tritt noch eine andere Art gliöser Zellen in den Vordergrund, die große helle Kerne mit ein oder zwei Kernkörperchen und einen zart gefärbten umfangreichen Protoplasmaleib besitzen, der mit teilweise sehr langen Fortsätzen in die Umgebung ausstrahlt. Die Kerne sind gewöhnlich randständig; an Größe konkurrieren die Zellen mit mittelgroßen Ganglienzellen. Vielerorts kommen sie dem Typus der gemästeten Gliazellen sehr nahe. Der Gesamteindruck solcher Gebiete ähnelt in ausgesprochenem Maße dem der langsam einsetzenden, entzündlichen Erweichungen. Dieses Bild wird noch vervollständigt durch stärkere proliferative Erscheinungen der Gefäßzellen, insbesondere der Adventitialzellen, die teilweise sich von der Gefäßwand loslösen und alle Utbergangsformen zu Körnchenzellen erkennen lassen. Voll ausdifferenzierte Körnchenzellen mesenchymaler wie gliöser Herkunft konnten in größeren Massen aber nicht beobachtet werden.

Gehen wir zu den Fällen mit langer Krankheitsdauer über, so sind an manchen Stellen die anatomischen Veränderungen zweifellos in Rückbildung begriffen. Die Gefäßinfiltrate und die diffuse Gliawuche- 
rung sind fast völlig verschwunden, es ist Ruhe eingetreten, und nur die relative Armut an Ganglienzellen und einzelne verstreut vorkommende Gliasterne und -rosetten, seltener größere, kompakte Herdchen mahnen daran, daß hier ein akuter Prozeß vorgelegen hat. Während wir also im akuten Stadium des Verlaufes $a$ die syncytialen Gliasterne und -rosetten als herdförmige Verdichtungen und Knotenpunkte eines großen, sichtbaren, lockeren Netzes kennengelernt hatten, liegen sie hier ganz unvermittelt inmitten einer wieder zur Ruhe gekommenen Glia von ganz anderem Charakter, als die Herdzellen sind. Neben der Verminderung ihrer Zahl hat auch ihre Durchschnittsgröße abgenommen,

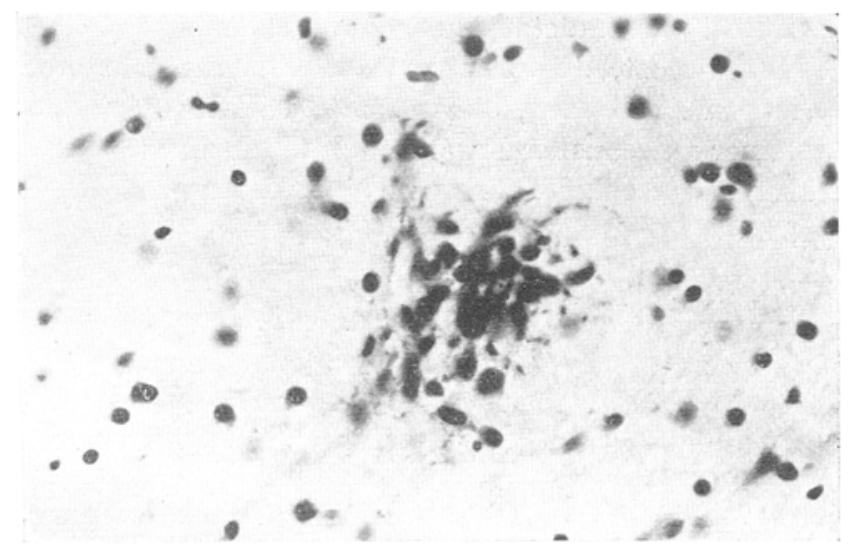

Abb. 17. Toluidinblau. Apochr. 8. Comp. Ok. 6. Encephahlıtis epidemica. In Rückbildung begriffene Gliarosette in der Med. obl. Man beobachtet zahlreiche Kerntrummer besonders in der Peripherie des Herdchens. Auch das Protoplasma zeıgt regressive Veränderungen, besonders körnig-krümeligen Zerfall.

so daß sie in einem der älteren Fälle zunächst ganz übersehen worden waren. Aber auch in der Struktur der Herdchen ist eine Änderung eingetreten. Sie enthalten jetzt keine artfremden Elemente mehr, die symplasmatischen Zellverbindungen treten im Nisslpräparat noch deutlicher hervor, da das Protoplasma spangig, knorrig und geschrumpft erscheint und in schöner tiefroter Farbe aus dem hellen Untergrund. herausleuchtet. Diesen zweifellos als Rückbildungserscheinungen am Protoplasma anzusprechenden Veränderungen gehen solche an den Kernen parallel, an denen jetzt die regressiven Vorgänge in Gestalt von Pyknose und Hyperchromatose die Utberhand gewonnen haben, auch Karyorrhexisformen sind nicht selten (s. Abb. 17). Nur ganz selten überwiegen in einem Herdchen einmal noch die progressiven Erscheinungen; das sind fast regelmäßig pericelluläre Herdchen. Damit hätten wir die eine Form der Rückbildung der Krankheitserscheinungen geschildert, die dem Verlauf a entspricht. Wir werden dabei 
eine teilweise Restitution der Funktionsfähigkeit der davon betroffenen Teile des Nervensystems erwarten dürfen.

Anders gestaltet sich die Weiterentwicklung des Krankheitsprozesses an den Orten, die das akute Bild des Verlaufes $b$ darbieten, wo also von Anfang an besonders stürmische Erscheinungen vorherrschten. Schon das Nisslbild spricht dafür, daß hier nicht wie im Verlauf $a$ eine doch noch mehr oder weniger elektive Erkrankung der einzelnen nervösen Elemente statthat, sondern daß das nervöse Parenchym herdförmig in seiner Gesamtheit von der Krankheit befallen wird. Das Auftreten mobiler Zellelemente gliogener und mesodermaler Abkunft vielfach mit den charakteristischen Merkmalen der Gitterzellen weist darauf hin, daß ein Abbau stattfindet, der auf den fixen Straßen nicht mehr zu bewältigen ist, das massenhafte Erscheinen sehr großer Gliazellen mit langen Ausläufern, daß Defekte vorhanden sind, zu deren Deckung es einer zu schneller Faserproduktion leistungsfähigen Zellart bedarf. Näheren Aufschluß darüber können wir erst aus den Gliafaserund Fettpräparaten erhalten.

Das führt uns dazu, die Abbauvcrgänge bei der Encephalitis im allgemeinen und insbesondere die Anteilnahme der syncytialen Gliaherdchen daran zu betrachten. Beim vorliegenden Material trat an den Orten mit Infiltration, diffuser und typisch-herdförmiger syncytialer Gliawucherung, also beim Verlauf a, der Lipoidabbau durch aus in den Hintergrund, wobei wir hier nur die scharlachfärbbaren, lipoiden Substanzen in Betracht ziehen wollen. Wir haben in den von syncytialer Glia umklammerten Ganglienzellen bei Encephalitis nie in stärkerem Maße Lipoid gefunden und ebensowenig in den Zellen der pericellulären Herdchen, auch dann nicht, wenn in den Herdchen nur noch spärliche Trümmer der untergehenden Ganglienzellen zu bemerken waren. Es ist fast charakteristisch, daß fettige Ablagerungen in den Ganglienzellen mit typisch syncytialer Umklammerung so gut wie immer fehlen. Im Scharlach-Hämatoxylinpräparat erscheint das Ganglienzellprotoplasma bläulich mit Hämatoxylin angefärbt, von krümeliger Struktur und oft zerbröckelt. Das spricht dafür, daß der Abbau der nervösen Substanz der Ganglienzellen auf einem anderen Wege als dem der lipoiden Umwandlung geschieht. Daß die umklammernden Gliazellen überhaupt in der Lage sind, Stoffe aus den zugehörigen Ganglienzellen aufzunehmen, beweist das in Locus coeruleus und Substantia nigra in ihnen hier und da in größeren Mengen nachweisbare Ganglienzellpigment (Abb. 18). Man wird deshalb auch dort, wo keine morphologisch darstellbaren Abbauprodukte in ihnen nachweisbar sind, sie mit Abbau- und Abräumungsvorgängen in Verbindung bringen müssen. Ebensowenig wie in den Ganglienzellgräbern sind bei diesem Verlauf des Prozesses auch in den perivaskulären Herd- 
chen und Gliazellmänteln und in den isolierten, meist sehr kleinen Gliasternen lipoide Stoffe nachweisbar.

Anders verhält es sich, wenn die Intensität des pathologischen

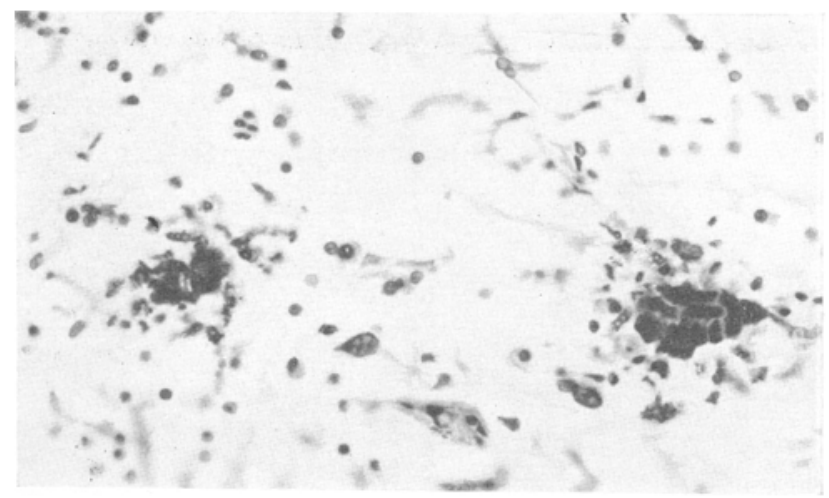

Abb. 18. Toluidinblau. Apochr. 8, Comı. Ok. 6. Encephalıtis epil. 2 pericellulare Gliarosetten im Locus coeruleus. Das Ganglıenzellpigment wird von den Rosettenzellen anfgenommen.

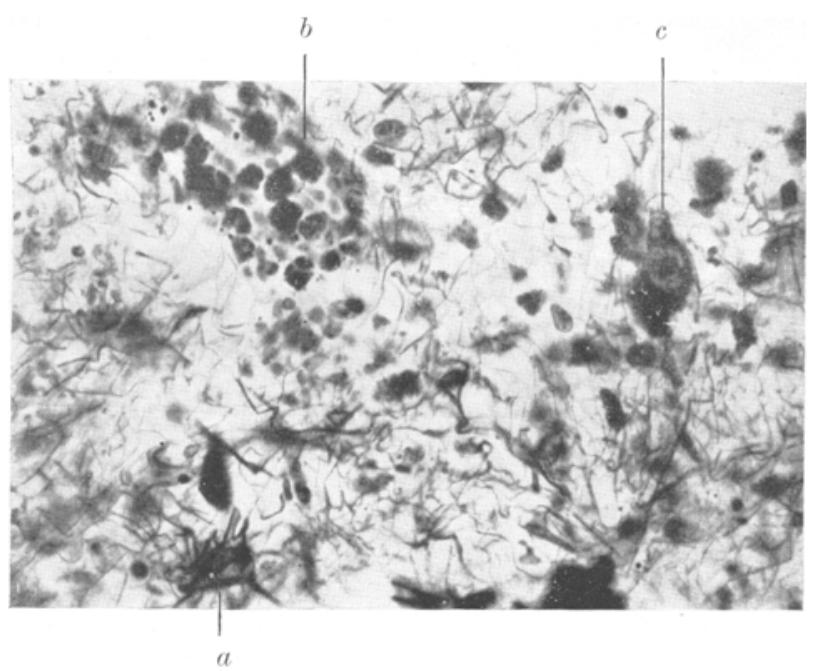

Abb. 19. Glıafaserfarbung nach Holzer. Apochr. 8, Comp. Ok. r'. Encephalitis epid. Stürmischer Verlauf in der Subst. nigra. Auftreten großer, faserbildender Gliazellformen a. Typische syncytiale Gliaherdchen finden sich hier nicht. Bei $b$ perivasculäre Ansammlung klemer, glıogener Kornchenzellen, die mit Ganglienzellnigment vollgepfroptt sind. $c$ Ganglienzelle. Kornchenzellen finden sich auch sonst überall zerstreut im Gewebe.

Vorgangs von vornherein einen stärkeren Zerfall nervöser Substanzen bedingt wie beim Verlauf $b$. Hier schlägt die Art des Unterganges der nervösen Elemente vielfach sofort die uns wohlbekannten Wege über den Fettabbau ein (vgl. auch Grütter). Dann finden wir von 
vornherein auch in den Ganglienzellen massige Fettablagerungen. Die Abräumung der fettigen Substanzen wird zunächst auf fixem Wege versucht. Vielfach wird aber, wie bereits hervorgehoben, die Produktion von Körnchenzellen notwendig, um die Abräumung zu bewältigen (s. Abb. 19), $\mathrm{Zu}$ ausgesprochenen Erweichungen ist es an unserem Material nirgends gekommen ${ }^{1}$ ). Wir haben bereits im Nisslpräparat gesehen, daß dann die Herdbildung eine atypische wird, indem der syncytiale Charakter nur wenig oder gar nicht in Erscheinung tritt. Da $B$ diese Art Herdchen ihn durchweg in ausgesprochenem Maße vorher besessen hätten, ist wenig wahrscheinlich, da die syncytiale Umwandlung von den Trabant- oder Gefäßbegleitzellen ihren Ausgang nimmt und nicht einzusehen ist, warum im stürmischen Geschehen dieser Zustand erst durchlaufen werden sollte, um zu Produkten zu gelangen, die auf anderem Wege schneller zu erreichen sind. Anders allerdings, wenn bereits vorhandene Veränderungen im Sinne des Verlaufes $a$ in den stürmischen Prozeß einbezogen werden. Dann beobachtet man allerdings unter degenerativen Erscheinungen wie Aufblähung: Vakuolisierung, Kammerbildung und pyknotischer Kernveränderung Loslösungsbestrebungen und Isolierung einzelner Zellelemente aus dem Symplasma. Und nun beteiligen sich die vorher lipoidfreien Herdchen unter gleichzeitiger Einbuße ihrer früheren Gestalt und Art an der Fettaufnahme und am Transport (vgl. auch Lotmar). Die Entstehung typischer, mobiler Körnchenzellen aus syncytialen Herdzellen war hier nirgends einwandfrei festzustellen. Dic isolierten Gliazellen der atypischen Herdchen besitzen von vornherein die Fähigkeit, Lipoid in größeren Mengen aufzunehmen.

Eine Beteiligung der faserigen Glia war in allen Fällen vorhanden. Wo die syncytiale Reaktion der Glia das Bild beherrschte (Verlauf $a$ ), trat sie weniger stark hervor, doch waren auch hier überall verstreut jüngere und ältere Spinnenzellen, die reichlich Fasern gebildet hatten, aufzufinden. Eine Neigung der Gliasterne und -rosetten, an der Faserbildung Anteil zu nehmen, war nirgends zu bemerken. Allerdings war vielerorts wahrzunehmen, daß feine Gliafasern die Herdchen durchzogen, doch gelang es kaum je mit Sicherheit, Beziehungen von Fasern zu den einzelnen Zellkernen der syncytialen Herdchen festzustellen. Auf dem Höhepunkt der Entwicklung beteiligen sich also niemals faserbildende Astrocyten an der Zusammensetzung der Herdchen. Es muß im Gegenteil vermerkt werden, daß die in der Umgebung der Herdchen deutlich zutage tretenden Fasern im Herdgebiet häufig wie ausgelöscht erscheinen. Bei dem anderen Verlaufstypus mit lebhaftem Fettabbau (Verlauf $b$ ) wurde der großen, fortsatzreichen Glia-

1) Erweichungsherde im Verlauf der Encephalitis epidemica hat Economo beschrieben. 
zellen bereits Erwähnung getan. Hier entwickelt sich nun im weiteren Fortschreiten des Prozesses eine zunehmende Gliose, die häufig subependymal und perivasculär eine exzessive Dichte erreicht. Immer mehr Faserzellen treten auf, die sich der Form der Gliamonstrezellen nähern (vgl. Abb. 20). Der Enderfolg wird eine dichte gliöse Narbe sein. Hier können wir nun auch da und dort die Teilnahme einzelner Zellen der atypischen Herdchen an der Faserbildung bemerken, da aber hier der syncytiale Charakter der Herdchen ganz zurücktritt, die Herdchen vielmehr gar keine einheitliche Zellstruktur mehr zeigen, so lassen sich hieraus keine weiteren Schlüsse über die Beteiligung syncytialer Elemente an der Gliafaserbildung ziehen.

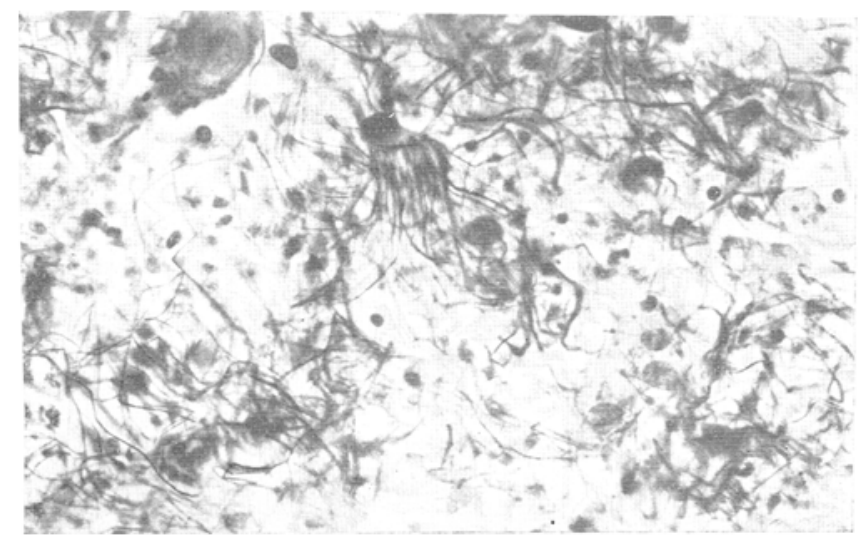

Abb. 20. (iliafaserfärbung nach Holzer. A pochr. 8, Comp. Ok. 6. Hncephalıtis ejul. Wine stelle dıchterer Glıose aus demselben Schntt, dem die vorige Abblding entnommen ist.

Auf eine andere Erscheinung im Verlaufe der Encephalitis sei noch hingewiesen, die grundsätzlich vom eigentlichen Prozeß zu trennen ist. Es ist die in den tieferen Teilen der Medulla oblongata und im Rückenmark öfters anzutreffende sekundäre Degeneration in den absteigenden Bahnen. Es kommt hier dann im Mark zu den bekannten Veränderungen, wobei öfters auch kleine, zwischen den Markfasern liegende Gliasternchen zu beobachten sind.

Den in der Literatur oft erwähnten Blutungen ins nervöse Gewebe konnte in unseren Fällen eine größere Bedeutung nicht zugesprochen werden. Es handelte sich immer um agonale oder postmortale Blutaustritte, die keinerlei gliöse Reaktionserscheinungen hervorgerufen hatten.

Wir kommen zum Schluß noch einmal auf unser Verlaufsschema zurück. Wenn wir dazu gekommen sind, von zwei verschiedenen Arten 
des Krankheitsverlaufes zu sprechen, so kann es sich dabei nur darum handeln, daß zwei möglichst differente, histologische Bilder cinander gegenübergestellt, gewissermaßen zwei Flügelpunkte einer kontinuier. lichen Reihe herausgehoben worden sind. Denn in Wirklichkeit finden wir in den akuten Stadien nicht selten Ubergänge von einem zum anderen Bild. Wir beobachten sowohl die eine wie die andere Verlaufsform in ihren verschiedensten Phasen bei einem und demselben Krank. heitsfall und können daraus schlicßen, daß dieselbe Noxe zu verschiedenen Zeiten in wechselnder Stärke das Nervensystem an verschiedenen Orten anzugreifen vermag. Wir lernen daraus auch das wechselvolle klinische Bild besser verstehen, wenn wir uns vor Augen halten, daß im akuten Stadium auch histopathologisch bedrohlich aussehende Vorgänge einer weitgehenden Restitution fähig sind, und daßs andererseits Verödung und gliöse Narben Dauerdefekte setzen müssen, solange nicht andere Teile des Nervensystems vikariierend eintreten.

Den eigentlichen Grund für die Differenzierung in zwei Verlaufsarten gab für uns aber die Frage nach den Entstehungsbedingungen, der Erscheinungsform und der Funktion der syncytialen Gliaherdchen. Es erübrigt sich, hier noch einmal auf die oben geschilderten Befunde zurückzukommen. Hervorgehoben sei nur, daß die Art der Zusammensetzung der Gliaherdchen in weitem Ausmaße abhängig ist von der Art der diffusen Gliawucherung. Beherrscht die syncytiale Gliazellform die diffuse Wucherung, so finden wir auch die Herdchen von einheitlich syncytialem Bau lediglich hin und wieder mit einigen hämatogenen Zellen vermischt, die aber auch in der diffusen Wucherung überall zerstreut umherliegen. Diese Art der Gliareaktion tritt ein, wenn das nervöse Gewebe nicht in zusammenhängender Weise zugrunde geht und dadurch die Reaktion der Glia eine gewisse Stärke nicht überschreitet.

Das Auftreten großer, protoplasmareicher Gliaelemente kann als Indicator für einen größeren, zusammenhängenden Untergang von Nervengewebe angesehen werden. Werden typische syncytiale Gliaherdchen in solche Bezirke einbezogen, dann geht ihre einheitliche Zusammensetzung und ihr syncytialer Charakter verloren. Zur Neubildung syneytialer Herdehen in solchen Gebieten kommt es nicht.

Es hätte der vorliegenden Untersuchungen nicht bedurft, um zu zeigen, daß den syncytialen Gliaherdchen, in welcher ihrer Erscheinungsformen sie auch vorkommen mögen, sei es als Stern, Rosette, als Knötchen oder lockeres Herdchen oder als Gliastrauchwerk, sei es pericellulär oder perivasculär, eine pathognomonische Bedeutung an sich nicht zukommt. Es fehlt in der Literatur nicht an entsprechenden Hin- 
weisen, und die eben vorgelegten Befunde bilden eine weitere Bestätigung. Wir haben das Vorkommen von syncytialen Gliaherdchen bei den verschiedenartigsten Erkrankungen in den mannigfaltigsten Formen beobachtet. Wir sahen sie bei Erkrankungen, die mit ausgesprochen infiltrativ-exsudativen Erscheinungen am Nervensystem einhergehen, wie Paralyse, Lues cerebri (Endarteriitis), multipler Sklerose und Encephalitis. Wir fanden sie aber auch bei Krankheitsbildern, die entzündliche Erscheinungen durchaus vermissen ließen, deren Wesen vielmehr in einer allgemeinen, parenchymatösen Degeneration der nervösen Elemente besteht, wie in unserem Fall von amaurotischer Idiotie. Weiterhin waren sie in der Umgebung von Erweichungsherden nicht entzündlicher Art, wie sie infolge von Zirkulationsstörungen bei Arteriosklerose oder durch Gefäßveränderungen aus anderer Ursache entstehen, zu finden. Ferner kamen sie vor bei Erkrankungen, die eine allgemeine Intoxikation des gesamten Organismus entweder als Folge einer Infektion mit Mikroorganismen oder als Folge von Stoffwechselstörungen darstellen, und die einen charakteristischen Hirnbefund nicht aufweisen (Sepsis, Urämie). Und schließlich haben wir die syncytialen Gliaherdchen bei einer Anzahl von Katatonien und einem Fall von zirkulärem Irresein beobachtet, die sämtlich in Erregungszuständen zum Teil mit schweren Allgemeininfektionen oder ausgedehnten Eiterungen ad exitum kamen. Gerade bei den letztgenannten Erkrankungen, deren spezifisch pathologisch-anatomische Veränderungen uns noch völlig unbekannt sind, beansprucht das Vorkommen der Gliaherdchen unser besonderes Interesse. Wir können ihr Auftreten aber nur dann mit den betreffenden Krankheiten einwandfrei in Beziehung setzen, wenn sie nicht, was freilich bei der Mehrzahl unserer Fälle zutrifft, von anderen schweren Erkrankungen, insbesondere solchen allgemeiner Infektion und Intoxikation begleitet sind. Wir wissen seit den Befunden Spielmeyers beim Typhus abdominalis, daß bei schweren Infektionskrankhseiten, die sonst keine charakteristischen Veränderungen am Zentralnervensystem hervorrufen, eine Neigung zur Bildung syncytialer Gliawucherungen besteht, besonders in der Molekularschicht der Kleinhirnrinde. Wir haben inzwischen gelegentlich syncytiale Gliaherdchen in der Medulla oblongata und im Hemisphärenmark auch bei Pneumonie und einmal bei einem infektiösen Darmkatarrh unbekannter Ätiologie beobachtet. Deshalb werden wir in den Fällen von Geisteskrankheit, die trotz vielfacher Untersuchungen bisher einen greifbaren anatomischen Befund nicht geliefert haben, gut daran tun, falls eine Komplikation mit schwereren körperlichen Erkrankungen obengenannter Art vorliegt, die Herdbildung auf letztere zurückzuführen. Wir können trotz ausgedehnter entzündlicher Erscheinungen an anderen Körperorganen 
dabei bisweilen von entzündlichen Veränderungen im Zentralnervensystem nicht reden, da infiltrativ-exsudative Erscheinungen häufig fehlen, und wir können daher in solchen Fällen auch den Herdchen nicht ohne weiteres eine entzündliche Genese zuschreiben. Vielmehr werden wir oft auf eine Art Fernwirkung durch Toxine von dem erkrankten Körperorgan her auf das Zentralnervensystem schließen müssen, die einerseits an den Ganglienzellen und andererseits an den Gefäßen Bedingungen geschaffen haben, die zur Bildung syncytialer Herdchen führen. Anders nun, wenn solche Komplikationen nicht vorliegen, wie wir in einem Falle von Katatonie und zirkulärem Irresein mit Sicherheit annehmen dürfen. Welche Ursachen hier einen Rolle spielen, darüber ist es schwer, auch nur Vermutungen zu äußern. Da es sich immer um Kranke handelte, die in heftiger motorischer Erregung zugrunde gegangen waren, so kann man immerhin daran denken, es möchten hier ähnliche Ursachen mitwirken, die beim Status epilepticus die Gliastrauchwerkbildung hervorrufen. Sicherlich werden wir aber den Herdchen schon ihrer kurzen Lebensdauer halber keine kausale Bedeutung für die Schizophrenie oder das zirkuläre Irresein zuschreiben wollen.

Wenn wir die Fälle der Literatur unter dem Gesichtspunkt der Beziehung der syncytialen Gliaherdchen zu bestimmten Gewebsbestandteilen ansehen, so finden wir auf der einen Seite die Erkrankungen mit entzündlichen Veränderungen am Nervensystem, bei denen die Herdbildung entweder nur perivasculär mit Ausnahme des Gliastrauchwerkes (Fleckfieber) oder perivasculär und pericellulär (Encephalitis, Malaria) auftritt, und auf der anderen Seite die nicht entzündlichen parenchymatös-degenerativen Erkrankungen mit nur pericellulärer Herdchenbildung (Fälle von Creutzfeld und Jakob). Wir wissen jetzt aus unseren Untersuchungen, daß zur Entstehung perivasculärer Herdchen eine Entzündung im Nervensystem nicht Bedingung ist, daß dazu auch entzündliche Veränderungen anderer Körperorgane nicht unbedingt notwendig sind, daß sie vielmehr auch bei Vergiftungen des Organismus vorkommen, die auf Stoffwechselstörungen zurückzuführen sind, und bei denen akut entzündliche Ursachen keine Rolle spielen (Urämie bei chronischer Schrumpfniere). Andererseits weist unser Fall von amaurotischer Idiotie neben den Creutzfeldschen Fällen darauf hin, daß dort, wo nur pericelluläre und keine Gefäßherdchen vorhanden sind, entzündliche Veränderungen am Zentralnervensystem immer zu fehlen scheinen. Keineswegs können wir dabei aber infektiöse Schädlichkeiten ausschließen, die das Nervensystem von anderen Körperorganen her angreifen, man denke nur an die Spielmeyerschen Typhusfälle, in denen außer dem Ersatz der Purkinje. dendriten durch Gliastrauchwerk einmal der ganze Nucleus dentatus mit 
perizellulären Gliarosetten besetzt war, ohne daß perivasculäre Herdchen vorhanden gewesen wären. Bei der amaurotischen Idiotie gehören neuronophagische Gliarosetten ganz gewiß nicht zu den gewöhnlichen Erscheinungen, und es fragt sich nun, ob in unserem Fialle die ante exitum bestehende Bronchopneumonie nicht den Anstoß zu den vornehmlich in Oliven und Nucleus dentatus lokalisierten Rosettenbildungen und zum Gliastrauchwerk in der Kleinhirnrinde gegeben hat. Sicherlich ist das Auftreten der syncytialen Herdchen gerade an diesen drei Orten mit der besonders hochgradigen Schädigung der Nervenzellen in Zusammenhang zu bringen, die an der sonst nirgends anders in solchem Maße zu beobachtenden Auftreibung der Ganglienzellen oder ihrer Dendriten einwandfrei festzustellen ist. Es wäre ja möglich, daß diese stark geschädigten Ganglienzellen ihr Leben unter den durch die primäre Erkrankung geschaffenen Bedingungen eben noch hätten fristen und ihre pathologischen Stoffwechselprodukte noch allmählich an die umgebenden Gliazellen hätten abgeben können, und daß erst die komplizierende Erkrankung den Ansto $B$ gegeben hätte, die lebensschwachen Zellen zum Zerfall zu bringen, wobei durch die plötzlich freiwerdenden, größeren Zerfallmassen ein besonders hoher Bedarf an abräumenden Gliazellen eintritt. Dieselbe Wirkung wird man im Hinblick auf die Befunde Spielmeyers und Sagels bei Epilepsie auch den vor dem Tode in gehäufter Zahl aufgetretenen epileptischen Anfällen zuschreiben können. Beweisen läßt sich die Richtigkeit dieser Auffassung freilich nicht, ebensowenig gibt sie uns eine Erklärung dafür, warum es gerade auf dem Umweg über die Gliarosetten zur gliogenen Körnchenbildung in diesem Falle kommt. Man wird aber an solche Teilursachen denken müssen, da man in allen anderen Fällen von amaurotischer Idiotie derartige Erscheinungen an der Glia nicht hat feststellen können. Wir konnten an unserem Material bei den Fällen $C 6$ und $C 9$ (Katatonie, Sepsis, Lang und Frauer) in den Oliven und im Nucleus dentatus ebenfalls die schwersten Ganglienzellveränderungen feststellen, die in kugelförmigen Auftreibungen durch lipoide Einlagerungen bestanden; trotz zahlreicher syncytialer Herdchen perivasculärer und pericellulärer Anordnung in den übrigen Teilen der Medulla oblongata zeigte sich nichts von einer herdartigen Gliareaktion in Olive oder Nucleus dentatus. Nur in der Molekularschicht der Kleinhirnrinde war es zu lebhafter Gliastrauchwerkbildung in einem Falle gekommen. Unter morphologisch in vielen Beziehungen sehr ähnlichen Bedingungen haben wir keine entsprechende Reaktion der Glia.

Mit einigem Vorbehalt wird man sagen können, daß, wenn syncytiale Gliaherdchen überhaupt auftreten, bei entzündlichen Erkrankungen des Zentralnervensystems Gefäßherdchen nie vermißt werden, und da $B$ man 
sie auch bei schweren toxischen Prozessen, seien sie nun infektiöser Art oder nicht, zu treffen pflegt, die ihren Ursprung in anderen Körper. organen nehmen und das Zentralnervensystem erst in zweiter Linie in Mitleidenschaft ziehen. Dagegen scheinen sie bei primären Degenerationsprozessen des Nervenparenchyms, bei denen eine auf dem Blutwege zugeführte exogene Schädlichkeit keine Rolle spielt und höchstens eine Teilursache darstellt, nicht vorhanden zu sein. Wie die Verbältnisse in den oben angezogenen Fällen $C 4$ und $C 8$ (Katatonie und Manie) liegen, die keinerlei akut entzündliche Veränderungen im Gehirn und den Körperorganen boten und doch Gefäßherdchen hatten, sind wir zu übersehen noch nicht in der Lage. Immerhin wird man bei lange Zeit motorisch hochgradig erregten Kranken am ehesten noch an eine Art der Autointoxikation mit Stoffwechselgiften als Ursache denken. Daß letztere ohne Mitwirkung infektiöser Faktoren zur Bildung von Gefäßherdchen führen können, haben wir ja bei Urämie $(C l$ und 2$)$ gesehen.

Ǔber die Beziehung der einzelnen Erkrankungen zu Form, Größe, Anzahl und Lokalisation der syncytialen Herdchen ist folgendes zu bemerken. Der Befund kleiner Gliasterne im Hemisphärenmark ist, solange es sich nur um einzelne handelt, ein recht häufiger, dem eine größere Bedeutung für die Beurteilung des histopathologischen Bildes nicht zukommt. Ich glaube, daß man ihn bei einiger Aufmerksamkeit in etwa einem Drittel des Materials, das einem zufällig durch die Hand geht, erheben kann. Erst bei gehäuftem Auftreten, wenn auch nur an einer Stelle des Zentralnervensystems, erlangen sie eine Bedeutung, die man nicht vernachlässigen darf. Wenn wir z. B. nur in der Medulla oblongata in der Höhe der Vaguskerne eine Anzahl größerer Gliaknötchen finden und sonst keine auffallenden Veränderungen in allen übrigen Hirnteilen nachweisen können, wenn die Körpersektion auch sonst keine schweren Organveränderungen ergibt, wie im Falle $C 8$ (Manie), so kann der Befund, der pathologische Vorgänge an einem lebenswichtigen Zentrum anzeigt, sehr wohl als Todesursache in Betracht kommen. Form, Größe, und Zahl der Herdchen schwanken in weiten Grenzen. Größere Gliaknötchen finden sich am verbreitetsten bei entzündlichen Gehirnerkrankungen (Encephalitis, Fleckfieber); dábei sind dann stets auch fast alle anderen Wachstumsformen vertreten (vgl. die Spielmeyersche Einteilung in typische und atypische Herdchen bei Fleckfieber). Auch bei den parenchymatös-degenerativen Erkrankungen können die allerdings im Durchschnitt kleineren, lockerer gebauten und weniger zellreichen, periccllulären Gliarosetten eine außerordentliche Häufigkeit erreichen. Die kleinen Gliasterne, meist ohne Gesellschaft umfangreicherer Herdchen, findet man mit Vorliebe in größerer Zahl in der Nähe von Erweichungen oder zusam- 
menhängenden, herdförmigen Untergängen von Nervenparenchym, und zwar stets außerhalb des die Erweichung oder den Herd umgebenden Gliareaktionswalles (arteriosklerotische und endarteriitische Erweichung, multiple Sklerose). Darauf wird später noch zurückzu. kommen sein. Auf die Häufigkeit des Gliastrauchwerkes bei infektiöstoxischen Prozessen ist von Spielmeyer bereits hingewiesen worden; wir haben die gleichen Erfahrungen bei septischen Erkrankungen und ausgedehnten Eiterungen gemacht. Es handelte sich dabei sowohl beim Strauchwerk als bei den anderen Gliaherdchen nicht etwa um entzündlich-metastische Prozesse.

Die größeren Gliaherdchen haben wir in Utbereinstimmung mit anderen Autoren vorzugsweise in den grauen Kernen der Medulla ab. longata lokalisiert gefunden. Nie haben wir bei einer anderen Erkrankung größere Gefäßknötchen in solcher Verbreitung in der Hirnrinde gesehen, wie beim Fleckfieber, ein Punkt, der uns zusammen mit dem Fehlen von sog. Ganglienzellgräbern (Gross) von nicht zu unterschätzender, differentialdiagnostischer Bedeutung erscheint. Eine übereinstimmende und von der eben genannten abweichende Lokalisation ergab die Untersuchung der drei Urämiegehirne. Hier fand sich die Medulla oblongata immer frei; die größeren, stets lockeren, und nicht immer ganz typischen, syncytialen Gliaherdchen traten dabei nur im Hemisphärenmark auf. Dort entstehen ohne die Gesellschaft größerer Herdchen auch mit Vorliebe die Gliasterne und -rosetten, die oft keine deutlichen Beziehungen zu Gewebsbestandteilen aufweisen. Wenn letztere durch die Nachbarschaft herdförmiger Erweichungen bedingt sind, sind sie natürlich von deren Lokalisation abhängig. Ganz verschieden sind die ohne entzündliche Begleiterscheinungen am Nervensystem auftretenden pericellulären Herdchen bei gehäuften Nervenzelluntergängen lokalisiert. Abgesehen vom Gliastrauchwerk in der Kleinhirnrinde fanden wir sie in den Oliven, im Nucleus dentatus bei amaurotischer Idiotie und in der Lage der Pyramidenzellen des Gyrus dentatus bei einem Fall von Katatonie $(C 7)$. Bemerkt sei noch, daß wir im letzten Falle auch eine strauchwerkartige Wucherung im Ammonshorn im Bereiche der Apicaldendriten derjenigen Ganglienzellen der Lamina pyramidalis antrafen, deren Leiber durch Einbezug in eine miliare Erweichung völlig zugrundegegangen waren.

Von Interesse mit Bezug auf die verschiedenartigen Erkrankungen ist noch die Frage, ob uns der celluläre Aufbau der Herdchen einen Rückschluß auf die Art der Erkrankung gestattet. Sie läßt sich nur mit Einschränkungen beantworten. Die kleinen Gliasterne haben wir in der Regel völlig frei von Elementen andersartiger Herkunft gefunden, ebenso die echten Gliastrauchwerkbildungen. Handelt es sich um größere Herdchen und zwar gleichgültig, ob perivasculärer oder peri- 
cellulärer Anordnung, so haben wir bei ausgesprochenen entzündlichen Erkrankungen einzelne Lymphocyten, Plasmazellen und in seltenen Fällen auch polynucleäre Leukocyten nur selten vermißt. Aber auch bei Fehlen aller infiltrativen Erscheinungen an den Hirngefäßen haben wir mitunter lympho- und plasmacytäre Elemente feststellen können, in einzelnen Fällen sogar dann, wenn entzündliche Veränderungen auch an anderen Körperorganen nicht nachweisbar waren. Immerhin ist ihr Auftreten bei Hirnerkrankungen ohne exsudativ-infiltrative Erscheinungen relativ selten; bei den rein parenchymatös-degenerativen Prozessen (amaurotische Idiotie, Creutzfelds Fall), wo ja auch keine Gefäßherdchen vorhanden sind, sind sie bisher nie gefunden worden. Gewucherte Bindegewebszellen haben wir in den typischen Herdchen mit absoluter Sicherheit niemals feststellen können. Wenn, wie bei gewissen Stadien der Encephalitis epidemica eine stärkere Wucherung der Gefäßwandzellen stattfindet, dann haben die syncytialen Herdchen ihre typische Gestalt längst verloren. In Erweichungsherden, gleichgültig welcher Genese, wie überhaupt an Orten schwerer, zusammenhängender Zerstörungen des Gewebes, in denen eine lebhaftere Bindegewebswucherung zustandekommt, finden wir ja nie syncytiale Gliaherdchen.

Wenn nach dem eben Gesagten die Gliaherdchen eine spezifische Bedeutung nicht haben können, so kommt ihnen $u$. U. unter Berücksichtigung der Gesamtheit der pathologischen Erscheinungen bei gewissen Krankheiten doch ein hoher differentialdiagnostischer Wert zu. Trotz der Mannigfaltigkeit der Erscheinungsformen, in denen die Herdchen bei den verschiedenartigen Erkrankungen unseres Materials auftraten, bleiben die beiden Krankheitsbilder des Fleckfiebers und der epidemischen Encephalitis unter Zuhilfenahme aller anderen Faktoren gut umrissene histologische Größen. Wertvoll kann unter Umständen das gehäufte Auftreten pericellulärer Herdchen als Indikator für die mehr oder weniger elektive Erkrankung eines Systemteiles sein, wie z. B. für die Oliven- und Nucleus dentatus-Erkrankungen in einem Typhusfall von Spielmeyer und in unserem Fall von amaurotischer Idiotie $\left.{ }^{1}\right)$.

Welche allgemein pathologischen Folgerungen für die Beurteilung der Gliaherdchen ergeben sich nun aus unseren Untersuchungen? Welche morphologischen und biologischen Eigenschaften kommen den in Frage stehenden Bildungen gemeinsam zu?

1) Wir hatten inzwischen Gelegenheit, das elektive Auftreten pericellulärer Gliaherdchen in der Olive auch in einem Falle von typischer Paralyse zu beobachten. 
Eine Betrachtung der syncytialen Gliaherdchen kann nach verschiedenen Gesichtspunkten unternommen werden:

1. nach rein morphologischen,

a) die ihre Form und die Elemente ihres Aufbaues berücksichtigt,

b) die sich auf ihre Beziehung zu Gewebsbestandteilen (Ganglienzellen, Gefäßen), stützt.

2. nach ihrer biologischen Funktion.

In seiner Fleckfieberarbeit hat Spielmeyer eine Einteilung im Sinne von $1 a$ durchgeführt und in der Folge weiterer Untersuchungen sind von ihm und anderen Autoren die Beziehungen zu bestimmten Gewebsbestandteilen festgestellt worden. Was die äußere Form der Herdchen anbetrifft, so ist es zweckmäßig, zwischen das Gliaknötchen und die Gliarosette noch das ,lockere Gliaherdchen" einzuschalten, das häufig größere Ausmaße als das Gliaknötchen und dabei einen weniger soliden, mehr der Rosette ähnlichen, Bau aufweist (s. Abb.11). Es steht so gut wie immer schon infolge seiner größeren Ausdehnung in Berührung mit kleinen Gefäßen, wobei es häufig nicht möglich ist, zu entscheiden, von welchem oder von wieviel Gefäßen es seinen Ausgang nimmt. Es kommt in der Art der Zellanordnung dem Gliastrauchwerk am nächsten. Scharfe Grenzen zwischen den einzelnen Herdformen sind nirgends zu ziehen, und es bleibt oft der willkürlichen Entscheidung überlassen, ob man ein Gliaherdchen als Gliastern oder Rosette bezw. als Rosette oder lockeres Herdchen bezeichnen will. Ebenso kann man mitunter im Zweifel sein, ob man Stellen besonders dichter diffuser Wucherung schon zu den lockeren Herdchen oder manche von den letzteren zur diffusen Wucherung zählen soll.

Wir sind bei unseren Untersuchungen von der Voraussetzung ausgegangen, daß es sich bei den Gliaherdchen, in welcher Form und in welchen Beziehungen zu Gewebsbestandteilen sie uns auch entgegentreten mögen, um etwas mindestens morphologisch gleichartiges handelt. Die morphologischen Hauptcharakteristica haben wir in der Überschrift niedergelegt und sie dabei folgendermaßen determiniert: gliöser Aufbau, progressive Zellveränderung, herdförmiges Auftreten, syncytiale Verbindungen der Zellen untereinander, wobei die Individualität der Einzelzelle bis, zu einem gewissen Grade gewahrt bleibt. Diese vier Eigenschaften müssen also alle Herdchen besitzen oder zu einem gewissen Zeitpunkt einmal besessen haben. Wir begehen, wenn wir den gliösen Wucherungen die letztgenannte Eigenschaft zulegen, streng genommen einen Pleonasmus, da wir als Anhänger der Heldschen Auffassung uns die Glia überhaupt als ein großes Syncytium verstellen. Die Bezeichnung ,,syncytial“ ist vom Nisslbild her übernommen, in dem sich uns, wie bei keiner anderen Färbung diese Eigenschaft der Herdchen 
deutlich und ohne weiteres in die Augen fallend darstellt, besonders durch die scharfe und metachromatisch dunkle Färbung des Gliaprotoplasmas. Wir können diese Eigenschaft aber auch in Alzheimerschen Gliapräparaten nachweisen, wobei ohne weiteres klar wird, daß die Gliazellen, aus denen sich die Herdchen aufbauen, mit der amöboiden Glia Alzheimers nicht das geringste zu tun haben. Da es nun unter normalen Verhältnissen nicht möglich ist, direkte protoplasmatische Verbindungen von Gliazelle zu Gliazelle nachzuweisen, ohne daß dabei das verbindende Protoplasma seine Eigenschaften in irgendeiner Weise ändert, so erscheint es wohl berechtigt, die Bezeichnung „syncytial" beizubehalten. Den nicht erkennbar zu den einzelnen Zellindividuen gehörigen Teil des allgemeinen Gliareticulums wird man vielleicht als den paraplastischen Substanzen nahestehend bezeichnen dürfen; jedenfalls stellt er aber ein modifiziertes Protoplasma dar.

Man wird uns entgegenhalten, daß die von Nissl beschriebenen Gliarasen die oben aufgeführten Eigenschaften auch besitzen. Nissl selbst hat sie oft Rasenzellen genannt und damit zum Ausdruck gebracht, daß darunter Gebilde zu verstehen sind, deren wesentliche Merkmale darin bestehen, daß mehrere Zellkerne in einer als Einheit imponierenden Protoplasmamasse liegen, so daß das Ganze als ein einzelnes Zellindividuum anzusehen ist. Bei unseren Herdchen hingegen haben wir eine Ansammlung von mit besonderen Merkmalen versehenen Einzelindividuen vor uns, deren Zusammenhänge untereinander lediglich durch mehr oder weniger breite Protoplasmabrücken gebildet werden, eine Erscheinung, die besonders an den Herdrändern augenfällig zutage tritt. Ein anderer Hauptunterschied besteht in der Kernplasmarelation der beiden Gebilde. Die Gesamtmasse der Kerne nähert sich bei den syncytialen Gliaherdchen ungleich mehr der Gesamtmasse des Protoplasmas, als es bei den Gliarasen der Fall ist, mindestens solange letztere nicht die bekannten großen, bläschenförmigen Kerne enthalten, die in den typischen Gliaherdchen überhaupt nicht vorkommen. Schließlich ist die Kernzahl in den syncytialen Gliaherdchen stets das Vielfache derjenigen der Gliarasen.

Ein zweites Hauptmerkmal für die morphologische Zusammengehörigkeit der Herdchen hatten wir in der Gleichartigkeit ihrer Bausteine erblickt. Es erübrigt sich, hier noch einmal alle Eigenschaften der Herdzellen zu beschreiben. Es mag genügen, darauf hinzuweisen, daß wir als besondere Eigentümlichkeiten erkannt haben: die relative Kleinheit und den starken Chromatingehalt der progressiven Kerne, ihre Neigung besonders am Herdrande stäbchenförmige Gestalt anzunehmen, die starke Tendenz zu mitotischen und amitotischen Kernteilungen und dabei das baldige Hervortreten regressiver Erscheinungen, das mitunter schon an Mitosen zu beobachten ist (Spielmeyer); 
ferner die starke Färbbarkeit des Gliaprotoplasmas mit basischen Anilinfarben, das von Zelle zu Zelle syncytiale Verbindungen unterhält und vom Herdrande aus mit oft vielfach verzweigten Ausläufern ins Netz der diffusen Neuroglia übergeht. Der Befund von Plasma. zellen, Lymphocyten oder gewucherten Bindegewebselementen im Bereich der voll ausgebildeten Herdchen ändert an der Eigenart dieser Wucherung der Glia an sich nichts, d.h. wir können ihnen für den Aufbau der Herdchen als artfremde Elemente nur eine untergeordnete Bedeutung zuerkennen. Inwieweit sie geeignet sind, die Entstehungsbedingungen der Herdchen zu beeinflussen, darauf haben wir in unseren Ausführungen über die Encephalitis epidemica aufmerksam gemacht. Wir weisen hier nochmals darauf hin, daß wir dabei ihr gehäuftes Auftreten in den Herdchen als einen Gradmesser für die Schwere des pathologischen Prozesses ansehen möchten, daß mit dem Anschwellen ihrer Zahl sich die Entstehungsbedingungen für typische Herdchen verschlechtern. Wir kommen hiermit dazu, der Entstehung und den Entstehungsbedingungen der Herdchen unser Augenmerk zu schenken.

Wir haben bei verschiedenen Fällen unseres Materials beobachten können, daß die Herdbildung von einer ganz bestimmten Art der Gliazellen aus ihren Ursprung zu nehmen pflegt. Schon ihre Beziehungen zu Ganglienzellen und Gefäßen legt die Vermutung nahe, daß einmal die Trabantzellen der nervösen Elemente (s. auch Creutzfeld) und anderer. seits die den Gefäßen oft in langer, zeilenförmiger Aneinanderordnung folgenden ,epitheloiden“ Gliazellen dafür in Betracht kämen. Tatsächlich haben wir in den allerersten Anfängen der Herdbildung mehr. fach beobachten können, daß an den normalerweise sehr protoplasmaarmen, nach außen durch einen scharfen Kontur begrenzten, rundlichen Gliazellen unter gleichzeitiger, leichter Vergrößerung des Kernes zunächst nach außen hin von der scharfen Begrenzungslinie metachromatisch gefärbte, oft vielfach gegabelte Ausläufer auftraten, die mit Ganglienzelle bezw. Gefäßrohr an der proximalen Seite in inniger Berührung standen. Erst im weiteren Verlauf der Entwicklung scheint sich dann der zwischen Kern und äußerer Begrenzungslinie normalerweise vorhandene Hohlraum mit metachromatischem Protoplasma anzufüllen unter gleichzeitiger Formveränderung der ganzen Zelle infolge des meist bipolaren Wachstums derselben. In nur wenig späteren Stadien ist es schon unmöglich, zu sagen, welchen Ursprungs die Herdzellen sind. Möglicherweise nehmen unter geeigneten Bedingungen durch Einbezug auch noch andere benachbarte Gliazellen unter gleichzeitiger, progressiver Veränderung an der Herdbildung teil. Bezüglich der Vermehrung der Zellen scheinen bei den verschiedenen Krankheiten und vielleicht auch bei der verschiedenen Loka. lisation der Herdchen weitgehende Unterschiede zu bestehen. Das

Z. f. d. g. Neur. u. Psych. LXXIX. 
massenhafte Auftreten von Mitosen, wie am Gliastrauchwerk bei Fleckfieber, Malaria, Typhus, haben wir sonst nirgends beobachtet. Ziemlich oft findet man ja Mitosen an den Gliarosetten bei Encephalitis epidemica, und auch in den Creutzfeld-Jakobschen Fällen scheinen sie nicht selten zu sein. An unserem Material waren sie aber Rarität, auch an den Herdchen, die in reiner Weise progressive Erscheinungen darboten. Viel häufiger gelang es uns, Kernfiguren zu beobachten, die Einkerbungen und Abschnürungen aufwiesen, Vorgänge, die man wohl als amitotische Teilungen auffassen darf. Bemerkenswerterweise sahen wir die Teilungserscheinungen, sowohl Mitosen- wie direkte Teilungen, fast ausschließlich am Herdrande, ein Umstand, der für ein vorwiegend peripheres, zentrifugales Wachstum der Herdchen spricht.

Wir wollen einen Augenblick bei der Wachstumsform verweilen und uns die Frage vorlegen, wie die stern- und netzförmige Gestalt der Herdchen zustande kommt. Die Fortsetzung der periphersten geisel- und wurzelartigen Zellausläufer am Herdrande in das diffuse Neuroglianetz deutet an, daß zwischen beiden ein inniger Zusammenhang besteht. Erinnern wir uns hier des unter $D$ beschriebenen Glioms, so sahen wir, daß das Gliom bis in seine dichtesten Teile ein Wachstum hatte, das sich streng an die normalerweise vorgezeichneten Bahnen hielt, Achsenzylinder und Nervenzellen waren auffallend gut respektiert worden. Nirgends war ein regelloses Wachstum oder wirres Durcheinander, wie es sonst bei Gliomen häufig zu finden ist; jeder Nervenfaserverlauf war im Zellbild durch die Aufeinanderfolge und die Richtung der langgestreckten Gliomzellen deutlich gekennzeichnet, nur an Dicke natürlich erheblich vergrößert. Diese Eigenschaft des Tumors, den durch das gliöse Reticulum normalerweise vorgezeichneten Bahnen im Wachstum zu folgen, dürfen wir mit Recht auch für die dort beschriebenen Gliomrosetten annehmen. Auf ihre frappante, morphologische Ähnlichkeit mit unseren Rosettenherdchen (s. Abb. 14) hatten wir schon früher hingewiesen, und ich glaube, daß wir auch für unsere Herdchen annehmen dürfen, daß ihr Wachstum nach Gesetzen geschieht, die durch den Bau des normalen, diffusen Gliareticulums vorgezeichnet sind. Alzheimer hat darauf aufmerksam gemacht, daß manche Wucherungserscheinungen der Glia besonders bei stärkerem Zerfall im Nervensystem keine andere Deutung finden können, als daß sich die Gliaelemente, auch wenn sie vorher einem syncytialen Verbande angehört hätten, aus diesem gelöst haben. Gerade bei den hier in Frage stehenden Wucherungen kann man aber mit ziemlicher Sicherheit annehmen, daß sie zum mindesten in ihren lockeren Teilen im gliösen Reticulum selbst verankert sind, daß die zellige Glia von einem Zentrum aus, das jeweils durch eine Nervenzelle oder ein Gefäßrohr gekennzeichnet ist, sozusagen in das diffuse Gliareticulum hinein 
wächst, ähnlich wie wir es bei dem oben geschilderten Gliom sahen. Die Auffassung Alzheimers, der in den protoplasmaarmen Gliazellen, aus denen wir die Gliaherdchen ihren Ursprung nehmen sahen, die Mutterzellen des diffusen Gliasyncytiums erblickte, gibt unseren Anschauungen eine weitere Stütze. Als eine der morphologischen Entstehungsbedingungen für die syncytialen Gliaherdchen werden wir daher ein in seinem architektonischen Aufbau nicht oder doch nicht wesentlich geschädigtes, diffuses Gliareticulum fordern müssen. Nun ist es bisher freilich nicht gelungen, die diffuse Glia in elektiver Weise so darzu. stellen, daß sie einer Analyse zugänglich wäre, und wir sind deshalb darauf angewiesen, in indirekter Weise Schlüsse auf ihren Zustand zu ziehen. Es ist klar, daß sie innerhalb von Erweichungsherden völlig zerstört ist, wir müssen aber auch dann auf eine wesentliche Änderung ihres Zustandes schließen, wenn wir zahlreiche mobile, gliöse Elemente finden oder wenn massenhaft große, pathologische Gliazellformen auftreten. Die beiden letzten Erscheinungen weisen ja immer darauf hin, daß Nervengewebe in zusammenhängender Weise in größerer Ausdehnung zugrunde geht, und damit ist notwendigerweise eine tiefgehende Strukturänderung des Nerven-Gliagewebes verbunden. Unter diesen Umständen würde eine von uns als wesentlich angesehene Bedingung für die Entstehung typischer, syncytialer Gliaherdchen in oben definiertem Sinne fortfallen, und es dürfte also zu ihrer Ausbildung an solchen Orten nicht kommen.

Sehen wir unser Material daraufhin an, so finden wir z. B. bei den herdförmigen Erweichungen (Arteriosklerose, Endarteriitis) typische, syncytiale Gliaherdchen erst außerhalb des den eigentlichen Bezirk der Erweichung umgrenzenden Gliareaktionswalles, und zwar dort, wo die Gliaelemente kleinzelliger und weniger zahlreich werden, wo man den Ubbergang in das strukturell weniger oder nicht veränderte Gewebe suchen darf. Von peripherwärts her nach dem Orte stärkster Gliawucherung zu fortschreitend treten hierbei zunächst atypische Herdformen auf, die eine ungleichartige Beschaffenheit ihrer Zellen aufweisen, indem sich solche mit größeren, hellen, bläschenförmigen Kernen darunter mischen, welche die wurzelförmigen Protoplasmaaufzweigungen am Herdrande vermissen lassen; schließlich findet sich überhaupt nichts mehr, was man als Gliaherdchen in unserem Sinne auch nur entfernt ansprechen dürfte. Ganz analog waren die Erscheinungen an den Herden der multiplen Sklerose. Bei den entzündlichen Erkrankungen ohne Erweichungen liegen die Verhältnisse ähnlich. Wir wollen uns hier, weil am eingehendsten untersucht, auf die Encephalitis epidemica beziehen. Wir haben bereits vorhin betont, daß mit dem Anwachsen der Zahl der Infiltrationszellen in den Herdchen sich ihre Entstehungsbedingungen verschlechtern. Die Stärke der Gefäßin- 
filtration und das Maß der Ausstreuung von Lymphocyten und Plasmazellen ins Nervengewebe kann man zweifellos als Gradmesser für die Stärke der einwirkenden Noxe ansehen. Parallel dazu ging in unseren Encephalitisfällen die Schwere des pathologischen Prozesses, der uns hier besonders in den gliösen Veränderungen interessiert. Utberstieg die Gefäßinfiltration und die Ausstreuung von Infiltrationszellen ins Gewebe ein gewisses Maß, so konnte man damit rechnen, daß die gliöse Reaktion eine qualitative Veränderung in dem Sinne erfuhr, wie man sie bei größeren, zusammenhängenden Untergängen von Nervengewebe zu finden pflegt. Während für gewöhnlich die reaktive Gliawucherung sich aus kleinzelligen Elementen zusammensetzte, innerhalb welcher dann die syncytialen Herdchen auftraten, kam es im letztgenannten Falle zur Ausbildung zahlreicher, großkerniger, protoplasmareicher Gliazellen und zur Mobilisierung von Gliaelementen. Hier, wo es also zu einer tiefgreifenden Strukturveränderung ausgedehnterer Teile des Nervengliagewebes gekommen war, konnten wir nach unserer oben entwickelten Ansicht über die morphologischen Entstehungsbedingungen der Gliaherdchen die sonst für das Bild der Encephalitis epidemica so charakteristischen, syncytialen Gliawucherungen nicht mehr erwarten. Tatsächlich waren, wie wir in den Befunden bei Encephalitis bereits oben aus. einandergesetzt haben, hier auch keine typischen, syncytialen Gliaherdchen mehr auffindbar. Was bei oberflächlicher Betrachtung so aussah, erwies sich bei näherem Zusehen als eine hauptsächlich aus Lymphocyten, Plasmazellen und Gliazellen uneinheitlicher Art bestehende Zellansammlung, die nicht selten auch noch gewucherte Bindegewebselemente enthielt. Syncytiale Glia in unserem Sinne fand sich höchstens in Rudimenten.

Die von uns geforderten morphologischen Vorbedingungen für die Entstehung syncytialer Gliaherdchen sind an sich gegeben, wenn es sich nur um Einzelausfälle nervöser Strukturen, also z. B. um disseminierten oder herdförmigen Ganglienzelluntergang handelt. Es ist dabei von untergeordneter Bedeutung, ob die Nervenzelle etwa infolge Entwicklungsstörung aus sich selbst heraus erkrankt, oder ob sie elektiv auf eine dem Nervensystem zugeführte Schädlichkeit anspricht. Die Hauptsache für uns bleibt hier, daß die Struktur des die Ganglienzellen umgebenden Gewebes eine tiefgreifende Veränderung zunächst nicht erleidet. Natürlich kann eine solche späterhin noch dazutreten; dann wird sich aber auch eine Änderung im Aufbau der syncytialen Herde bemerkbar machen, indem die Herdelemente ungleichartig werden. Es mischen sich dann Zellen mit großen, hellen Kernen darunter; die eigentlichen Herdzellen selbst sind an Zahl spärlicher und weisen wohl auch oft etwas größere, chromatinärmere Kerne als gewöhnlich auf, wobei auch das Protoplasma an seiner metachromatischen Färbbarkeit einbüßt. (Creutzfelds Fall?) 
Betrachten wir nun einmal zunächst morphologisch, welche Veränderungen an den Gewebsbestandteilen des Zentralnervensystems wir für die Entstehung der Gliaherdchen verantwortlich machen können. Dabei kann von einer Wiederholung von Einzelheiten bereits bekannter Tatsachen abgesehen werden, da sich unsere Feststellungen größten. teils mit denen anderer Autoren decken. Da liegen nun die Verhältnisse bei den als Gliaumklammerung der Ganglienzellen und Neuronophagie bekannten Erscheinungen am einfachsten. Hier haben wir schwere Schädigungen der Ganglienzellen nie vermißt; auch dort, wo es sich lediglich um eine Umklammerung und nicht um ein Eindringen der Gliazellen in das Territorium der Ganglienzellen handelte, war die umklammerte Zelle stets dem Untergang verfallen. Daß die in Frage stehende, gliöse Reaktion nicht an eine besondere Art von Ganglienzellerkrankung gebunden ist, wie z. B. die amöboide Glia an die ,schwere Zellveränderung", haben wir ebenso wie andereUntersucher immer wieder feststellen können. Mit besonderer Vorliebe und in außerordentlich großer Zahl traten die pericellulären Herdchen allerdings auf, wenn die zum Ganglienzelluntergang führende Zellveränderung im besonderen Falle eine gleichartige war, wie z. B. die homogenisierende Zellerkrankung bei'Typhus und Gasödem oder die Zellveränderung im Creutzfeldschen Falle, die wir übrigens sowohl bei Encephalitis als auch bei unseren KatatonieSepsis-Fällen hier und da wieder fanden. Wir konnten dieses Verhalten bei unserem Falle von amaurotischer Idiotie und in einem Falle von Katatonie $(C 7)$ im Gyrus dentatus beobachten. Bei letzterem fanden wir in herdförmiger Verbreitung eine ganz eigenartige Ganglienzellerkrankung, die in der Kernveränderung der ,schweren Zellveränderung" Nissls und in der Beschaffenheit des Protoplasmas der „homogenisierenden Zellerkrankung“ Spielmeyers nahekam (vergl. Abb. 8 bis 10). Auffällig war dabei die spärliche Zahl der Herdzellen in den Rosetten besonders im Vergleich mit denen bei der amaurotischen Idiotie (s. Abb. 2 u. 3). Auf die scheinbare Wahllosigkeit der Verknüpfung der reaktiven Gliawucherung mit genau gleich erkrankten Nervenzellen sei hier in Úbereinstimmung mit anderen Untersuchern gleichfalls hingewiesen.

Viel weniger klar liegen die Verhältnisse bei den Gefäßherdchen. Gewiß kann man hier oft eine Schädigung der Gefäßwandelemente feststellen, die in regressiven Veränderungen der Endothel- und Adventitialzellen, in einer verwaschenen Zeichnung der Elastika und der feinen, fibrillären Strukturen, in Fibrinniederschlägen, ja vereinzelt sogar in Zerstörungen der Wand ihren Ausdruck findet; aber bereits Spielmeyer hat beim Fleckfieber darauf hingewiesen, daß die Herdgefäße in vielen Fällen nicht die geringsten morphologischen Veränderungen erkennen lassen. Wir haben diese Beobachtung an unserem 
Material bestätigen können. Andererseits haben wir des öfteren gesehen, daß in den Fällen, wo sonst zahlreiche syncytiale Herdchen vorhanden waren, Gefäße mit zweifellos geschädigten Endothel- und Adventitialzellen keine Spur von Herdchenbildung zeigten. Auch wir haben die Herdchen immer nur an Capillaren und Präcapillaren feststellen können. Eine auffällige Erscheinung, die unseres Erachtens nicht ohne Bedeutung sein kann, stellt das Verhältnis zwischen Herdbildung und Gefäßinfiltration dar. Wir haben hierbei beobachten können, daß zwischen diesen beiden Phänomenen ein gewisser Antagonismus besteht insofern, als wir niemals an stärker infiltrierten Gefäßen eine Herdbildung zustandekommen sahen. Selbst bei mit schwersten Gefäßinfiltrationen einhergehenden Erkrankungen, wie bei der Encephalitis epidemica fanden sich in den Herdgefäßen nur ganz vereinzelte Infiltrationszellen. Die in dem Herdbereich liegenden nervösen Strukturen ließen, solange die Herdchen nicht zu dicht waren, meist keine weitere Schädigung als eine gewisse Verdrängung erkennen. Man kann an Alzheimerpräparaten häufig genug sehen, daß Nervenfasern mit wohlerhaltener Markscheide und unverändertem Achsenzylinder mitten durch die Herdchen, ja sogar durch das Protoplasma einzelner Herdzellen hindurch ziehen. Also auch in einer Zerstörung des den Gefäßen anliegenden, nervösen Gewebes konnte die Ursache ihrer Entstehung nicht ermittelt werden. Daß in den dichten Fleckfieberherden die nervösen Strukturen zugrunde gehen können, ist seit Spielmeyers Untersuchungen bekannt; dabei ist die Frage jedoch nicht entschieden, ob und inwiefern eins vom andern abhängig ist.

Es bleiben schließlich noch die kleinen Gliarosetten und Gliasterne der Marksubstanz, die häufig keinen bestimmten Zusammenhang mit einem Gewebsbestandteil erkennen lassen. Auf Serienschnitten gelingt es nicht selten, den einen oder anderen Gliastern doch noch zu einem Gefäß in Beziehung zu bringen. Zweifellos bleibt aber eine Anzahl übrig, die scheinbar einsam dastehen. Nach Jakobs Ansicht entstehen sie auf dem Boden von Einzelausfällen nervöser Strukturen, und ihr gelegentliches Auftreten im Gefolge der sekundären Degeneration spricht auch für diese am nächsten liegende Annahme. Der direkte Nachweis der Schädigung der nervösen Bestandteile im Bereich der Gliasterne ist uns jedoch nicht geglückt. Wir haben innerhalb der im Mark zerstreuten Gliaherdchen, wenn keine sekundäre Degeneration vorlag, mit den üblichen Methoden weder Achsenzylinderveränderungen noch Markscheidenzerfall feststellen können. Es handelte sich immer nur um eine Auseinanderdrängung der Nervenfasern. Die Osmiummethoden konnten wir leider bei unseren Untersuchungen nicht anwenden.

Eng verknüpft mit dem eben behandelten Thema ist die Frage 
nach der biologischen Funktion dieser gliösen Erscheinungen. Es ist klar, daß ihre Funktion im Rahmen der Aufgaben liegen muß, die der Glia ganz allgemein zu erfüllen obliegt. Nach den neueren Anschauungen ist es ja erst die gesteigerte Erregung der spezifischen Funktion, die die entscheidende Bedingung für das Wachstum einer Zelle darstellt (Borst). Nun kennen wir aber eine ganze Reihe von Funktionen der Glia und es ist im Prinzip nicht zulässig, die eine zugunsten der anderen im Wert zurückzustellen. Wir wissen jedoch, daß unter gewissen pathologischen Bedingungen einzelne Funktionen der Glia besonders vordringlich werden, $d$. $h$. daß gewisse morphologische Merkmale erlauben, ihren gewucherten Zellen als Hauptaufgabe eine ganz bestimmte und oft alleinige ihrer vielfältigen Funktionen zuzuschreiben. Wir müssen daher auch einer Erregung gewisser Teilfunktionen die Fähigkeit zuerkennen, auf das Wachstum der Glia bestim. mend einzuwirken. Als solche Teilfunktionen, die unter Umständen zur Haupt- oder alleinigen Funktion werden können, sind uns die im Dienste der Statik und des Stoffaustausches stehenden bekannt, und bezeichnenderweise vermag das einseitige Überwiegen einer dieser Funktionen ganz eminent verschiedene Zellformen hervorzurufen, deren Bau es in den ausgesprochensten Fällen ohne weiteres anzusehen ist, welche Tätigkeit ihnen zufällt (Faserzelle, gliogene Körnchenzelle). Je intensiver eine Gliazelle der einen Aufgabe obliegt, um so mehr pflegt sie im Dienste der anderen zu versagen. Wie gesagt, tritt uns das morphologische Ergebnis der Erregung dieser beiden Teilfunktionen bei pathologischen Prozessen am augenfälligsten entgegen; für die Tätigkeit der Glia bei der nervösen Reizleitung fehlen uns heute noch alle beweisenden, morphologischen Befunde. Wir müssen diese letztgenannte Funktion daher notgedrungen bei unseren folgenden Betrachtungen beiseite stellen und uns auf die beiden anderen beschränken. So ist auch die Entstehung der Gliaherdchen aufs engste mit der Erregung einer gewissen Funktion der Glia verknüpft und wir werden uns fragen müssen, sofern ihnen ihre Eigenschaft an ihrem Bau oder durch den Befund an Fasern oder Abbaustoffen nicht ohne weiteres abzulesen ist, inwieweit ihre Beziehung zu irgendwelchen pathologischen Erscheinungen an anderen Gewebsbestandteilen einen Rückschluß auf ihre Funktion erlaubt.

Die Fähigkeit syncytialer Glia, deren morphologische Merkmale unseren Befunden entsprechen, zur Umwandlung in Körnchenzellen und von im syncytialen Verbande verharrender Glia zum Lipoidabbau ist bereits von Lotmar bei der experimentellen Dysenterie-Encephalomyelitis betont worden. Die für unsere Behandlung wichtige Unterscheidung in pericelluläre und Gefäßherdchen ist dabei aber nicht durchgeführt worden. 
Hier liegen die Verhältnisse wiederum am übersichtlichsten bei den pericellulär entstandenen Gliaherdchen.

Als wir unsere Untersuchungen bei den Ganglienzellgräbern der Encephalitis epidemica begannen, konnten wir zunächst nichts feststellen, was auf eine abbauende oder resorbierende Tätigkeit der Ro. settenherdchen mit Sicherheit hätte schließen lassen. Zwar legte die Zellumklammerung und die seltenere Substitution den Verdacht sehr nahe, daß die Herdchen die Zerfallsprodukte der Ganglienzellen aufnähmen, morphologisch nachweisbar waren letztere zunächst aber nicht. Es stellte sich heraus, daß die Nervenzellen in den Stadien der Erkrankung, in welchen die Herdchenbildung typisch war, keine Verfettung aufzuweisen pflegten. Thr Protoplasma stellte vielmehr im Scharlachpräparat, das mit Ehrlichs Haematoxylin nachgefärbt war, gewöhnlich eine körnig-krümelige, hellblau gefärbte Masse dar. Erst als es uns gelang, Rosettenherde in den pigmentführenden Nervenzellen des Locus coeruleus und der Substantia nigra zu finden und das Ganglienzellpigment in den Herdzellen nachzuweisen (s. Abb. 18), konnte der morphologische Nachweis als erbracht gelten, daß die Zerfallsprodukte der Ganglienzellen auch bei der Encephalitis epidemica von den Gliarosetten aufgenommen werden, daß ihnen also eine $a b$ räumende Tätigkeit zufällt. Auf die Fähigkeit der Gliaelemente der diffusen Wucherung Pigment aufzunehmen, hat Gross schon hingewiesen. Hier reiht sich unser Fall von amaurotischer Idiotie an, in dem die beim Zerfall der Ganglienzellen freiwerdenden, der Krankheit eigentümlichen, lipoidähnlichen Massen in unverändertem Zustande von den Gliarosetten und vom Gliastrauchwerk aufgenommen wurden. Anders verhält es sich in dem Fall von Creutzfeld. Zwar bewegte sich hier der Prozeß in der Richtung des gewöhnlichen Scharlachlipoidabbaues; es wird aber ausdrücklich betont, daß die von den lipoidführenden Rosetten eingeschlossenen Ganglienzellen in der Mehrzahl der Fälle kein mit Scharlach darstellbares Fett enthielten. Noch eigenartiger ist der Lipoidbefund in den Strauchwerkzellen eines Epilepsiefalles von Sagel, wobei die dem Untergang verfallenen, nervösen Elemente gleichfalls kein Fett enthielten und sich auch sonst im Kleinhirn kein lipoider Abbau nachweisen ließ. Handelt es sich hier und in den Creutzfeld-Jakobschen Fällen um einen fixen Abbau, so konnten wir in unserem Falle von amaurotischer Idiotie nachweisen, da $\beta$ die Rosettenzellen auch eine Metamorphose in kleine, mit allen charakteristischen Kennzeichen versehene Körnchenzellen eingehen können. Es erfolgte mit zunehmender Zerfallsstoffanfüllung zunächst ein Einwuchern der Herdzellen in die Zerfallmasse und dann unter gleichzeitiger Abrundung des Zelleibes und Pyknose des Kernes die allmähliche Loslösung aus dem Syncytium und schließlich die Abwanderung 
mach den Gefäßen (s. Abb. 3a-c). Wir haben eine Körnchenzelldifferenzierung aus Gliastrauchwerkzellen bisher nicht mit Sicherheit feststellen können. Zwar war hier die Molekularschicht der Kleinhirnrinde von kleinen, runden, mit den eigenartigen Abbaustoffen angefüllten Gliazellen in zahlreichen Anhäufungen dicht bevölkert, häufig entsprach die topographische Lage dieser Ansammlungen auch dem Verlauf der Purkinjedendriten, eine direkte Umwandlung der Strauchwerkzellen in derartig typische Körnchenzellen wie an den Gliarosetten konnten wir jedoch nicht beobachten. Wir bezweifeln aber nicht, daß die Möglichkeit einer entsprechenden Umwandlung hier an sich gleichfalls gegeben ist.

Wir werden also zusammenfassend sagen können, daß alles dafür spricht, daß die percellulären, syncytialen Gliawucherungen im Dienste des Abbaues und der Abräumung stehen, und zwar erleiden dabei die neurogenen Zerfallsprodukte in vielen Fällen einen weiteren Abbau nicht, sondern sie werden in unverändertem Zustande aufgenommen und weitergeführt. Andererseits können die neurogenen Zerfallsprodukte in den syncytialen Herden aber auch in gewöhnliche Lipoide weiter abgebaut werden, wie das bereits Sagel betont hat. Die Wege der Fortführung der Zerfallsmassen sind verschieden. Sind die örtlichen Verhältnisse günstig, so können sie direkt auf den Protoplasmastraßen des Syncytiums in die nächtsgelegenen Gefäßwände abgeladen werden. In anderen Fällen werden mit Fett beladene Stäbchenzellen differenziert, auf deren langen Protoplasmabahnen die Abbauprodukte entweder direkt oder auf dem Umwege über andere Gliazellen den Gefäßen zugeführt werden. Sind endlich die am Orte der Entstehung auf einmal freiwerdenden Zerfallsmassen zu groß, sodaß die fixe Abräumung nicht mehr genügt, dann differenzieren sich aus den Herdzellen typische Körnchenzellen, die die Fortschaffung besorgen. Eine Vorbedingung für die letzte Art der Abräumung dürfte darin bestehen, daß der Abbau der nervösen Substanz in Lipoide oder lipoidähnliche Substanzen erfolgt.

Nicht so einfach liegen die Dinge bei den Gefäßherdchen. Hier gelingt uns der Nachweis von Gewebsschädigung und von Abbaustoffen in den Herdzellen häufig nicht. Es fragt sich nun, inwiefern wir die Lokalisation der Gefäßherdchen oder andere gleichzeitig vorhandene pathologische Erscheinungen in den Kreis unserer Betrachtungen ziehen können, um uns ein mutmaßliches Bild von der speziellen Funktion der Herdchen zu machen. Es ist auffällig, daß auch die Gefäßherdchen, solange es sich nicht um grobe Zerstörungen an den Gefäßen oder deren nächster Umgebung handelt (Ringblutungen, Malaria), ganz vorwiegend in den grauen Substanzen lokalisiert sind. Es besteht hier ein Parallelismus mit der vorzugsweisen Lokalisation der Ge- 
fäßinfiltrationen, den man besonders deutlich bei den ausgesprochen entzündlichen Erkrankungen wie Fleckfieber und Encephalitis epidemica beobachten kann. Andererseits ist aber bereits oben auf die auffallende Polarität zwischen Gefäßinfiltration und Gefäßherdbildung hingewiesen worden, d.h. da $\beta$ beide Erscheinungen nicht zusammen an einem Gefäß vorkommen, worauf auch schon Spielmeyer bei seinen Fleckfieberuntersuchungen aufmerksam gemacht hat. Wir haben dieses Verhalten in allen unseren Fällen, wo beide Erscheinungen gleichzeitig vorhanden waren, immer wieder feststellen können und sind zu der Überzeugung gekommen, daß es sich hier nicht um einen reinen Zufall handeln kann. Wie ist das Verhalten dieser Erscheinungen zueinander aber nun zu erklären? Die gemeinsame Lokalisation mit den Gefäßinfiltrationen in begrenzten Gewebsbezirken allein würde zunächst nur den Schluß erlauben, daß hier eine schädigende Noxe infektiöser Art im Gewebe vorhanden ist, und daß die Gefäßherdchen dadurch besonders günstige, biologische Entstehungsbedingungen vorfinden. Für die Erklärung der Polarität allein sind zwei Auffassungen denkbar. Entweder schließt das Vorhandensein einer Gefäßinfiltration die Entstehung eines Gefäßherdchens an gleicher Stelle von vorn herein aus, oder es ist an dem Orte, wo eine der beiden Erscheinungen bereits aufgetreten ist, die andere überflüssig geworden. Da die morphologischen Verhältnisse uns zu einer Gegenüberstellung der beiden pathologischen Phänomene keinen Grund geben, so müßte im ersten Falle ein funktioneller Unterschied, ja sogar eine funktionelle Gegensätzlichkeit vorhanden sein. Im zweiten Falle wäre man genötigt, eine sehr ähnliche oder gleiche Funktion der beiden Erscheinungen und in gewissen Grenzen die Möglichkeit gegenseitiger Stellvertretung anzunehmen. Abgesehen davon, daß es schwer sein dürfte, sich bei Annahme einer-den Infiltraten entgegengesetzten Funktion der Gefäßherdchen eine klare Vorstellung davon zu machen, welche der uns bekannten Leistungen der Neuroglia die Herdchen in diesem Falle zu erfüllen hätten, fällt für uns die gemeinsame Lokalisation in begrenzten Gewebsbezirken, die auf gemeinsame biologische Entstehungsursachen hinweist, entscheidend für die zweite Auffassung ins Gewicht. Dann läßt sich die Funktion der Gefäßherdchen auch unschwer in dem großen allgemeinen Rahmen der Aufgaben, die der Neuroglia zu erfüllen obliegen, unterbringen. Eine weitere Tatsache, die zugunsten der eben dargelegten Auffassung spricht, besteht darin, da $B$ die Wucherung der syncytialen Glia, sei es in herdförmiger oder diffuser Weise, bei entzündlichen Prozessen, oft über das Maß hinausgeht, welches wir im Hinblick auf die nachweisbaren Schädigungen des Nervengewebes erwarten dürfen. Wenn wir in folgendem der syncytialen Glia eine abräumende und abbauende Aufgabe zuteilen, die sich nicht nur auf 
die neurogenen Zerfallsprodukte beschränkt, so wird auch dieses scheinbare Mißverhältnis einer Erklärung nähergebracht.

Was also auf der einen Seite die Gefäßinfiltrate besorgten, müßten auf der anderen die Gefäßherdchen ganz oder teilweise übernehmen können. Natürlich können die Gefäßherdchen nur dann stellvertretend für die Gefäßinfiltrationen eintreten, wenn die oben erörterten morphologischen Voraussetzungen für ihre Entstehung gegeben sind. Die Funktion der Infiltratzellen ist nun wohl in einer gewissen resorptiven Tätigkeit Toxinen, besonders bakterieller Art, gegenüber zu suchen, und man müßte also annehmen, daß auch die Gefäßherdchen eine Affinität zu diesen Toxinen besitzen und imstande sind, sie auf resorptivem Wege aufzunehmen. Der innige gewebliche Zusammenhang der Herdchen mit der diffusen Glia wird es ermöglichen, die im Gewebe enthaltenen, schädlichen Stoffe auf den Protoplasmastraßen des diffusen Gliareticulums von allen Seiten zusammenzuziehen und alsdann gesammelt an die Gefäße abzugeben. Der erste Anstoß zur Herdbildung muß aber immerhin durch eine gesteigerte funktionelle Erregung der in loco befindlichen Zellen gegeben sein. Man ist immer geneigt, dafür einen Gewebsdefekt verantwortlich zu machen; jedoch hat Borst erst kürzlich darauf hingewiesen, daß diese Defekte nicht immer morphologisch greifbar sind, daß sie auch chemischer Natur sein können. In unserem Falle wird das gelöste Toxin als körperfremid empfunden werden und auf Beseitigung drängen und infolgedessen diejenigen Gewebe, die normalerweise den Säfteaustausch besorgen, zu vermehrter Funktion und dadurch zum Wachstum anregen in dem Zeitpunkt, in dem die vorhandene Gewebsmasse den an sie gestellten Anforderungen nicht mehr genügt. Es ist dies im Grunde dasselbe Verhalten, wie wir es bei lebhaftem Abbau nervöser Substanz auch finden. Daß es gerade an den Gefäßen zu solch lebhaften Wucherungserscheinungen kommt, erklärt sich daraus, daß dort die körperfremden Substanzen infolge des konzentrischen Zusammenströmens nach den Gefäßen zu in größerer Menge vorhanden sind. Ist der Vorgang an den Gefäßen einmal eingeleitet, dann wird er sich automatisch weiterentwickeln, indem einerseits die gewucherten Zellen infolge ihrer stärkeren Resorptionsfähigkeit mehr Toxine heranziehen und letztere als Reizstoffe wiederum eine Zellwucherung hervorrufen. Dieses Wechselspiel der Kräfte wird so lange seinen Fortgang nehmen, bis sich die Funktionsfähigkeit des Zellherdchens in einem gewissen Gleichgewichtszustand gegenüber der Gesamtmenge der im weiteren Bereich noch vorhandenen körperfremden Stoffe befindet. Alsdann wird ein weiteres Wachstum nicht mehr stattfinden. Vielleicht haben die Herdchen außer ihrer rein resorptiven Tätigkeit auch noch eine giftbindende Wirkung, indem sie die Toxine entweder in ungiftige Produkte aufspalten oder an andere 
aufnahmefähige Eiwejßstoffe binden. Daß die Gefäßherdchen eine größere Rolle bei der Abräumung neurogener Zerfallsprodukte spielen, ist wenig wahrscheinlich. Selbst in den Fällen, in denen die Ganglienzellen sich in schwerer, fettiger Degeneration befanden und in denen auch die diffus verstreuten Gliazellen Fett in größeren Mengen aufgenommen hatten, fanden wir nur selten in winzigen Mengen mit Scharlach gefärbte Substanzen innerhalb der Gefäßherdchen, und zwar nur dann, wenn zufällig degenerierte Nervenzellen sekundär in den Herdbereich einbezogen worden waren.

Daß Gefäßherdchen in manchen Fällen auch ohne infiltrative Erscheinungen an den Gefäßen vorkommen, wie z. B. bei Urämie, spricht nicht gegen unsere oben entwickelte Ansicht. Körperfremde Stoffe brauchen ja nicht immer bakterielle Toxine zu sein, es kann sich dabei auch um giftige Stoffwechselprodukte handeln, die an sich keine entzündlichen Erscheinungen hervorrufen. Wir werden deshalb die Gefäßherdchen auch nicht ohne weiteres als entzündlich bezeichnen wollen, wenn sie auch häufig eine entzündliche Genese haben dürften.

Den im Mark zerstreuten Gliarosetten und Gliasternen ohne bestimmte Beziehung zu Gewebsbestandteilen darf man wohl, solange sie bei sekundärer Degeneration auftreten, eine ähnliche Aufgabe zuschreiben, wie den pericellulären Gliaherdchen. Wenn ein Zusammenhang mit Gefäßen besteht, muß man sie in die Gefäßherdchen einreihen. Bei einer Reihe von Gliasternen, bei denen keine nervösen Gewebsschädigungen zu beobachten sind, und die auch zu Gefäßen keine Beziehung unterhalten, fehlen uns noch alle Anhaltspunkte für die Beurteilung ihrer Funktion.

Wir kommen nun zu der Frage, ob den Gliaherdchen auch für die Statik eine Bedeutung zukommt, insonderheit ob sie Veränderungen oder Umbildungen erleiden, aus denen eine stützende Funktion ohne weiteres abzulesen wäre. Diese Frage läßt sich von der nach dem endgültigen Schicksal der Herdchen, deren Beantwortung wir nachher versuchen werden, nur künstlich trennen. Wir wollen ihr hier zunächst nur einmal für die vollausgebildeten Herdchen nähertreten. Eine von allen Untersuchern immer wieder hervorgehobene Tatsache ist die, daß man in den frischen Herdchen jedenfalls eine Faserbildung nicht beobachten konnte. Mehrfach wurde sogar festgestellt, daß die Gliafasern im Herdbereich wie ausgelöscht erscheinen. Auch wir haben entsprechende Beobachtung machen können. Es braucht aber nicht in allen Fällen so zu sein; wir haben oft mühelos sehen können, daß eine Unterbrechung eines durch ein Herdchen laufenden Gliafaserzuges nicht stattfindet. Es ist, wenn es in der Herdumgebung zu reichlicher Faserentwicklung gekommen ist, mitunter nicht leicht und bisweilen wohl unmöglich zu entscheiden, ob gewisse, das Herdchen durch- 
laufende Fasern nicht doch Beziehungen zu einzelnen Herdzellen haben. Man findet durch Anwendung besonderer Kunstgriffe bei der Holzerschen Methode dann hin und wieder in dem Protoplasma der Herdzellen äußerst feine, nur mit sehr starken Vergrößerungen sichtbare, schattenhafte, faserartige Strukturen, die vielleicht ein Vorstadium der eigentlichen Fasern darstellen. Es scheint aber doch weiterhin nicht zur Differenzierung wohlausgebildeter Fasern zu kommen. Eine Beteiligung faserbildender Astrocyten an der Herdbildung durch mehr als zufällige Anlagerung haben wir jedenfalls nie mit einiger Sicherheit feststellen können. Kann man den Gliaherdchen nun auch eine statische Funktion durch Faserbildung absprechen, so wird man es doch nicht schlechthin tun können. Ihre Tätigkeit bei der Neuronophagie ist ja neben der Abräumung zunächst eine raumfüllende, die das Gewebe am unmittelbaren Zusammenrücken hindert. Weiterhin machen es ihre Verankerung in dem diffusen Glianetz und die Pfeilerstellung der Herdrandzellen gegen das von allen Seiten auf den Ort verminderten Widerstandes eindrückende Gewebe sehr wahrscheinlich, daß sie für die Gewebsstatik eine gewisse Bedeutung haben. Wenn sie, wie wir sehen werden, später ohne Spuren zu hinterlassen wieder verschwinden können, wenn wir an dem Orte ihrer früheren Existenz keine Lücken und auch keine Gliafasern, jedenfalls aber das diffuse Glianetz wiederfinden, so werden wir ihnen vielleicht auch die Fähigkeit zuschreiben können, an Stellen, an denen z. B. durch Ganglienzellausfall Lücken im Gewebe entstanden sind, das diffuse Glianetz neu zu bilden und damit ein Gewebe zu schaffen, das den normalerweise vorhandenen biologischen Anforderungen ganz oder annähernd vollständig entspricht.

Wir wollen schließlich sehen, welche Auskunft uns unsere Befunde über das Schicksal der Herdchen geben. Wie schon in der Einleitung gesagt ist, sind die Untersucher fast ausnahmslos zu dem Ergebnis gelangt, daß die Gliaherdchen unbeständige Gebilde sind. Eine abweichende Auffassung vertritt nur Dürck, der die perivasculären Gliaherdchen bei Malaria, für bleibende Bildungen hält, die einer spontanen Rückbildung nicht fähig wären. Da es sich aber hier ähnlich wie bei den Ringblutungen um eine gliöse Reaktion in der Peripherie einer zentralen Nekrose handelt, sich wohl auch im morphologischen Aufbau Unterschiede ergeben, so möchten wir diese Erscheinungen mit den unseren Untersuchungen zugrundeliegenden gliösen Wucherungen nicht identifizieren und sie aus dem Kreise unserer Betrachtungen ausschalten. Wir haben in vielen unserer Fälle, besonders schön bei Encephalitis epidemica, die erstgenannten Ergebnisse bestätigen können. Schon die frühzeitigen Degenerationserscheinungen, die an manchen Herdelementen bereits auftreten, solange die progressive Weiterent- 
wicklung des Herdchens noch in vollem Gange ist, deutet auf die Unbeständigkeit der Erscheinungen hin. Wir haben dann in älteren Encephalitisfällen öfter beobachten können, daß als Rest der akuten Veränderungen außer einem diffusen Ganglienzellausfall nur noch eine Reihe winziger Gliasterne vorhanden waren, die bei oberflächlicher Betrachtung zunächst ganz übersehen worden waren. Bei genauerem Zuschauen zeigte die Mehrzahl dieser Herdchen fast rein regressive Erscheinungen, die besonders in einer Zerbröckelung des spangenartigen Protoplasmas und in Pyknose und Karyorrhexis der Kerne zum Ausdruck kamen (s. Abb. 17). Das Auftreten größerer progressiver Kernformen innerhalb der Herdchen, wie es von Creutzfeld und Jakob beschrieben worden ist, haben wir nicht beobachten können. Daß die Herdchen vollständig wieder verschwinden können, entzieht sich zwar dem direkten Nachweis; wir können aber indirekt darauf schließen aus der Tatsache, daß sich die Zahl der Herdchen an Stellen, wo der akute Prozeß abgelaufen ist, wesentlich verringert, und $\mathrm{da} ß$ die noch vorhandenen unter Zunahme der degenerativen Erscheinungen ihrer Bausteine an Größe erheblich abnehmen. Ob schließ. lich eine oder mehrere Zellen dauernd erhalten bleiben, diese Eigenschaft haben wir diesen einzelnen persistierenden Zellen nicht mehr anzusehen vermocht. Wenn man auch diese Möglichkeit zugeben muß, so büßen doch diese persistierenden Elemente späterhin ihre frühere Eigenart völlig ein. Es müßten in unseren Fällen gewöhnliche, ruhende, protoplasmaarme Gliazellen daraus geworden sein. Wir haben aber niemals Anhaltspunkte dafür gefunden, daß etwa eine lokale Gliose oder eine Ansammlung faserbildender Astrocyten der Enderfolg sein könnte. Hingegen wird unter geeigneten Bedingungen sich eine völlige Auflösung der Herdchen unter unseren Augen vollziehen können, nämlich dann, wenn eine Umbildung der Herdelemente in Körnchenzellen stattfindet (Abb. 3b u. c), deren Abwanderung nach den Gefäßen hin sich leicht beobachten läßt.

\section{Zusammenfassung.}

1. Das Vorkommen vereinzelter, kleiner Gliasterne ist ein sehr häufiges Ereignis, dem keine größere Bedeutung für das Gesamtbild eines pathologischen Vorganges beizumessen ist.

2. Größere, syncytiale Gliaherdchen in allen Formen und Beziehungen zu Gewebsbestandteilen finden sich bei einer ganzen Reihe infektiöser und toxischer Allgemeinerkrankungen mit und ohne entzündliche Erscheinungen am Zentralnervensystem, außerdem bei einer Anzahl entzündlicher und parenchymatös-degenerativer Erkrankungen, die das Nervensystem vorwiegend oder ausschließlich betreffen. 
3. Ferner treten kleinere Gliaherdchen sehr oft im Gefolge herdförmiger Untergänge von Nervengewebe auf, und zwar immer außerhalb des den Herd umgebenden Gliareaktionswalles.

4. Das Vorkommen der Gliaherdchen bei Dementia praecox und zirkulärem Irresein ist teils auf begleitende Allgemeininfektionen, teils auf noch nicht genügend geklärte Ursachen (Folge der heftigen motorischen Erregungen?) zurückzuführen. Ob mit den Psychosen selbst ein unmittelbarer Zusammenhang besteht, ist zweifelhaft.

5. Auch bei primären Parenchymdegenerationen sind für das Auftreten von pericellulären Gliaherdchen mitunter begleitende Infektionen, die ihren Ausgang von anderen Körperorganen nehmen, als Teilursachen anzusehen.

6. Bei reinen Parenchymdegenerationen, vor allem bei gehäuften Ganglienzellausfällen finden sich gewöhnlich nur die als Umklammerungen und Neuronophagien bekannten pericellulären Herdchen. Die Ganglienzellerkrankung kann dabei nach Art des Falles eine ganz verschiedene sein.

7. Gefäßherdchen fehlen, falls syncytiale Glia in unserem Sinne überhaupt vorkommt, selten, wenn infiltrativ-exsudative Erscheinungen am Nervensystem vorhanden sind. Sie werden für gewöhnlich auch angetroffen bei infektiösen oder toxischen Allgemeinerkrankungen.

8. Der Prädilektionssitz für die größeren, syncytialen Gefäßherdchen ist die Medulla oblongata. Eine Ausnahme, die differentialdiagnostisch nicht ohne Bedeutung ist, macht das Fleckfieber mit seinen zahlreichen Knötchen in der Rinde. Auch die Urämie lokalisiert ihre Gefäßherdchen gewöhnlich nicht in die Medulla oblongata, sondern in das Großhirnmark. Bei herdförmigen oder Systemerkrankungen (Erweichung, multiple Sklerose, herdförmiger Ganglienzellausfall, Oliven- und Nucleus dentatus-Erkrankung), ist ihre Lokalisation von dem Sitz der Erkrankung abhängig.

9. Der Befund einzelner nicht gliöser Zellen (Lymphocyten, Plasmazellen usw.) in den syncytialen Herdchen ist am häufigsten bei entzündlichen Erscheinungen am Nervensystem, seltener bei Allgemeininfektionen ohne infiltrative Vorgänge am Nervensystem. Bei reinen Parenchymdegenerationen pflegt er zu fehlen. Für den Aufbau der Herdchen aus einer einheitlichen und eigentümlichen Art von Gliazellen kommt ihm keine Bedeutung zu.

10. Wenn den Herdchen auch eine pathognomische Bedeutung nicht zukommt, so sind sie doch unter Berücksichtigung der Gesamtheit der pathologischen Erscheinungen unter Umständen von differentialdiagnostischer Bedeutung (Fleckfieber, Encephalitis). Eine engere Beziehung scheinen die Gefäßherdchen zu den infiltrativ-exsudativen 
Gehirnprozessen und infektiösen und toxischen Allgemeinerkrankungen zu haben.

11. Ihren Ursprung nehmen die Gliaherdchen von den Trabant zellen und den „,epitheloiden“ Gefäßbegleitzellen. Die Vermehrung erfolgt durch Mitose und direkte Teilung, das Wachstum vorwiegend an der Herdperipherie, indem die Herdzellen gewissermaßen in das diffuse Gliareticulum hineinwuchern.

12. Eine morphologische Vorbedingung für die Entstehung typischer syncytialer Gliaherdchen ist die Erhaltung der Struktur des diffusen Gliareticulums. Bei groben Strukturveränderungen des Nervengliagewebes findet man keine Gliaherdchen mehr. Tritt in Gebieten, welche syncytiale Gliaherdchen enthalten, eine solche später hinzu, dann erleiden je nach dem Grade der Störung auch die Gliaherdchen mehr oder minder schwere Veränderungen.

13. In vielen Fällen ist für die Entstehung der Herdchen eine primäre Gewebsschädigung nachzuweisen. Sie findet sich immer bei den als Ganglienzellumklammerungen und Neuronophagien bekannten Erscheinungen, häufig aber nicht bei den Gefäßherdchen und den Gliasternen, die keine Beziehung zu bestimmten Gewebsbestandteilen erkennen lassen. Auffällig ist ein gewisser Antagonismus zwischen Gefäßinfiltration und Gefäßherdbildung, insofern als stärkere Infiltrate und syncytiale Herdchen nie an derselben Stelle eines Gefäßes zu beobachten waren, obgleich bei entzündlichen Gehirnprozessen mit herdförmiger Ausbreitung die Gefäßherdchen immer nur in den infiltrierten Partien des Nervengewebes zu finden waren.

14. Die pericellulären Gliaherdchen stehen im Dienste des Abbaues und der Abräumung neurogener Zerfallsprodukte, wobei letztere innerhalb der Herdzellen einer weiteren Umwandlung unterzogen werden können. Unter besonderen Umständen können die Herdzellen dabei eine Umbildung in Körnchenzellen erfahren.

15. Die perivasculären Herdchen stehen mutmaßlich mit der Fortschaffung morphologisch nicht nachweisbarer, körperfremder Stoffe (bakterieller Toxine oder giftiger Stoffwechselprodukte) in Beziehung.

16. Für die Beurteilung der Funktion der isolierten Gliasterne fehlen zur Zeit noch einwandfreie Beobachtungen, die Schlüsse in dieser Richtung erlauben würden.

17. Die Gliaherdchen nehmen an der Gliafaserbildung keinen Anteil; trotzdem haben sie z. B. bei Ganglienzelluntergängen als raumfüllende Wucherung auch für die Gewebsstatik eine gewisse Bedeutung. Es spricht vieles dafür, daß sie an diesen Stellen unter Umständen auch das diffuse Gliareticulum neu bilden können.

18. Die syncytialen Herdbildungen sind als unbeständige Gebilde 
anzusehen, die frühzeitiger Rückbildung verfallen und wieder völlig verschwinden können, gewöhnlich unter Schrumpfung des Protoplasmas und Pyknose und Rhexis der Kerne. In seltenen Fällen können sich pericelluläre Herdchen in Körnchenzellen auflösen, die dann ihren Weg zu den Gefäßen nehmen. Persistierende Gliazellen aus den Herdchen haben wir nicht beobachtet, es müßten denn in unseren Fällen gewöhnhliche ruhende Gliazellen daraus geworden sein.

Unsere Untersuchungen haben aufs neue gezeigt, daß die Begriffsdeterminierung der Gliaherdehen nach biologischen Gesichtspunkter. jetzt noch nicht möglich ist. Zwar sind wir bei den als Ganglienzellumklammerungen und Neuronophagien auftretenden Gliaherdchen heute in der Lage, ihnen eine Stellung im Dienste des Abbaues, der Abräumung und vermutlich auch des Gewebsersatzes zuzuweisen; bezüglich der Funktion der Gefäßherdchen und der im Mark ohne Beziehung zu bestimmten Gewebsbestandteilen vorkommenden Gliasterne können wir aber günstigenfalls auf Wahrscheinlichkeitsgründen aufgebaute Vermutungen äußern. Wir werden uns also vorläufig auch weiterhin darauf beschränken müssen, sie rein morphologisch zu charakterisieren. Und zwar finden wir die allen Gliaherdchen gemeinsamen Eigenschaften in der Eigenart der gliösen Bausteine und der Art ihrer Aneinanderfügung. Dabei muß es zunächst gleichgültig bleiben, welches die äußere Form der Herdchen ist, ob sie also ein Strauchwerk, eine Rosette oder ein Knötchen bilden, gleichgültig auch, welche Beziehung zu bestimmten Gewebsbestandteilen sie unterhalten oder welche Erkrankung ihrem Auftreten zugrunde liegt, ob ihnen fremdartige Gewebselemente beigemischt sind oder nicht; dies sind alles Eigensehaften von nur sekundärer Bedeutung, die erst zu einer weiteren Einteilung nach den verschiedenen Gesichtspunkten Verwendung finden können. Wir haben in Utbereinstimmung mit allen Autoren, die sich mit diesen Erscheinungen beschäftigt haben, gesehen, daß schari umschriebene, morphologische Merkmale existieren, welche die in Frage stehenden Bildungen von anderen Arten gliöser Wucherung abzutrennen erlauben; wir halten es deshalb für angängig, die syncytiale Gliaherdchenbildung ganz allgemein als eine unter geeigneten Bedingungen auftretende, besondere Reaktionsform der Glia zu bezeichnen.

\section{Literaturverzeichnis.}

Alzheimer, A., Beiträge zur Kenntnis der pathologischen Neuroglia und ihrer Beziehungen zu den Abbauvorgängen im Nervengewebe. Histologische und histopathologische Arbeiten über die GroBhirnrinde Bd. 3, 1910. - Alzheimer, A., Ưber eine eigenartige Erkrankung des zentralen Nervensystems mit bulbären Symptomen und schmerzhaften spastischen Krampfzuständen der Extremitäten. Zeitschr. f. d. ges. Neurol. u. Psychiatr. 1916, Orig. 33. - Borst, M., Über Entzündung und Rei- 
zung. Zieglers Beitr. z. pathol. Anat. u. z. allg. Pathol. 63, H. 3. 1916. - Creutzfeld, G., ťber eine eigenartige, herdförmige Erkrankung des Zentralnervensystems. Histologische und histopathologische Arbeiten über die Großhirnrinde. Ergänzungsband 1920. - Creutzfeld, G., Pathologisch-anatomische Beiträge zur Encephalitis epidemica. Zeitschr. f. d. ges. Neurol. u. Psychiatr. Ref. 24. 1921. - Dürck, Die pathologische Anatomie der Malaria. Münch. med. Wochenschr. 1921, Nr. 2. v. Economo, C., Die Encephalitis lethargica. Jahrbücher für Psychiatr. u. Neurol. 38, H. 1. 1917. - v. Economo, C., Ein Fall von chronischer, schubweise verlaufender Encephalitis lethargica. Münch. med. Wochenschr. 1919, Nr. 46. - Groß, W., Über Encephalitis epidemica. Zeitschr. f. d. ges. Neurol. u. Psychiatr. 1921. Orig. 63.

- Grïtter: UUber Encephalitis epidemica. Zeitschr. f. d. ges. Neurol. u. Psychiatr. r2. 1922. - Jakob, A., Über eigenartige Erkrankungen des Zentralnervensystems mit bemerkenswertem anatomischem Befunde. Zeitschr. f. d. ges. Neurol. u. Psychiatr. 1921. Orig. 64. - Lotmar, $F$., Beiträge zur Histologie der akuten Mye. litis und Encephalitis, sowie verwandter Prozesse. Auf Grund von Versuchen mit Dysenterietoxin. Histologische und histopathologische Arbeiten über die Großhirnrinde. 6. 1918. - Nissl, F., Zur Histopathologie der paralytischen Rindenerkrankung. Histologische und histopathologische Arbeiten über die Großhinrinde. 1. 1904. - Sagel, W., Zur histologischen Analyse des Gliastrauchwerks der Kleinhimrinde. Zeitschr. f. d. ges. Neurol. u. Psychiatr. 1921. Orig. r1. - Spielmeyer, $W$., Die zentralen Veränderungen beim Fleckfieber und ihre Bedeutung für die Histcpathologie der Hirnrinde. Zeitschr. f. d. ges. Neurol. u. Psychiatr. 1919. Orig. 47. Spielmeyer, $W$., Über Kleinhirnveränderungen bei Typhus abdominalis. Münch. med. Wochenschr. 1919, Nr. 12. - Spielmeyer, W., Die Kleinhimveränderungen bei Typhus in ihrer Bedeutung für die Pathologie der Hirnrinde. Münch. med. Wochenschr. 1919, Nr. 26. - Spielmeyer, W., UUber єinige Beziehungen zwischen Ganglienzellveränderungen und gliösen Erscheinungen, besonders am Kleinhirn. Zeitschr. f. d. ges. Neurol. u. Psychiatr. Orig. 54. 1920.

\section{Nachtrag.}

Nach Fertigstellung vorliegender Arbeit bekamen wir die Abhandlung von Klarfeld „Einige allgemeine Betrachtungen zur Histopathologie des Zentralnervensystems (auf Grund von Untersuchungen über die Encephalitis epidemica)"II) zu Gesicht. Seine Stellungnahme zu der Funktion der pericellulären Gliaherdchen deckt sich im allgemeinen mit der unsrigen. Wenn er einen prinzipiellen Unterschied zwischen Umklammerung und Neuronophagie nicht gelten läßt, so können wir ihm auf Grund unserer Befunde nur zustimmen. Ein Ein. dringen der Herdzellen in die Ganglienzellen war nur da festzustellen, wo der Zerfall der Nervenzellen bereits morphologisch deutlich war. Gerade an den pigmentführenden Ganglienzellen kann man aber beabachten, daß sie Pigment schon zu einer Zeit ausstoßen, in der ihre Konturen noch keine groben Zerstörungen erkennen lassen, in der man noch eine gewisse Lebensfähigkeit der Ganglienzellen vermuten darf. Da das Pigment in diesem Falle nicht in solchen Mengen frei wird wie beim Zellzerfall, so wird man es auch

1) Zeitschr, f. d. ges. Neurol. u. Psychiatr. Orig. 77, H. 1/2. 
nicht in so großen Mengen in den umklammernden Gliazellen finden können. Den von Klarfeld gebrauchten Ausdruck "Chemotaxis" möchten wir nur mit einer gewissen Einschränkung annehmen. Da wir uns mit ihm in sachlicher Utbereinstimmung glauben, so handelt es sich wohl nur um eine Frage der Nomenklatur. Der Ausdruck "Chemotaxis" könnte in der heute üblichen Form zu der Meinung verleiten, die Gliazellen würden durch die beim Protoplasmazerfall der Ganglienzellen produzierten Reizstoffe angelockt zu der Ganglienzelle hinwandern, die Herde seien also aus mobilen Gliazellen zusammengesetzt. Die Untersuchungen haben aber gezeigt, daß die syncytiale Gliawucherung in loco entstanden ist. Deshalb möchten wir diesen Ausdruck Klarfelds lieber ganz vermeiden und unsere Ansicht dahin präzisieren, daß die von den Ganglienzellen abgeschiedenen Reizstoffe die in loco befindlichen Gliazellen infolge des auf sie ausgeübten, funktionellen Reizes zu der eigenartigen Form ihres Wachstums veranlassen. Daß es von der Schnelligkeit des Verlaufes und der Intensität des Krankheitsprozesses abhänge, ob Umklammerung oder wirkliche Neuronophagie zustande komme, haben unsere Befunde besonders auch bei Encephalitis epidemica nicht durchweg bestätigen können. Bei großer Intensität des Krankheitsprozesses haben wir, wie oben dargelegt, keine von beide Erscheinungen in typischer Form mehr vorfinden können. 